\title{
Guidelines of the American Thyroid Association for the Diagnosis and Management of Thyroid Disease During Pregnancy and Postpartum
}

\author{
The American Thyroid Association Taskforce on Thyroid Disease During Pregnancy and Postpartum \\ Alex Stagnaro-Green (Chair), ${ }_{1}^{1}$ Marcos Abalovich, ${ }^{2}$ Erik Alexander, ${ }^{3}$ Fereidoun Azizi, ${ }^{4}$ Jorge Mestman, ${ }^{5}$ \\ Roberto Negro, ${ }^{6}$ Angelita Nixon, ${ }^{7}$ Elizabeth N. Pearce, ${ }^{8}$ Offie P. Soldin, ${ }^{9}$ \\ Scott Sullivan, ${ }^{10}$ and Wilmar Wiersinga ${ }^{11}$
}

\section{INTRODUCTION}

$\mathbf{P}$ REGNANCY HAS A profound impact on the thyroid gland and thyroid function. The gland increases $10 \%$ in size during pregnancy in iodine-replete countries and by $20 \%-$ $40 \%$ in areas of iodine deficiency. Production of thyroxine $\left(\mathrm{T}_{4}\right)$ and triiodothyronine $\left(\mathrm{T}_{3}\right)$ increases by $50 \%$, along with a $50 \%$ increase in the daily iodine requirement. These physiological changes may result in hypothyroidism in the later stages of pregnancy in iodine-deficient women who were euthyroid in the first trimester. The range of thyrotropin (TSH), under the impact of placental human chorionic gonadotropin (hCG), is decreased throughout pregnancy with the lower normal TSH level in the first trimester being poorly defined and an upper limit of $2.5 \mathrm{mIU} / \mathrm{L}$. Ten percent to $20 \%$ of all pregnant women in the first trimester of pregnancy are thyroid peroxidase (TPO) or thyroglobulin (Tg) antibody positive and euthyroid. Sixteen percent of the women who are euthyroid and positive for TPO or Tg antibody in the first trimester will develop a TSH that exceeds $4.0 \mathrm{mIU} / \mathrm{L}$ by the third trimester, and $33 \%-50 \%$ of women who are positive for TPO or Tg antibody in the first trimester will develop postpartum thyroiditis. In essence, pregnancy is a stress test for the thyroid, resulting in hypothyroidism in women with limited thyroidal reserve or iodine deficiency, and postpartum thyroiditis in women with underlying Hashimoto's disease who were euthyroid prior to conception.
Knowledge regarding the interaction between the thyroid and pregnancy/the postpartum period is advancing at a rapid pace. Only recently has a TSH of $2.5 \mathrm{mIU} / \mathrm{L}$ been accepted as the upper limit of normal for TSH in the first trimester. This has important implications in regards to interpretation of the literature as well as a critical impact for the clinical diagnosis of hypothyroidism. Although it is well accepted that overt hypothyroidism and overt hyperthyroidism have a deleterious impact on pregnancy, studies are now focusing on the potential impact of subclinical hypothyroidism and subclinical hyperthyroidism on maternal and fetal health, the association between miscarriage and preterm delivery in euthyroid women positive for TPO and/or Tg antibody, and the prevalence and long-term impact of postpartum thyroiditis. Recently completed prospective randomized studies have begun to produce critically needed data on the impact of treating thyroid disease on the mother, fetus, and the future intellect of the unborn child.

It is in this context that the American Thyroid Association (ATA) charged a task force with developing clinical guidelines on the diagnosis and treatment of thyroid disease during pregnancy and the postpartum. The task force consisted of international experts in the field of thyroid disease and pregnancy, and included representatives from the ATA, Asia and Oceania Thyroid Association, Latin American Thyroid Society, American College of Obstetricians and Gynecologists, and the Midwives Alliance of North America. Inclusion of thyroidologists, obstetricians, and midwives on the task

\footnotetext{
${ }^{1}$ Departments of Medicine and Obstetrics/Gynecology, George Washington University School of Medicine and Health Sciences, Washington, District of Columbia.

${ }^{2}$ Endocrinology Division, Durand Hospital, Favaloro University, Buenos Aires, Argentina.

${ }^{3}$ Division of Endocrinology, Diabetes, and Hypertension, Brigham \& Women's Hospital, Harvard Medical School, Boston, Massachusetts.

${ }^{4}$ Internal Medicine and Endocrinology, Research Institute for Endocrine Sciences, Shahid Beheshti University of Medicine Sciences, Tehran, Iran.

${ }^{5}$ Department of Medicine and Obstetrics and Gynecology, Keck School of Medicine, University of Southern California, Los Angeles, California.

${ }^{6}$ Division of Endocrinology, V. Fazzi Hospital, Lecce, Italy

${ }^{7}$ Angelita Nixon, CNM, LLC, Scott Depot, West Virginia.

${ }^{8}$ Section of Endocrinology, Diabetes, and Nutrition, Boston University School of Medicine, Boston, Massachusetts.

${ }^{9}$ Departments of Medicine, Oncology, and Obstetrics and Gynecology, Georgetown University Medical Center, Washington, District of Columbia.

${ }^{10}$ Department of Obstetrics/Gynecology, Medical University of South Carolina, Charleston, South Carolina.

${ }^{11}$ Endocrinology, Academic Medical Center, University of Amsterdam, Amsterdam, The Netherlands.
} 
force was essential to ensuring widespread acceptance and adoption of the developed guidelines.

The clinical guidelines task force commenced its activities in late 2009. The guidelines are divided into the following nine areas: 1) thyroid function tests, 2) hypothyroidism, 3) thyrotoxicosis, 4) iodine, 5) thyroid antibodies and miscarriage/ preterm delivery, 6) thyroid nodules and cancer, 7) postpartum thyroiditis, 8) recommendations on screening for thyroid disease during pregnancy, and 9) areas for future research. Each section consists of a series of questions germane to the clinician, followed by a discussion of the questions and concluding with recommendations.

Literature review for each section included an analysis of all primary papers in the area published since 1990 and selective review of the primary literature published prior to 1990 that was seminal in the field. In the past 15 years there have been a number of recommendations and guideline statements relating to aspects of thyroid and pregnancy $(1,2)$. In deriving the present guidelines the task force conducted a new and comprehensive analysis of the primary literature as the basis for all of the recommendations. The strength of each recommendation was graded according to the United States Preventive Services Task Force (USPSTF) Guidelines outlined below (3).

Level A. The USPSTF strongly recommends that clinicians provide (the service) to eligible patients. The USPSTF found good evidence that (the service) improves important health outcomes and concludes that benefits substantially outweigh harms.

Level B. The USPSTF recommends that clinicians provide (this service) to eligible patients. The USPSTF found at least fair evidence that (the service) improves important health outcomes and concludes that benefits outweigh harms.

Level C. The USPSTF makes no recommendation for or against routine provision of (the service). The USPSTF found at least fair evidence that (the service) can improve health outcomes but concludes that the balance of benefits and harms is too close to justify a general recommendation.
Level D. The USPSTF recommends against routinely providing (the service) to asymptomatic patients. The USPSTF found at least fair evidence that (the service) is ineffective or that harms outweigh benefits.

Level I. The USPSTF concludes that evidence is insufficient to recommend for or against routinely providing (the service). Evidence that (the service) is effective is lacking, or poor quality, or conflicting, and the balance of benefits and harms cannot be determined.

The organization of these guidelines is presented in Table 1. A complete list of the Recommendations is included in the Appendix. It should be noted that although there was unanimity in the vast majority of recommendations there were two recommendations for which one of the committee members did not agree with the final recommendation. The two recommendations for which there were dissenting opinions are Recommendations 9 and 76. The alternative view points are included in the body of the report.

The final document was approved by the ATA Board of Directors and officially endorsed by the American Association of Clinical Endocrinologists (AACE), British Thyroid Association (BTA), Endocrine Society of Australia (ESA), European Association of Nuclear Medicine (EANM), European Thyroid Association (ETA), Italian Association of Clinical Endocrinologists (AME), Korean Thyroid Association (KTA), and Latin American Thyroid Society (LATS).

Finally, the committee recognizes that knowledge on the interplay between the thyroid gland and pregnancy/ postpartum is dynamic, and new data will continue to come forth at a rapid rate. It is understood that the present guidelines are applicable only until future data refine our understanding, define new areas of importance, and perhaps even refute some of our recommendations. In the interim, it is our hope that the present guidelines provide useful information to clinicians and help achieve our ultimate goal of the highest quality clinical care for pregnant women and their unborn children.

Table 1. Organization of Pregnancy Management Guidelines: Sections, Questions, and Recommendations

\begin{tabular}{|c|c|c|c|}
\hline & & & $\begin{array}{c}\text { Page } \\
\text { number }\end{array}$ \\
\hline \multicolumn{4}{|c|}{ INTRODUCTION } \\
\hline \multicolumn{4}{|c|}{ THYROID FUNCTION TESTS IN PREGNANCY } \\
\hline $\mathrm{Q}$ & 1 & How do thyroid function tests change during pregnancy? & 1086 \\
\hline $\mathrm{Q}$ & 2 & What is the normal range for TSH in each trimester? & 1086 \\
\hline$\widehat{\mathrm{R}}$ & 1 & Trimester-Specific Reference Ranges for TSH, \# 1 & 1087 \\
\hline $\mathrm{R}$ & 2 & Trimester-Specific Reference Ranges for TSH, \# 2 & 1087 \\
\hline Q & 3 & What is the optimal method to assess $\mathrm{FT}_{4}$ during pregnancy? & 1087 \\
\hline $\mathrm{R}$ & 3 & $\mathrm{FT}_{4}$ Assay Methods, \# 1 & 1088 \\
\hline $\mathrm{R}$ & 4 & $\mathrm{FT}_{4}$ Assay Methods, \# 2 & 1088 \\
\hline $\mathrm{R}$ & 5 & $\mathrm{FT}_{4}$ Assay Methods, \# 3 & 1088 \\
\hline \multicolumn{4}{|c|}{ HYPOTHYROIDISM IN PREGNANCY } \\
\hline Q & 4 & What are the definitions of $\mathrm{OH}$ and $\mathrm{SCH}$ in pregnancy? & 1088 \\
\hline $\mathrm{Q}$ & 5 & How is isolated hypothyroxinemia defined in pregnancy? & 1088 \\
\hline $\mathrm{Q}$ & 6 & What adverse outcomes are associated with $\mathrm{OH}$ in pregnancy? & 1088 \\
\hline$\hat{\mathrm{Q}}$ & 7 & What adverse outcomes are associated with SCH in pregnancy? & 1089 \\
\hline $\mathrm{Q}$ & 8 & What adverse outcomes are associated with isolated hypothyroxinemia in pregnancy? & 1089 \\
\hline $\mathrm{Q}$ & 9 & Should $\mathrm{OH}$ be treated in pregnancy? & 1090 \\
\hline
\end{tabular}


Table 1. (Continued)

\begin{tabular}{|c|c|c|c|}
\hline & & & $\begin{array}{l}\text { Page } \\
\text { number }\end{array}$ \\
\hline $\mathrm{R}$ & 6 & Treatment of $\mathrm{OH}$ in Pregnancy & 1090 \\
\hline Q & 10 & Should isolated hypothyroxinemia be treated in pregnancy? & 1090 \\
\hline$\widehat{\mathrm{R}}$ & 7 & Isolated Hypothyroxinemia in Pregnancy & 1090 \\
\hline Q & 11 & Should SCH be treated in pregnancy? & 1090 \\
\hline $\mathrm{R}$ & 8 & Treatment of SCH in Pregnancy, \# 1 & 1090 \\
\hline $\mathrm{R}$ & 9 & Treatment of SCH in Pregnancy, \# 2 & 1090 \\
\hline Q & 12 & When provided, what is the optimal treatment of $\mathrm{OH}$ and $\mathrm{SCH}$ ? & 1090 \\
\hline$\widehat{R}$ & 10 & The Optimal Form of Thyroid Hormone to Treat $\mathrm{OH}$ and $\mathrm{SCH}$ & 1090 \\
\hline Q & 13 & When provided, what is the goal of $\mathrm{OH}$ and $\mathrm{SCH}$ treatment? & 1090 \\
\hline $\mathrm{R}$ & 11 & Goal of $\mathrm{LT}_{4}$ Treatment for $\mathrm{OH}$ and $\mathrm{SCH}$ & 1090 \\
\hline Q & 14 & $\begin{array}{l}\text { If pregnant women with } \mathrm{SCH} \text { are not initially treated, how should they be monitored } \\
\text { through gestation? }\end{array}$ & 1090 \\
\hline $\mathrm{R}$ & 12 & $\begin{array}{l}\text { Monitoring Women with SCH Who Are Not Initially Treated During Their } \\
\text { Pregnancy }\end{array}$ & 1090 \\
\hline Q & 15 & $\begin{array}{l}\text { How do hypothyroid women (receiving } \mathrm{LT}_{4} \text { ) differ from other patients during } \\
\text { pregnancy? } \\
\text { What changes can be anticipated in such patients during gestation? }\end{array}$ & 1091 \\
\hline Q & 16 & $\begin{array}{l}\text { What proportion of treated hypothyroid women (receiving } \mathrm{LT}_{4} \text { ) require changes in their } \\
\mathrm{LT}_{4} \text { dose during pregnancy? }\end{array}$ & 1091 \\
\hline Q & 17 & $\begin{array}{l}\text { In treated hypothyroid women (receiving } \mathrm{LT}_{4} \text { ) who are planning pregnancy, how should } \\
\text { the } \mathrm{LT}_{4} \text { dose be adjusted? }\end{array}$ & 1091 \\
\hline $\mathrm{R}$ & 13 & $\begin{array}{l}\mathrm{LT}_{4} \text { Dose Adjustment for Hypothyroid Women Who Miss a Menstrual Period or } \\
\text { Have a Positive Home Pregnancy Test }\end{array}$ & 1091 \\
\hline Q & 18 & $\begin{array}{l}\text { In hypothyroid women (receiving } \mathrm{LT}_{4} \text { ) who are newly pregnant, what factors influence } \\
\text { thyroid status and } \mathrm{LT}_{4} \text { requirements during gestation? }\end{array}$ & 1091 \\
\hline $\mathrm{R}$ & 14 & Factors Influencing Changes in $\mathrm{LT}_{4}$ Requirements During Pregnancy & 1091 \\
\hline $\mathrm{R}$ & 15 & Adjustment of $\mathrm{LT}_{4}$ Dose in Hypothyroid Women Planning Pregnancy & 1091 \\
\hline $\mathrm{Q}$ & 19 & $\begin{array}{l}\text { In hypothyroid women (receiving } \mathrm{LT}_{4} \text { ) who are newly pregnant, how often should } \\
\text { maternal thyroid function be monitored during gestation? }\end{array}$ & 1091 \\
\hline $\mathrm{R}$ & 16 & $\begin{array}{l}\text { Frequency that Maternal Serum TSH Should Be Monitored During Pregnancy in } \\
\text { Hypothyroid Women Taking } \mathrm{LT}_{4} \# 1\end{array}$ & 1092 \\
\hline $\mathrm{R}$ & 17 & $\begin{array}{l}\text { Frequency that Maternal Serum TSH Should Be Monitored During Pregnancy in } \\
\text { Hypothyroid Women Taking } \mathrm{LT}_{4}, \# 2\end{array}$ & 1092 \\
\hline Q & 20 & How should the $\mathrm{LT}_{4}$ dose be adjusted postpartum? & 1092 \\
\hline$\overline{\mathrm{R}}$ & 18 & Dose Adjustment and Serum TSH Testing Postpartum & 1092 \\
\hline Q & 21 & $\begin{array}{l}\text { What is the outcome and long-term prognosis when } \mathrm{SCH} \text { and } \mathrm{OH} \text { are effectively treated } \\
\text { through gestation? }\end{array}$ & 1092 \\
\hline Q & 22 & $\begin{array}{l}\text { Except for measurement of maternal thyroid function, should additional maternal or } \\
\text { fetal testing occur in treated, hypothyroid women during pregnancy? }\end{array}$ & 1092 \\
\hline $\mathrm{R}$ & 19 & $\begin{array}{l}\text { Tests Other Than Serum TSH in Hypothyroid Women Receiving } \text { LT }_{4} \text { Who Have an } \\
\text { Uncomplicated Pregnancy }\end{array}$ & 1092 \\
\hline Q & 23 & $\begin{array}{l}\text { In euthyroid women who are TAb+ prior to conception, what is the risk of } \\
\text { hypothyroidism once they become pregnant? }\end{array}$ & 1092 \\
\hline Q & 24 & How should $\mathrm{TAb}+$ euthyroid women be monitored and treated during pregnancy? & 1092 \\
\hline $\mathrm{R}$ & 20 & $\begin{array}{l}\text { Monitoring Women Without a History of Hypothyroidism, but Who Are TAb+ } \\
\text { During Pregnancy }\end{array}$ & 1092 \\
\hline Q & 25 & $\begin{array}{l}\text { Should TAb + euthyroid women be monitored or treated for complications other than } \\
\text { the risk of hypothyroidism during pregnancy? }\end{array}$ & 1092 \\
\hline $\mathrm{R}$ & 21 & Selenium Supplementation During Pregnancy for Women Who Are TPOAb+ & 1093 \\
\hline \multicolumn{4}{|c|}{ THYROTOXICOSIS IN PREGNANCY } \\
\hline Q & 26 & What are the causes of thyrotoxicosis in pregnancy? & 1093 \\
\hline Q & 27 & $\begin{array}{l}\text { What is the appropriate initial evaluation of a suppressed serum TSH concentration } \\
\text { during the first trimester of pregnancy? }\end{array}$ & 1093 \\
\hline Q & 28 & $\begin{array}{l}\text { How can gestational hyperthyroidism be differentiated from Graves' hyperthyroidism in } \\
\text { pregnancy? }\end{array}$ & 1093 \\
\hline $\mathrm{R}$ & 22 & Workup of Suppressed Serum TSH in First Trimester of Pregnancy & 1093 \\
\hline $\mathrm{R}$ & 23 & Ultrasound to Work-up Differential Diagnosis of Thyrotoxicosis in Pregnancy & 1093 \\
\hline $\mathrm{R}$ & 24 & Prohibition of Radioactive Iodine Scans and Uptake Studies During Pregnancy & 1093 \\
\hline Q & 29 & What is the appropriate management of gestational hyperthyroidism? & 1093 \\
\hline $\mathrm{R}$ & 25 & $\begin{array}{l}\text { Management of Women with Gestational Hyperthyroidism and Hyperemesis } \\
\text { Gravidarum }\end{array}$ & 1094 \\
\hline
\end{tabular}


Table 1. (Continued)

\begin{tabular}{|c|c|c|c|}
\hline & & & $\begin{array}{l}\text { Page } \\
\text { number }\end{array}$ \\
\hline $\mathrm{R}$ & 26 & Antithyroid Drugs in the Management of Gestational Hyperthyroidism & 1094 \\
\hline Q & 30 & How should women with Graves' disease be counseled before pregnancy? & 1094 \\
\hline $\mathrm{R}$ & 27 & Need to Render Hyperthyroid Women Euthyroid Before Pregnancy & 1094 \\
\hline $\mathrm{Q}$ & 31 & What is the management of patients with Graves' hyperthyroidism in pregnancy? & 1094 \\
\hline $\mathrm{R}$ & 28 & Timing of PTU and MMI Use in Pregnancy & 1094 \\
\hline $\mathrm{R}$ & 29 & Combining ATDs and $\mathrm{LT}_{4}$ During Pregnancy & 1094 \\
\hline $\mathrm{Q}$ & 32 & $\begin{array}{l}\text { What tests should be performed in women treated during pregnancy with ATDs? What } \\
\text { is the target value of } \mathrm{FT}_{4} \text { ? }\end{array}$ & 1095 \\
\hline $\mathrm{R}$ & 30 & $\begin{array}{l}\text { Monitoring Frequency of } \mathrm{FT}_{4} \text { and Target } \mathrm{FT}_{4} \text { in Women on Antithyroid Drugs During } \\
\text { Pregnancy }\end{array}$ & 1095 \\
\hline Q & 33 & $\begin{array}{l}\text { What are the indications and timing for thyroidectomy in the management of Graves' } \\
\text { disease during pregnancy }\end{array}$ & 1095 \\
\hline $\mathrm{R}$ & 31 & $\begin{array}{l}\text { Relative Role of Thyroidectomy and Its Timing for Managing Thyrotoxicosis in } \\
\text { Pregnancy }\end{array}$ & 1095 \\
\hline $\mathrm{Q}$ & 34 & $\begin{array}{l}\text { What is the value of TRAb measurement in the evaluation of a pregnant women with } \\
\text { Graves' hyperthyroidism? }\end{array}$ & 1095 \\
\hline $\mathrm{R}$ & 32 & $\begin{array}{l}\text { History of Graves' Disease as a Determinant of TRAb Measurement, and Timing of } \\
\text { TRAb Measurement, in Pregnancy }\end{array}$ & 1095 \\
\hline $\mathrm{Q}$ & 35 & $\begin{array}{l}\text { Under what circumstances should additional fetal ultrasound monitoring for growth, } \\
\text { heart rate, and goiter be performed in women with Graves' hyperthyroidism } \\
\text { in pregnancy? }\end{array}$ & 1095 \\
\hline $\mathrm{R}$ & 33 & Recommendations for Pregnant Women with High Risk of Fetal Thyroid Dysfunction & 1096 \\
\hline Q & 36 & $\begin{array}{l}\text { When should umbilical blood sampling be considered in women with Graves' disease in } \\
\text { pregnancy? }\end{array}$ & 1096 \\
\hline $\mathrm{R}$ & 34 & Cordocentesis in Pregnancy & 1096 \\
\hline Q & 37 & What are the etiologies of thyrotoxicosis in the postpartum period? & 1096 \\
\hline $\mathrm{Q}$ & 38 & How should the etiology of new thyrotoxicosis be determined in the postpartum period? & 1096 \\
\hline $\mathrm{Q}$ & 39 & How should Graves' hyperthyroidism be treated in lactating women? & 1096 \\
\hline $\mathrm{R}$ & 35 & Safe Doses of Antithyroid Drugs for Infants of Breastfeeding Mothers & 1096 \\
\hline \multicolumn{4}{|c|}{ CLINICAL GUIDELINES FOR IODINE NUTRITION } \\
\hline Q & 40 & $\begin{array}{l}\text { Why is increased iodine intake required in pregnancy and lactation, and how is iodine } \\
\text { intake assessed? }\end{array}$ & 1096 \\
\hline Q & 41 & What is the impact of severe iodine deficiency on the mother, fetus, and child? & 1096 \\
\hline $\mathrm{Q}$ & 42 & What is the impact of mild to moderate iodine deficiency on the mother, fetus, and child? & 1097 \\
\hline$\hat{\mathrm{Q}}$ & 43 & What is the iodine status of pregnant and breastfeeding women in the United States? & 1097 \\
\hline $\mathrm{Q}$ & 44 & What is the iodine status of pregnant and breastfeeding women worldwide? & 1097 \\
\hline $\mathrm{Q}$ & 45 & $\begin{array}{l}\text { Does iodine supplementation in pregnancy and lactation improve outcomes in severe } \\
\text { iodine deficiency? }\end{array}$ & 1097 \\
\hline $\mathrm{Q}$ & 46 & $\begin{array}{l}\text { Does iodine supplementation in pregnancy and lactation improve outcomes in mildly to } \\
\text { moderately iodine-deficient women? }\end{array}$ & 1097 \\
\hline Q & 47 & $\begin{array}{l}\text { What is the recommended daily iodine intake in women planning pregnancy, women } \\
\text { who are pregnant, and women who are breastfeeding? }\end{array}$ & 1097 \\
\hline $\mathrm{R}$ & 36 & Minimum Iodine Intake Requirements in Pregnant Women, \# 1 & 1098 \\
\hline $\mathrm{R}$ & 37 & Minimum Iodine Intake Requirements in Pregnant Women, \# 2 & 1098 \\
\hline $\mathrm{R}$ & 38 & Minimum Iodine Intake Requirements in Pregnant Women, \# 3 & 1098 \\
\hline $\mathrm{Q}$ & 48 & $\begin{array}{l}\text { What is the safe upper limit for iodine consumption in pregnant and breastfeeding } \\
\text { women? }\end{array}$ & 1098 \\
\hline $\mathrm{R}$ & 39 & Recommendation Against High Amounts of Iodine in Pregnancy, \# 1 & 1098 \\
\hline $\mathrm{R}$ & 40 & Recommendation Against High Amounts of Iodine in Pregnancy, \# 2 & 1098 \\
\hline \multicolumn{4}{|c|}{ SPONTANEOUS PREGNANCY LOSS, PRETERM DELIVERY, AND THYROID ANTIBODIES } \\
\hline Q & 49 & $\begin{array}{l}\text { Is there an association between thyroid antibody positivity and sporadic spontaneous } \\
\text { abortion in euthyroid women? }\end{array}$ & 1099 \\
\hline Q & 50 & $\begin{array}{l}\text { Should women be screened for TPO antibodies before or during pregnancy with the } \\
\text { goal of treating TPOAb+ euthyroid women with } \mathrm{LT}_{4} \text { to decrease the rate of spontaneous } \\
\text { miscarriage? }\end{array}$ & 1099 \\
\hline $\mathrm{R}$ & 41 & Screening for Thyroid Antibodies in the First Trimester & 1099 \\
\hline $\mathrm{Q}$ & 51 & $\begin{array}{l}\text { Is there an association between thyroid antibodies and recurrent spontaneous } \\
\text { abortion in euthyroid women? }\end{array}$ & 1099 \\
\hline $\mathrm{Q}$ & 52 & $\begin{array}{l}\text { Should women with recurrent abortion be screened for TAb before or during } \\
\text { pregnancy with the goal of treating euthyroid TAb }+ \text { women with } \mathrm{LT}_{4} \text { or IVIG } \\
\text { therapy to decrease the rate of recurrent spontaneous abortion? }\end{array}$ & 1099 \\
\hline
\end{tabular}


Table 1. (Continued)

\begin{tabular}{|c|c|c|c|}
\hline & & & $\begin{array}{l}\text { Page } \\
\text { number }\end{array}$ \\
\hline $\mathrm{R}$ & 42 & Screening for $\mathrm{TAb}+$ and Treating $\mathrm{TAb}+$ Women with $\mathrm{LT}_{4}$ in the First Trimester & 1099 \\
\hline Q & 53 & $\begin{array}{l}\text { Should euthyroid women who are known to be } \mathrm{TAb}+\text { either before or during pregnancy } \\
\text { be treated with } \mathrm{LT}_{4} \text { in order to decrease the chance of sporadic or recurrent miscarriage? }\end{array}$ & 1100 \\
\hline $\mathrm{R}$ & 43 & Treating Euthyroid, $\mathrm{TAb}+$ Women with $\mathrm{LT}_{4}$ in Pregnancy & 1100 \\
\hline Q & 54 & $\begin{array}{l}\text { Is there an association between thyroid antibody positivity and pregnancy loss in } \\
\text { euthyroid women undergoing IVF? }\end{array}$ & 1100 \\
\hline Q & 55 & $\begin{array}{l}\text { Should women undergoing in vitro fertilization be screened for TPOAb }+ \text { before or } \\
\text { during pregnancy with the goal of treating euthyroid TPOAb }+ \text { women with } \mathrm{LT}_{4} \text { to } \\
\text { decrease the rate of spontaneous miscarriage? }\end{array}$ & 1100 \\
\hline $\mathrm{R}$ & 44 & $\begin{array}{l}\text { Treating Euthyroid TAb+ Women Undergoing Assisted Reproduction Technologies } \\
\text { with } \mathrm{LT}_{4}\end{array}$ & 1100 \\
\hline Q & 56 & $\begin{array}{l}\text { Is there an association between thyroid antibodies and preterm delivery in } \\
\text { euthyroid women? }\end{array}$ & 1100 \\
\hline Q & 57 & $\begin{array}{l}\text { Should women be screened for thyroid antibodies before or during pregnancy with } \\
\text { the goal of treating } \mathrm{TAb}+\text { euthyroid women with } \mathrm{LT}_{4} \text { to decrease the rate of preterm } \\
\text { delivery? }\end{array}$ & 1100 \\
\hline $\mathrm{R}$ & 45 & $\begin{array}{l}\text { First Trimester Screening for Thyroid Antibodies with Consideration of } \mathrm{LT}_{4} \\
\text { Therapy to Decrease the Risk of Preterm Delivery }\end{array}$ & 1100 \\
\hline \multicolumn{4}{|c|}{ THYROID NODULES AND THYROID CANCER } \\
\hline $\mathrm{Q}$ & 58 & What is the frequency of thyroid nodules during pregnancy? & 1100 \\
\hline $\mathrm{Q}$ & 59 & $\begin{array}{l}\text { What is the frequency of thyroid cancer in women with thyroid nodules discovered } \\
\text { during pregnancy? }\end{array}$ & 1101 \\
\hline Q & 60 & What is the optimal diagnostic strategy for thyroid nodules detected during pregnancy? & 1101 \\
\hline$\hat{\mathrm{R}}$ & 46 & Workup of Thyroid Nodules During Pregnancy & 1101 \\
\hline $\mathrm{R}$ & 47 & Measurement of Serum Calcitonin in Pregnant Women with Thyroid Nodules & 1101 \\
\hline $\mathrm{R}$ & 48 & Risk of FNA of Thyroid Nodules in Pregnancy & 1102 \\
\hline $\mathrm{R}$ & 49 & FNA of Thyroid Nodules in Pregnancy & 1102 \\
\hline $\mathrm{R}$ & 50 & Recommendation Against Use of Radioiodine in Pregnancy & 1102 \\
\hline Q & 61 & Does pregnancy impact the prognosis of thyroid carcinoma? & 1102 \\
\hline$\tilde{R}$ & 51 & Time of Surgery for Pregnant Women with Well-Differentiated Thyroid Carcinoma & 1102 \\
\hline $\mathrm{R}$ & 52 & Time of Surgery for Pregnant Women with Medullary Thyroid Carcinoma & 1102 \\
\hline Q & 62 & $\begin{array}{l}\text { What are the perioperative risks to mother and fetus of surgery for thyroid cancer } \\
\text { during pregnancy? }\end{array}$ & 1102 \\
\hline $\mathrm{R}$ & 53 & Risk of Surgery for Thyroid Carcinoma in the Second Trimester & 1102 \\
\hline Q & 63 & How should benign thyroid nodules be managed during pregnancy? & 1103 \\
\hline$\tilde{R}$ & 54 & Surgery During Pregnancy for Benign Thyroid Nodules & 1103 \\
\hline Q & 64 & How should DTC be managed during pregnancy? & 1103 \\
\hline $\mathrm{R}$ & 55 & Role of Thyroid Ultrasound in Pregnant Women with Suspected Thyroid Carcinoma & 1103 \\
\hline $\mathrm{R}$ & 56 & Time of Surgery for Pregnant Women with Differentiated Thyroid Carcinoma & 1103 \\
\hline $\mathrm{R}$ & 57 & LT $_{4}$ Treatment in Pregnant Women with Differentiated Thyroid Carcinoma & 1103 \\
\hline Q & 65 & How should suspicious thyroid nodules be managed during pregnancy? & 1103 \\
\hline$\tilde{R}$ & 58 & Time of Surgery for Pregnant Women with FNA Suspicious for Thyroid Cancer & 1103 \\
\hline Q & 66 & $\begin{array}{l}\text { What are the TSH goals during pregnancy for women with previously treated thyroid } \\
\text { cancer and who are on } \mathrm{LT}_{4} \text { therapy? }\end{array}$ & 1103 \\
\hline $\mathrm{R}$ & 59 & Goal for TSH Level in Pregnant Women with History of Thyroid Cancer & 1104 \\
\hline Q & 67 & What is the effect of RAI treatment for DTC on subsequent pregnancies? & 1104 \\
\hline $\bar{R}$ & 60 & Timing of Pregnancy in Women with a History of Radioactive Iodine Treatment & 1105 \\
\hline Q & 68 & Does pregnancy increase the risk of DTC recurrence? & 1105 \\
\hline Q & 69 & $\begin{array}{l}\text { What type of monitoring should be performed during pregnancy in a patient who has } \\
\text { already been treated for DTC prior to pregnancy? }\end{array}$ & 1105 \\
\hline $\mathrm{R}$ & 61 & $\begin{array}{l}\text { Role of Ultrasound and Tg Monitoring During Pregnancy in Women with a History } \\
\text { of Low-Risk DTC }\end{array}$ & 1105 \\
\hline $\mathrm{R}$ & 62 & $\begin{array}{l}\text { Role of Ultrasound Monitoring in Women with DTC and High Thyroglobulin Levels } \\
\text { or Persistent Structural Disease }\end{array}$ & 1105 \\
\hline \multicolumn{4}{|c|}{ POSTPARTUM THYROIDITIS } \\
\hline $\mathrm{Q}$ & 70 & What is the definition of PPT and what are its clinical implications? & 1105 \\
\hline$\tilde{Q}$ & 71 & What is the etiology of PPT? & 1105 \\
\hline $\mathrm{Q}$ & 72 & Are there predictors of PPT? & 1105 \\
\hline$\hat{Q}$ & 73 & What is the prevalence of PPT? & 1106 \\
\hline Q & 74 & What symptoms are associated with PPT? & 1106 \\
\hline
\end{tabular}


TABle 1. (CONTINUED)

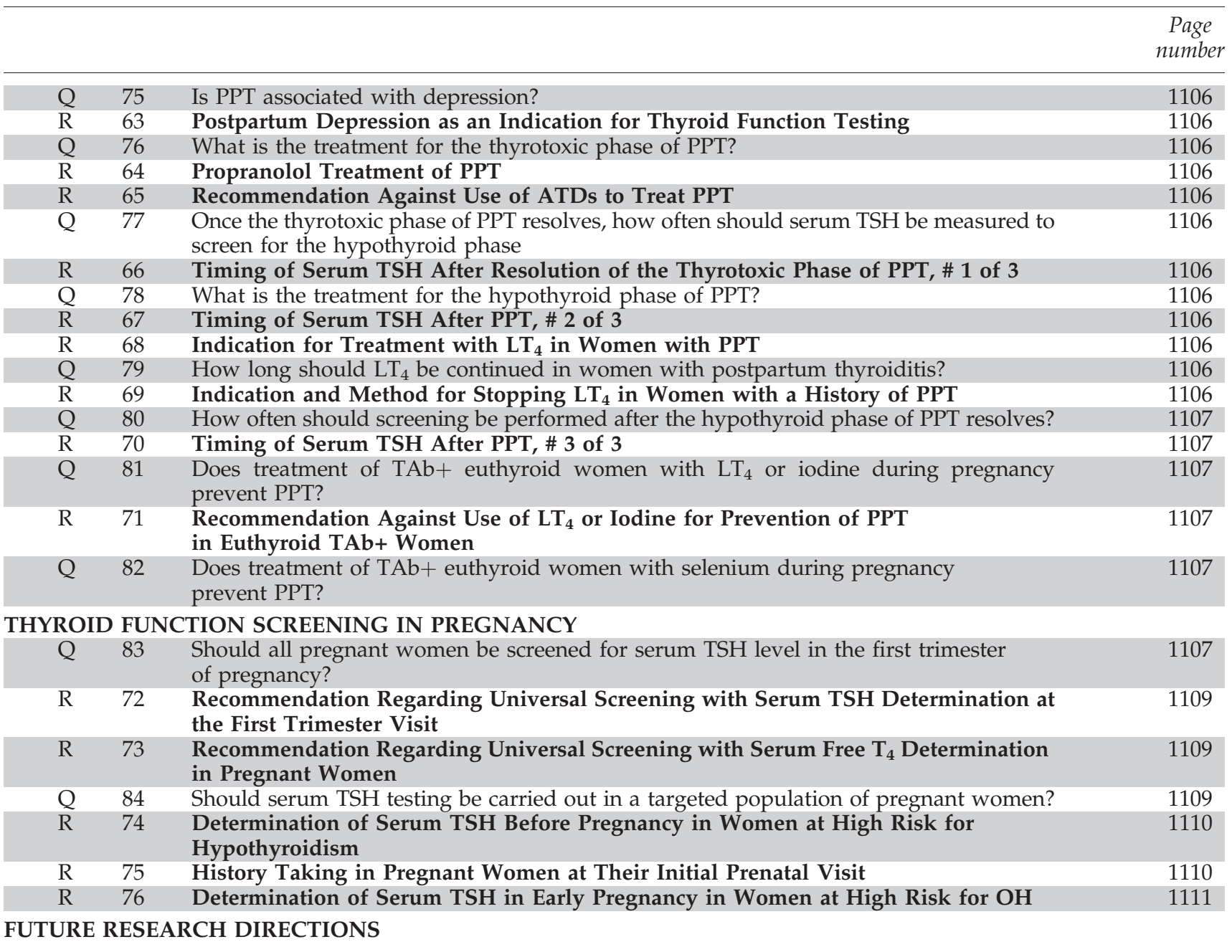

ATD, antithyroid drug; DTC, differentiated thyroid carcinoma; FNA, fine-needle aspiration; $\mathrm{FT}_{4}$, free thyroxine; IVF, in vitro fertilization; IVIG, intravenous immunoglobin; $\mathrm{LT}_{4}$, levothyroxine; MMI, methimazole; $\mathrm{OH}$, overt hypothyroidism; PPT, postpartum thyroiditis; PTU, propylthiouracil; Q, Question; R, Recommendation; RAI, radioactive iodine; SCH, subclinical hypothyroidism; TAb+, positive for thyroid peroxidase antibody and/or thyroglobulin antibody; $\mathrm{Tg}$, thyroglobulin; TPOAb+, positive for thyroid peroxidase antibody; TRAb, TSH receptor antibodies; TSH, thyrotropin.

\section{RESULTS}

\section{Thyroid Function Tests in Pregnancy}

\section{Question 1: How do thyroid function tests change during pregnancy?}

To meet the challenge of increased metabolic needs during pregnancy, the thyroid adapts through changes in thyroid hormone economy and in the regulation of the hypothalamicpituitary-thyroid axis $(4,5)$. Consequently, thyroid function test results of healthy pregnant women differ from those of healthy nonpregnant women. This calls for pregnancyspecific and ideally trimester-specific reference intervals for all thyroid function tests but in particular for the most widely applied tests, $\mathrm{TSH}$ and free $\mathrm{T}_{4}\left(\mathrm{FT}_{4}\right)$.

Following conception, circulating total $\mathrm{T}_{4}\left(\mathrm{TT}_{4}\right)$ and $\mathrm{T}_{4}$ binding globulin (TBG) concentrations increase by $6-8$ weeks and remain high until delivery. Thyrotropic activity of hCG results in a decrease in serum TSH in the first trimester $(5,6)$.
Therefore, during pregnancy, women have lower serum TSH concentrations than before pregnancy, and frequently TSH is below the classical lower limit of $0.4 \mathrm{mIU} / \mathrm{L}(7,8)$.

Most studies also report a substantial decrease in serum $\mathrm{FT}_{4}$ concentrations with progression of gestation $(7,9,10)$. Serum $\mathrm{FT}_{4}$ measurements in pregnant women are complicated by increased TBG and decreased albumin concentrations that can cause immunoassays to be unreliable $(11,12)$. Therefore the analytical method used for serum $\mathrm{FT}_{4}$ analysis should be taken into consideration.

\section{Question 2: What is the normal range for TSH in each trimester?}

There is strong evidence in the literature that the reference range for TSH is lower throughout pregnancy; i.e., both the lower normal limit and the upper normal limit of serum TSH are decreased by about $0.1-0.2 \mathrm{mIU} / \mathrm{L}$ and $1.0 \mathrm{mIU} / \mathrm{L}$, respectively, compared with the customary TSH reference in- 
Table 2. Sample Trimester-Specific Reference Intervals for Serum TSH

\begin{tabular}{|c|c|c|c|}
\hline \multirow[b]{2}{*}{ Reference } & \multicolumn{3}{|c|}{ Trimester $^{\mathrm{a}}$} \\
\hline & First & Second & Third \\
\hline Haddow et al. (13) & $0.94(0.08-2.73)$ & $1.29(0.39-2.70)$ & - \\
\hline Stricker et al. (14) & $1.04(0.09-2.83)$ & $1.02(0.20-2.79)$ & $1.14(0.31-2.90)$ \\
\hline Panesar et al. (15) & $0.80(0.03-2.30)$ & $1.10(0.03-3.10)$ & $1.30(0.13-3.50)$ \\
\hline Soldin et al. (16) & $0.98(0.24-2.99)$ & 1.09 (0.46-2.95) & $1.20(0.43-2.78)$ \\
\hline Bocos-Terraz et al. (17) & $0.92(0.03-2.65)$ & $1.12(0.12-2.64)$ & $1.29(0.23-3.56)$ \\
\hline Marwaha et al. (18) & $2.10(0.60-5.00)$ & $2.40(0.43-5.78)$ & $2.10(0.74-5.70)$ \\
\hline
\end{tabular}

${ }^{a}$ Median TSH in $\mathrm{mIU} / \mathrm{L}$, with parenthetical data indicating 5 th and 95 th percentiles $(13,15,18)$ or 2.5 th and 97.5 th percentiles $(14,16,17)$.

terval of $0.4-4.0 \mathrm{mIU} / \mathrm{L}$ of nonpregnant women. The largest decrease in serum TSH is observed during the first trimester and is transient, apparently related to hCG levels, which are highest early in gestation (Table 2). The median TSH values in the three trimesters in Table 2 are quite consistent, except for the study by Marwaha et al. (18) which, for unexplained reasons, reports higher TSH values throughout pregnancy. Serum TSH and its reference range gradually rise in the second and third trimesters, but it is noteworthy that the TSH reference interval remains lower than in nonpregnant women $(13,15)$. Since hCG concentrations are higher in multiple pregnancies than in singleton pregnancies, the downward shift in the TSH reference interval is greater in twin pregnancies than in singleton pregnancies (19). In a study of 63 women with hCG concentrations $>200,000 \mathrm{IU} / \mathrm{L}$, TSH was suppressed $(\leq 0.2 \mathrm{mIU} / \mathrm{L})$ in $67 \%$ of women, and in $100 \%$ of women if hCG concentrations were $>400,000 \mathrm{IU} / \mathrm{L}$ (20).

In a small percentage of women, TSH can be very suppressed $(<0.01 \mathrm{mIU} / \mathrm{L})$ and yet still represent a normal pregnancy. There are slight but significant ethnic differences in serum TSH concentrations. Black and Asian women have TSH values that are on average $0.4 \mathrm{mIU} / \mathrm{L}$ lower than in white women; these differences persist during pregnancy $(21,22)$. Pregnant women of Moroccan, Turkish, or Surinamese descent residing in The Netherlands, have TSH values $0.2-0.3 \mathrm{mIU} / \mathrm{L}$ lower than Dutch women throughout pregnancy (23). TSH ranges vary slightly depending on differences between methods of analysis (24). Subclinical hyperthyroidism is not associated with adverse pregnancy outcomes; therefore, a TSH value that is within detection is unlikely to be clinically significant (25).

\section{- RECOMMENDATION 1}

Trimester-specific reference ranges for TSH, as defined in populations with optimal iodine intake, should be applied. Level B-USPSTF

\section{- RECOMMENDATION 2}

If trimester-specific reference ranges for TSH are not available in the laboratory, the following reference ranges are recommended: first trimester, $0.1-2.5 \mathrm{mIU} / \mathrm{L}$; second trimester, $0.2-3.0 \mathrm{mIU} / \mathrm{L}$; third trimester, $0.3-3.0 \mathrm{mIU} / \mathrm{L}$. Level I-USPSTF

\section{Question 3: What is the optimal method to assess $\mathrm{FT}_{4}$ during pregnancy?}

The normal ranges for $\mathrm{FT}_{4}$ index are calculated by $\mathrm{TT}_{4} \times \mathrm{T}_{3}$ uptake or a ratio of $\mathrm{TT}_{4}$ and $\mathrm{TBG}$, but trimester-specific reference intervals for $\mathrm{FT}_{4}$ index have not been established in a reference population. Only $0.03 \%$ of serum $\mathrm{TT}_{4}$ content is unbound to serum proteins and is the $\mathrm{FT}_{4}$ available for tissue uptake. Sera $\mathrm{TT}_{4}$ concentrations are in the nanomolar range, but $\mathrm{FT}_{4}$ concentrations are in the picomolar range. Measuring $\mathrm{FT}_{4}$ in the presence of high concentrations of bound $\mathrm{T}_{4}$ has proved challenging especially in abnormal binding-protein states such as pregnancy.

Equilibrium dialysis and ultrafiltration are used for physical separation of serum $\mathrm{FT}_{4}$ from bound $\mathrm{T}_{4}$ prior to analysis of the dialysate or ultrafiltrate. Assays based on classical equilibrium dialysis or ultrafiltration are laborious, timeconsuming, expensive, and not widely available.

$\mathrm{FT}_{4}$ immunoassay approaches are liable to error by disrupting the original equilibrium, which is dependent on dilution, temperature, buffer composition, affinity, and concentration of the $\mathrm{T}_{4}$ antibody reagent and $\mathrm{T}_{4}$-binding capacity of the serum sample (26). High TBG concentrations in serum samples tend to result in higher $\mathrm{FT}_{4}$ values, whereas low albumin in serum likely will yield lower $\mathrm{FT}_{4}$ values. In order to decrease nonspecific binding and neutralize the effect of nonesterified fatty acids on serum $\mathrm{FT}_{4}$, some assays add albumin; however, albumin binds $\mathrm{T}_{4}$ and when it is added in sufficient amounts, it may disrupt the equilibrium. Nevertheless, the currently used $\mathrm{FT}_{4}$ immunoassays perform reasonably well under most circumstances, accurately reporting low $\mathrm{FT}_{4}$ levels in thyroid hormone deficiency and high $\mathrm{FT}_{4}$ levels in thyroid hormone excess (27).

The serum of pregnant women is characterized by higher concentrations of TBG and nonesterified fatty acids and by lower concentrations of albumin relative to the serum of nonpregnant women. Many current $\mathrm{FT}_{4}$ immunoassays fail to account for the effect of dilution $(26,28)$. Because $\mathrm{FT}_{4}$ reference intervals in pregnancy varied widely between methods, interpretation of $\mathrm{FT}_{4}$ values requires method-specific ranges $(11,12,29)$. Moreover, such ranges are also influenced by the iodine status of the population studied. Whereas it is customary for manufacturers to suggest that laboratories establish their own reference range for a test, this is impractical in clinical practice. It is especially difficult to recruit subjects with specific conditions such as pregnancy in order to independently establish method- and trimester-specific ranges. It follows that it is customary for laboratories to adopt the ranges provided by the manufacturer of the test. Typically, the characteristics of these reference pregnant cohorts are not disclosed and may differ in iodine intake and ethnicity to an extent that compromises the value of adopting the manufacturer ranges across different populations.

Current uncertainty around $\mathrm{FT}_{4}$ estimates in pregnancy has led some to question the wisdom of relying on $\mathrm{FT}_{4}$ immunoassays during pregnancy $(30,31)$. In contrast to $\mathrm{FT}_{4}$ as measured by two commercial immunoassays, $\mathrm{TT}_{4}$ and the $\mathrm{FT}_{4}$ index 
showed the expected inverse relationship with TSH (30). The authors argue that $\mathrm{TT}_{4}$ measurements may be superior to $\mathrm{FT}_{4}$ measurements by immunoassay in sera of pregnant women, provided the reference values take into account the 50\% increase of TBG in pregnancy by calculating the $\mathrm{FT}_{4}$ index with the help of a serum thyroid hormone uptake test.

The latest development in the field of $\mathrm{FT}_{4}$ analysis is to measure free thyroid hormones in the dialysate or ultrafiltrate using online solid phase extraction-liquid chromatography/ tandem mass spectrometry (LC/MS/MS). The method is regarded as a major advance, with higher specificity in comparison to immunoassays and great potential to be applied in the routine assessment of $\mathrm{FT}_{4}$ and $\mathrm{FT}_{3}$. Using direct equilibrium dialysis and $\mathrm{LC} / \mathrm{MS} / \mathrm{MS}$, the $95 \% \mathrm{FT}_{4}$ reference intervals decreased gradually with advancing gestational age: from $1.08-1.82 \mathrm{ng} / \mathrm{dL}$ in week 14 to $0.86-1.53 \mathrm{ng} / \mathrm{dL}$ in week 20 (32). Using ultrafiltration followed by isotope dilution LC/ $\mathrm{MS} / \mathrm{MS}$, serum $\mathrm{FT}_{4}$ concentrations (given as mean $\pm \mathrm{SE}$ ) were $0.93 \pm 0.25 \mathrm{ng} / \mathrm{dL}$ in nonpregnant women, $1.13 \pm 0.23 \mathrm{ng} / \mathrm{dL}$ in the first trimester, $0.92 \pm 0.30 \mathrm{ng} / \mathrm{dL}$ in the second trimester, and $0.86 \pm 0.21 \mathrm{ng} / \mathrm{dL}$ in the third trimester (9). Serum $\mathrm{FT}_{4}$ measured by a direct analog immunoassay in the same samples also demonstrated decreasing values during pregnancy: $1.05 \pm 0.22 \mathrm{ng} / \mathrm{dL}, 0.88 \pm 0.17 \mathrm{ng} / \mathrm{dL}$, and $0.89 \pm 0.17 \mathrm{ng} / \mathrm{dL}$ in the first, second, and third trimesters, respectively. Serum $\mathrm{FT}_{4}$ by $\mathrm{LC} / \mathrm{MS} / \mathrm{MS}$ correlated very well with serum $\mathrm{FT}_{4}$ measured by classical equilibrium dialysis, but correlation with results from the $\mathrm{FT}_{4}$ immunoassay were less satisfactory (9).

Free thyroid hormone concentrations measured by LC/ MS/MS correlate generally to a greater degree with log TSH values compared with concentrations measured by immunoassay (31). In pregnancy, however, there is little relationship between $\log \mathrm{TSH}$ and $\mathrm{FT}_{4}\left(r=0.11\right.$ for $\mathrm{FT}_{4} \mathrm{LC} / \mathrm{MS} / \mathrm{MS}$, and $r=-0.06$ for $\mathrm{FT}_{4}$ immunoassay) (33), suggesting changes in the set point of the hypothalamic-pituitary-thyroid axis during pregnancy. Application of LC/MS/MS for measurement of free thyroid hormones is currently in routine clinical use in a few centers. The method is ideally suited for generating reliable, reproducible trimester-specific reference ranges for $\mathrm{FT}_{4}(9)$. A working group of the International Federation of Clinical Chemistry and Laboratory Medicine recommends the use of isotope dilution-LC/MS/MS for measuring $\mathrm{T}_{4}$ in the dialysate from equilibrium dialysis of serum in order to obtain a trueness-based reference measurement procedure for serum $\mathrm{FT}_{4}$ (34). This assay technology, unfortunately, is currently not widely available due to high instrument and operating costs.

\section{- RECOMMENDATION 3}

The optimal method to assess serum $\mathrm{FT}_{4}$ during pregnancy is measurement of $\mathrm{T}_{4}$ in the dialysate or ultrafiltrate of serum samples employing on-line extraction/liquid chromatography/tandem mass spectrometry (LC/MS/ MS). Level A-USPSTF

\section{- RECOMMENDATION 4}

If $\mathrm{FT}_{4}$ measurement by LC/MS/MS is not available, clinicians should use whichever measure or estimate of $\mathrm{FT}_{4}$ is available in their laboratory, being aware of the limitations of each method. Serum TSH is a more accurate indication of thyroid status in pregnancy than any of these alternative methods. Level A-USPSTF

\section{- RECOMMENDATION 5}

In view of the wide variation in the results of $\mathrm{FT}_{4}$ assays, method-specific and trimester-specific reference ranges of serum $\mathrm{FT}_{4}$ are required. Level B-USPSTF

\section{Hypothyroidism in Pregnancy}

In the absence of rare exceptions (TSH-secreting pituitary tumor, thyroid hormone resistance, a few cases of central hypothyroidism with biologically inactive TSH) primary maternal hypothyroidism is defined as the presence of an elevated TSH concentration during gestation. Historically, the reference range for serum TSH was derived from the serum of healthy, nonpregnant individuals. Using these data, values greater than $\sim 4.0 \mathrm{mIU} / \mathrm{L}$ were considered abnormal. More recently, normative data from healthy pregnant women suggest the upper reference range may approximate 2.5-3.0 $\mathrm{mIU} / \mathrm{L}(15,19)$. When maternal TSH is elevated, measurement of serum $\mathrm{FT}_{4}$ concentration is necessary to classify the patient's status as either subclinical $(\mathrm{SCH})$ or overt hypothyroidism $(\mathrm{OH})$. This is dependent upon whether $\mathrm{FT}_{4}$ is within or below the trimester-specific $\mathrm{FT}_{4}$ reference range. The distinction of $\mathrm{OH}$ from $\mathrm{SCH}$ is important because published data relating to the maternal and fetal effects attributable to $\mathrm{OH}$ are more consistent and easier to translate into clinical recommendations in comparison to those regarding $\mathrm{SCH}$.

Several investigations report that at least $2 \%-3 \%$ of apparently healthy, nonpregnant women of childbearing age have an elevated serum TSH $(35,36)$. Among these healthy nonpregnant women of childbearing age it is estimated that $0.3 \%-0.5 \%$ of them would, after having thyroid function tests, be classified as having $\mathrm{OH}$, while $2 \%-2.5 \%$ of them would be classified as having $\mathrm{SCH}$. These data derive from a population in the United States, which is considered a relatively iodinesufficient country. It would be anticipated that such percentages would be higher in areas of iodine insufficiency. When iodine nutrition is adequate, the most frequent cause of hypothyroidism is autoimmune thyroid disease (also called Hashimoto's thyroiditis). Thyroid auto-antibodies were detected in $\sim 50 \%$ of pregnant women with $\mathrm{SCH}$ and in more than $80 \%$ with $\mathrm{OH}(36)$.

\section{Question 4: What are the definitions of $\mathrm{OH}$ and $\mathrm{SCH}$ in pregnancy?}

Elevations in serum TSH during pregnancy should be defined using pregnancy-specific reference ranges. $\mathrm{OH}$ is defined as an elevated TSH $(>2.5 \mathrm{mIU} / \mathrm{L})$ in conjunction with a decreased $\mathrm{FT}_{4}$ concentration. Women with TSH levels of 10.0 $\mathrm{mIU} / \mathrm{L}$ or above, irrespective of their $\mathrm{FT}_{4}$ levels, are also considered to have $\mathrm{OH}$. SCH is defined as a serum TSH between 2.5 and $10 \mathrm{mIU} / \mathrm{L}$ with a normal $\mathrm{FT}_{4}$ concentration.

\section{Question 5: How is isolated hypothyroxinemia defined in pregnancy?}

Isolated hypothyroxinemia is defined as a normal maternal TSH concentration in conjunction with $\mathrm{FT}_{4}$ concentrations in the lower 5 th or 10 th percentile of the reference range.

\section{Question 6: What adverse outcomes are associated with $\mathrm{OH}$ in pregnancy?}

$\mathrm{OH}$ in pregnancy has consistently been shown to be associated with an increased risk of adverse pregnancy com- 
plications, as well as detrimental effects upon fetal neurocognitive development (37). Specific adverse outcomes associated with maternal $\mathrm{OH}$ include an increased risk of premature birth, low birth weight, and miscarriage. Abalovich et al. (38) demonstrated such patients carry an estimated $60 \%$ risk of fetal loss when $\mathrm{OH}$ was not adequately detected and treated. Leung et al. (39) demonstrated a $22 \%$ risk of gestational hypertension in pregnant women with $\mathrm{OH}$, higher in comparison to euthyroid women or those with $\mathrm{SCH}$. Allan and colleagues (36) also describe an increased risk of fetal death among pregnant women with $\mathrm{OH}$. In conclusion, a firm association between $\mathrm{OH}$ and adverse risk to the maternalfetal unit has been demonstrated.

\section{Question 7: What adverse outcomes are associated with $\mathrm{SCH}$ in pregnancy?}

$\mathrm{SCH}$ is associated with an increased risk of adverse pregnancy complications and possibly with an increased risk of neurocognitive deficits in the developing fetus. In comparison to $\mathrm{OH}$, however, data regarding $\mathrm{SCH}$ are variable. In the best study to date, Negro and colleagues (40) published data suggesting $\mathrm{SCH}$ increases the risk of pregnancy complications in anti-thyroid peroxidase antibody positive (TPOAb + ) women. In a prospective, randomized trial of $>4000$ women, a group of "low-risk" individuals was universally screened in early pregnancy for TPOAb + and TSH elevation $>2.5 \mathrm{mIU} /$ L. When this combination was identified, $\mathrm{LT}_{4}$ treatment was initiated in order to normalize serum TSH. In a control population of equal size serum samples were obtained in early pregnancy, but measurement of serum TSH and TPO Ab was delayed until after delivery, and thus no $\mathrm{LT}_{4}$ was provided to this group. This allowed direct comparison of the effects of $\mathrm{LT}_{4}$ administration in women who were TPOAb+ and had TSH values above $2.5 \mathrm{mIU} / \mathrm{L}$ with the findings in untreated controls. The results confirmed a significant reduction in a combined endpoint of pregnancy complications. In a follow-up analysis of the same data, Negro et al. (41) reported a significantly higher miscarriage rate in TPOAb - women with TSH levels between 2.5 and $5.0 \mathrm{mIU} /$ L compared with those with TSH levels below $2.5 \mathrm{mIU} / \mathrm{L}$ ( $6.1 \%$ vs. $3.6 \%$ respectively, $p=0.006)$. The latter trial had no interventional component. These prospective data are supported by previous retrospective data published by Casey and colleagues (35). In that investigation, a two- to threefold increased risk of pregnancy-related complications was demonstrated in untreated women with SCH. Similarly, Benhadi and colleagues (42) performed a case-control study investigating risk of pregnancy loss in 2497 Dutch women. In this cohort of pregnant women without $\mathrm{OH}$, the risk of child loss increased with higher levels of maternal TSH.

However, some published data demonstrate contrasting conclusions. Cleary-Goldman et al. (43) reported no adverse effect from subclinical maternal hypothyroidism (detected in the first and second trimester) in a cohort of 10,990 pregnant women. However, the study analysis was performed only utilizing a selected subgroup of the entire study cohort ( $29 \%$ of the study cohort analyzed) with a mean gestational age of screening between 10.5 and 14 weeks gestation. Furthermore, women were only included in the study if their pregnancy remained viable until a second trimester serum sample could be obtained. Mannisto and colleagues $(44,45)$ evaluated the relationship between pregnancy outcome and thyroid function tests obtained at 12 weeks gestation in 5805 women, from an initial cohort of 9247 women, and found no adverse consequence on perinatal mortality. However, because only $63 \%$ of the full study cohort was included in this analysis (5805/9247), interpretation of the data is limited.

In the most recently published study on pregnancy loss Ashoor et al. (46) evaluated TSH and $\mathrm{FT}_{4}$ levels in 202 singleton pregnancies at 11-13 weeks in pregnancies that subsequently resulted in miscarriage or fetal death and compared the thyroid function tests with those of 4318 normal pregnancies. Women who experienced either miscarriage or fetal loss had increased TSH levels above the 97.5th percentile $(5.9 \%$ vs. $2.5 \%, p<0.05)$ and $\mathrm{FT}_{4}$ levels below the 2.5 th percentile $(5.0 \%$ vs. $2.5 \%, p<0.05)$. At present, the majority of high-quality evidence suggests that $\mathrm{SCH}$ is associated with increased risk of adverse pregnancy outcomes.

The detrimental effect of $\mathrm{SCH}$ on fetal neurocognitive development is less clear. Data from a large, case-control study demonstrated a reduction in intelligence quotient (IQ) among children born to untreated hypothyroid women when compared with euthyroid controls. These data by Haddow et al. (37) describe a 7-point IQ deficit in the offspring of untreated hypothyroid women in addition to delays in motor, language, and attention at 7-9 years of age. Similar retrospective data were previously published by Man and colleagues $(47,48)$, although it is worth noting that such older data identified patients based on serum butanolextractable iodine as opposed to thyroid function measurement. Preliminary data from the Controlled Antenatal Thyroid Screening trials, presented at the International Thyroid Congress in 2010, have questioned these findings. Primary outcomes of the study were the mean IQ of children at 3.5 years and the percentage of children with an IQ $<85$ at 3.5 years among children whose mothers were treated for $\mathrm{SCH}$ and/or isolated hypothyroxinemia as compared to children whose mothers were not treated. In the intention to treat analysis there were no differences in either of these outcomes. In the secondary endpoint, which consisted of an analysis based on study completion, there was no difference in mean IQ. However, the percentage of children with IQs $<85$ was higher in the untreated group vs. the treated group $(15.6 \%$ vs. $9.2 \%, p=0.009)$. The data presented at the International Thyroid Congress did not break down the findings based on whether the women had $\mathrm{SCH}$ or isolated hypothyroxinemia. In summary, an association between maternal SCH and adverse fetal neurocognitive development is biologically plausible (49), though not clearly demonstrated.

\section{Question 8: What adverse outcomes are associated with isolated hypothyroxinemia in pregnancy?}

It is debated whether isolated hypothyroxinemia causes any adverse effects on the developing fetus. Pop and colleagues (50) reported a decrease in psychomotor test scores among offspring born to women with $\mathrm{FT}_{4}$ indices in the lowest 10th percentile. These mothers often had normal serum TSH values. Li et al. (51) observed a similar reduction in the IQ of the offspring whose mothers experienced either 
hypothyroidism or isolated hypothyroxinemia during the first trimester. These data have been subject to much debate concerning methodological processes and the plausibility of their conclusion. However, renewing such debate, Henrichs and colleagues (52) recently published data from the Generation $\mathrm{R}$ study, conducted in the Netherlands. This prospective, nonrandomized investigation evaluated communication development in children born to women with isolated hypothyroxinemia. A 1.5- to 2-fold increased risk of adverse findings (at 3 years of age) was associated with maternal $\mathrm{FT}_{4}$ in the lower 5th and 10th percentiles. As noted above, the subanalysis of the data from the Controlled Antenatal Thyroid Study on the impact of treating maternal isolated hypothyroxinemia on IQ of the child at 3.5 years has not yet been reported.

\section{Question 9: Should $\mathrm{OH}$ be treated in pregnancy?}

Numerous retrospective and case-controlled studies confirm the detrimental effects of $\mathrm{OH}$ on pregnancy and fetal health. Though no prospective, randomized investigation of $\mathrm{LT}_{4}$ intervention has occurred in $\mathrm{OH}$ pregnant women, such an investigation would be unethical and prohibitive to complete. The available data confirm the benefits of treating $\mathrm{OH}$ during pregnancy.

\section{- RECOMMENDATION 6}

$\mathrm{OH}$ should be treated in pregnancy. This includes women with a TSH concentration above the trimester-specific reference interval with a decreased $\mathrm{FT}_{4}$, and all women with a $\mathrm{TSH}$ concentration above $10.0 \mathrm{mIU} / \mathrm{L}$ irrespective of the level of $\mathrm{FT}_{4}$. Level A-USPSTF

\section{Question 10: Should isolated hypothyroxinemia be treated in pregnancy?}

To date, no randomized, interventional trial of $\mathrm{LT}_{4}$ therapy has been performed in pregnant women with isolated hypothyroxinemia (this will change with the publication of the Controlled Antenatal Thyroid Study). Thus, because only limited data exist suggesting harm from isolated hypothyroxinemia and no interventional data have been published, the committee does not recommend therapy for such women at present.

\section{- RECOMMENDATION 7}

Isolated hypothyroxinemia should not be treated in pregnancy. Level C-USPSTF

\section{Question 11: Should SCH be treated in pregnancy?}

A large amount of retrospective data provides circumstantial evidence supporting an increased risk of adverse outcomes from maternal SCH. Clinicians should be aware of these potential increased risks associated with $\mathrm{SCH}$, and it is reasonable to consider $\mathrm{LT}_{4}$ treatment under these circumstances. There is a single randomized controlled trial that demonstrated that $\mathrm{LT}_{4}$ intervention at $\sim 9$ weeks gestation resulted in a reduction in adverse pregnancy outcomes in $\mathrm{TPOAb}+$ women with SCH (40). However, the majority of women with $\mathrm{SCH}$ detected in this investigation were $\mathrm{TPOAb}-$, and no intervention or treatment was provided for them. This study also used a composite study endpoint including hard-to-interpret variables such as cesarean section rates and postdelivery admission to the neonatal intensive care unit. Another randomized controlled trial (RCT) demonstrated a decrease in preterm delivery and miscarriage in euthyroid (defined as TSH $<4.2 \mathrm{mIU} / \mathrm{L}$ ) TPOAb+ women who were treated with $\mathrm{LT}_{4}$ beginning in the first trimester of pregnancy. It should be noted that some of the women diagnosed as euthyroid in this study (TSH $<4.2 \mathrm{mIU} / \mathrm{L}$ ), would now be classified as having SCH (TSH $>2.5 \mathrm{mIU} / \mathrm{L})$.

\section{- RECOMMENDATION 8}

SCH has been associated with adverse maternal and fetal outcomes. However, due to the lack of randomized controlled trials there is insufficient evidence to recommend for or against universal $\mathrm{LT}_{4}$ treatment in $\mathrm{TAb}-$ pregnant women with SCH. Level I-USPSTF

\section{- RECOMMENDATION 9}

Women who are positive for TPOAb and have $\mathrm{SCH}$ should be treated with $\mathrm{LT}_{4}$. Level B-USPSTF

Dissent from one committee member: There is no consistent prospective evidence demonstrating that women who are TPOAb +, but who have SCH only, achieve maternal or perinatal benefit from $\mathrm{LT}_{4}$ treatment. Correspondingly, there is no indication to treat women who are TPOAb+ and have SCH with $L T_{4}$.

\section{Question 12: When provided, what is the optimal treatment of $\mathrm{OH}$ or $\mathrm{SCH}$ ?}

\section{- RECOMMENDATION 10}

The recommended treatment of maternal hypothyroidism is with administration of oral $\mathrm{LT}_{4}$. It is strongly recommended not to use other thyroid preparations such as $\mathrm{T}_{3}$ or desiccated thyroid. Level A-USPSTF

\section{Question 13: When provided, what is the goal of $\mathrm{OH}$ or $\mathrm{SCH}$ treatment?}

\section{- RECOMMENDATION 11}

The goal of $\mathrm{LT}_{4}$ treatment is to normalize maternal serum TSH values within the trimester-specific pregnancy reference range (first trimester, 0.1-2.5 $\mathrm{mIU} / \mathrm{L}$; second trimester, $0.2-3.0 \mathrm{mIU} / \mathrm{L}$; third trimester, $0.3-3.0 \mathrm{mIU} / \mathrm{L}$ ). Level A-USPSTF

\section{Question 14: If pregnant women with $\mathrm{SCH}$ are not initially treated, how should they be monitored through gestation?}

\section{- RECOMMENDATION 12}

Women with $\mathrm{SCH}$ in pregnancy who are not initially treated should be monitored for progression to $\mathrm{OH}$ with a serum TSH and $\mathrm{FT}_{4}$ approximately every 4 weeks until 1620 weeks gestation and at least once between 26 and 32 weeks gestation. This approach has not been prospectively studied. Level I-USPSTF 


\section{Question 15: How do treated hypothyroid women (receiving $L T_{4}$ ) differ from other patients during pregnancy? What changes can be anticipated in such patients during gestation?}

The physiologic changes of the thyroid system during pregnancy have been well elucidated. Total body $\mathrm{T}_{4}$ requirements are not static throughout gestation. Rather, data demonstrate that total body $\mathrm{T}_{4}$ concentrations must increase $20 \%-50 \%$ to maintain a euthyroid state $(53,54)$. In a healthy woman who becomes pregnant, the intact hypothalamicpituitary-thyroid axis self-regulates to increase the $T_{4}$ pool for the maternal-fetal unit. Additionally, hCG plays a major role in the stimulus of maternal thyroid hormone, especially throughout the first trimester of pregnancy. Together, placental hCG and pituitary TSH stimulate endogenous $\mathrm{T}_{4}$ (and $\mathrm{T}_{3}$ ) production when an intact thyroid is present, and maintain a euthyroid state during gestation.

In women with known hypothyroidism, however, serum hCG and TSH cannot stimulate $\mathrm{T}_{4}$ production. If exogenous $\mathrm{LT}_{4}$ is not adjusted, the increased demand of pregnancy will outstrip supply and maternal hypothyroidism will occur. Clinical studies have confirmed that the increased requirement for $\mathrm{T}_{4}$ (or exogenous $\mathrm{LT}_{4}$ ) occurs as early as 4-6 weeks of pregnancy (54). Such requirements gradually increase through 16-20 weeks of pregnancy, and thereafter plateau until time of delivery. These data provide the basis for recommending adjustments to thyroid hormone in affected women once pregnant and for the timing of follow-up intervals for TSH in treated patients.

\section{Question 16: What proportion of treated hypothyroid women (receiving $L T_{4}$ ) require changes in their $L T_{4}$ dose during pregnancy?}

Between $50 \%$ and $85 \%(38,53,54)$ of hypothyroid women being treated with exogenous $\mathrm{LT}_{4}$ need to increase dosing during pregnancy. The incremental increase depends, in part, on the etiology of the hypothyroidism. There is a greater likelihood that dose increase will be required in those patients without functional thyroid tissue (e.g., due to radioablation, surgery) in comparison with patients with Hashimoto's thyroiditis $(55,56)$.

\section{Question 17: In treated hypothyroid women (receiving $L T_{4}$ ) who are planning pregnancy, how should the $L T_{4}$ dose be adjusted?}

The $\mathrm{LT}_{4}$ adjustment, when necessary, should be made as soon as possible after pregnancy is confirmed to reduce the probability of hypothyroidism. Normalization of TSH levels throughout gestation is the goal. A prospective, randomized study has recently provided evidence in support of one dose adjustment strategy for women receiving $\mathrm{LT}_{4}$ who are newly pregnant (57). For women who are euthyroid while receiving once-daily dosing of $\mathrm{LT}_{4}$ (regardless of amount), a recommendation to increase by two additional tablets weekly (nine tablets per week instead of seven tablets per week; 29\% increase) can effectively prevent maternal hypothyroidism during the first trimester and mimic gestational physiology. This augmented dose should occur immediately after a missed menstrual cycle or suspected pregnancy occurs. Confirmatory biochemical testing should also occur simultaneously. A separate option is to increase the dosage of daily $\mathrm{LT}_{4}$ by approximately $25 \%-30 \%$.

\section{- RECOMMENDATION 13}

Treated hypothyroid patients (receiving $\mathrm{LT}_{4}$ ) who are newly pregnant should independently increase their dose of $\mathrm{LT}_{4}$ by $\sim 25 \%-30 \%$ upon a missed menstrual cycle or positive home pregnancy test and notify their caregiver promptly. One means of accomplishing this adjustment is to increase $\mathrm{LT}_{4}$ from once daily dosing to a total of nine doses per week (29\% increase). Level B-USPSTF

\section{Question 18: In treated hypothyroid women (receiving $L T_{4}$ ) who are newly pregnant, what factors influence thyroid status and $L T_{4}$ requirements during gestation?}

The difficulties inherent in trying to achieve rapid TSH normalization following conception have focused attention upon preconception TSH modulation. Some advocate that TSH levels be lower than $2.5 \mathrm{mIU} / \mathrm{L}$ in women planning to become pregnant (1). Others advocate that preconception TSH levels be lower than $1.2 \mathrm{mIU} / \mathrm{L}$. In a study favoring the latter, only $17 \%$ of women with TSH values under this cutoff had to increase $\mathrm{LT}_{4}$ dose later during pregnancy (58). Separate, however, from preconception TSH values, it is increasingly apparent that other factors can also influence the rapidity and extent of $\mathrm{LT}_{4}$ augmentation necessary to maintain a euthyroid state during pregnancy. For example, variation and changes in maternal estrogen levels during pregnancy correlate with variations in the gestational requirements for $\mathrm{LT}_{4}(54)$.

Given the above, it is recommended that all treated hypothyroid women (currently receiving $\mathrm{LT}_{4}$ ) optimize thyroid status preconception. Maternal serum TSH concentration of $<2.5 \mathrm{mIU} / \mathrm{L}$ is a reasonable goal for all such women. Ideally, lower TSH values $(<1.5 \mathrm{mIU} / \mathrm{L})$ will likely further reduce the risk of mild hypothyroidism in early pregnancy, though no difference in pregnancy outcomes has been demonstrated by this approach.

\section{- RECOMMENDATION 14}

There exists great interindividual variability regarding the increased amount of $\mathrm{T}_{4}$ (or $\mathrm{LT}_{4}$ ) necessary to maintain a normal TSH throughout pregnancy, with some women requiring only $10 \%-20 \%$ increased dosing, while others may require as much as an $80 \%$ increase. The etiology of maternal hypothyroidism, as well as the preconception level of TSH, may provide insight into the magnitude of necessary $\mathrm{LT}_{4}$ increase. Clinicians should seek this information upon assessment of the patient after pregnancy is confirmed. Level A-USPSTF

\section{- RECOMMENDATION 15}

Treated hypothyroid patients (receiving $\mathrm{LT}_{4}$ ) who are planning pregnancy should have their dose adjusted by their provider in order to optimize serum TSH values to $<2.5$ $\mathrm{mIU} / \mathrm{L}$ preconception. Lower preconception TSH values (within the nonpregnant reference range) reduce the risk of TSH elevation during the first trimester. Level B-USPSTF

\section{Question 19: In hypothyroid women (receiving $L T_{4}$ ) who are newly pregnant, how often should maternal thyroid function be monitored during gestation?}

A study by Yassa and colleagues (57) investigated the optimal timing of subsequent assessment of thyroid function following dose modification. Following $\mathrm{LT}_{4}$ adjustment, $92 \%$ 
of abnormal maternal TSH values were detected when blood testing was performed every 4 weeks through midpregnancy. In comparison, a strategy assessing thyroid function every 6 weeks detected only $73 \%$ of abnormal values.

\section{- RECOMMENDATION 16}

In pregnant patients with treated hypothyroidism, maternal serum TSH should be monitored approximately every 4 weeks during the first half of pregnancy because further $\mathrm{LT}_{4}$ dose adjustments are often required. Level B-USPSTF

\section{- RECOMMENDATION 17}

In pregnant patients with treated hypothyroidism, maternal TSH should be checked at least once between 26 and 32 weeks gestation. Level I-USPSTF

\section{Question 20: How should the $L T_{4}$ dose be adjusted postpartum?}

The necessary $\mathrm{LT}_{4}$ dose adjustments during gestation are a function of pregnancy itself. Therefore, following delivery, maternal $\mathrm{LT}_{4}$ dosing should be reduced to prepregnancy levels, and a serum TSH assessed 6 weeks thereafter. However, a recent study demonstrated that more than $50 \%$ of women with Hashimoto's thyroiditis experienced an increase in the pregestational thyroid dose in the postpartum period, presumably due an exacerbation of autoimmune thyroid dysfunction postpartum (59).

\section{- RECOMMENDATION 18}

Following delivery, $\mathrm{LT}_{4}$ should be reduced to the patient's preconception dose. Additional TSH testing should be performed at approximately 6 weeks postpartum. Level B-USPSTF

\section{Question 21: What is the outcome and long-term prognosis when $\mathrm{SCH}$ and/or $\mathrm{OH}$ are effectively treated through gestation?}

Although many investigations suggest that untreated (or incompletely treated) hypothyroid women have an increased chance of pregnancy complications such as pregnancyinduced hypertension, abruption, low birth weight, and preterm deliveries $(35,40)$, there are no data to suggest that women with adequately treated $\mathrm{SCH}$ or $\mathrm{OH}$ have an increased risk of any obstetrical complication. Consequently, there is no indication for any additional testing or surveillance in pregnancies of women with either $\mathrm{SCH}$ or $\mathrm{OH}$ who are being monitored and being treated appropriately.

\section{Question 22: Except for measurement of maternal thyroid function, should additional maternal or fetal testing occur in treated, hypothyroid women during pregnancy?}

\section{- RECOMMENDATION 19}

In the care of women with adequately treated Hashimoto's thyroiditis, no other maternal or fetal thyroid testing is recommended beyond measurement of maternal thyroid function (such as serial fetal ultrasounds, antenatal testing, and/or umbilical blood sampling) unless for other pregnancy circumstances. Level A-USPSTF

\section{Question 23: In euthyroid women who are TAb+ prior to conception, what is the risk of hypothyroidism once they become pregnant?}

In 1994, Glinoer et al. (60) performed a prospective study on 87 thyroid autoantibody positive $(\mathrm{TAb}+)$ euthyroid women evaluated before and during early pregnancy. Twenty percent of women in the study developed a TSH level of $>4 \mathrm{mIU} / \mathrm{L}$ during gestation despite normal TSH and no requirement for $\mathrm{LT}_{4}$ prenatally. This occurred despite the expected decrease in $\mathrm{TAb}$ titers during pregnancy. Twelve years later, in a prospective and randomized study, Negro et al. demonstrated similar results (28). The authors found that in $\mathrm{TAb}+$ euthyroid women, TSH levels increased progressively as gestation progressed, from a mean of $1.7 \mathrm{mIU} / \mathrm{L}$ (12th week ) to 3.5 $\mathrm{mIU} / \mathrm{L}$ (term), with $19 \%$ of women having a supranormal TSH value at delivery. These findings confirm that an increased requirement for thyroid hormone occurs during gestation. In women who are $\mathrm{TAb}+$, both $\mathrm{OH}$ and $\mathrm{SCH}$ may occur during the stress of pregnancy as the ability of the thyroid to augment production is compromised and increasing demand outstrips supply. When this happens, an elevated TSH occurs. In summary, patients who are $\mathrm{TAb}+$ have an increased propensity for hypothyroidism to occur later in gestation because some residual thyroid function may still remain and provide a buffer during the first trimester.

\section{Question 24: How should TAb+ euthyroid women be monitored and treated during pregnancy?}

TSH elevation should be avoided during gestation because of the theoretical and demonstrated harm both $\mathrm{SCH}$ and $\mathrm{OH}$ may cause to the pregnancy and developing fetus. Because these risks are increased in this population, increased surveillance of euthyroid $\mathrm{TAb}+$ women should occur. Based on findings extrapolated from investigations of treated hypothyroid women who are newly pregnant (54), it is reasonable to evaluate euthyroid $\mathrm{TAb}+$ women for TSH elevation approximately every 4-6 weeks during pregnancy. TSH values that are elevated beyond trimester-specific reference ranges should be treated as described above. Serial testing should occur through midpregnancy because the increased $\mathrm{T}_{4}$ demand continues throughout the first half of gestation.

\section{- RECOMMENDATION 20}

Euthyroid women (not receiving $\mathrm{LT}_{4}$ ) who are $\mathrm{TAb}+$ require monitoring for hypothyroidism during pregnancy. Serum TSH should be evaluated every 4 weeks during the first half of pregnancy and at least once between 26 and 32 weeks gestation. Level B-USPSTF

\section{Question 25: Should TAb+ euthyroid women be monitored or treated for complications other than the risk of hypothyroidism during pregnancy?}

In addition to the risk of hypothyroidism, it has been described that being $\mathrm{TAb}+$ constitutes a risk factor for miscarriage, premature delivery $(28,60)$, perinatal death $(44)$, postpartum dysfunction, and low motor and intellectual development (IQ) in the offspring (51). Some studies have found, in nonpregnant women, that selenium is capable of diminishing the TPOAb titers (61-63). Other authors have described conflicting data (64). It has also been described that the selenium level can be low in full- 
term pregnant women compared with nonpregnant women. Recently, Negro et al. (65) observed that TPOAb+ euthyroid pregnant women treated with $200 \mu \mathrm{g} / \mathrm{d}$ of selenium not only had a significant decrease in the frequency of postpartum thyroid dysfunction $(p<0.01)$, but also had lower TPOAb levels during pregnancy compared with women in the untreated group. However, patients under treatment with selenium could be at higher risk of developing type 2 diabetes mellitus (66). At present, the risk to benefit comparison does not support routine selenium supplementation during pregnancy.

\section{- RECOMMENDATION 21}

A single RCT has demonstrated a reduction in postpartum thyroiditis from selenium therapy. No subsequent trials have confirmed or refuted these findings. At present, selenium supplementation is not recommended for TPOAb+ women during pregnancy. Level C-USPSTF

\section{Thyrotoxicosis in Pregnancy}

\section{Question 26: What are the causes of thyrotoxicosis in pregnancy?}

Thyrotoxicosis is defined as "the clinical syndrome of hypermetabolism and hyperactivity that results when the serum concentrations of free thyroxine hormone $\left(\mathrm{T}_{4}\right)$ and/or free triiodothyronine $\left(\mathrm{T}_{3}\right)$ are high" (67). Graves' disease is the most common cause of autoimmune hyperthyroidism in pregnancy, occurring in $0.1 \%-1 \%(0.4 \%$ clinical and $0.6 \%$ subclinical) of all pregnancies $(68,69)$. It may be diagnosed for the first time in pregnancy or may present as a recurrent episode in a woman with a past history of hyperthyroidism. Less common non-autoimmune causes of thyrotoxicosis include toxic multinodular goiter, toxic adenoma, and factitious thyrotoxicosis. Subacute painful or silent thyroiditis or struma ovarii are rare causes of thyrotoxicosis in pregnancy. More frequent than Graves' disease as the cause of thyrotoxicosis is the syndrome of gestational hyperthyroidism defined as "transient hyperthyroidism, limited to the first half of pregnancy characterized by elevated $\mathrm{FT}_{4}$ or adjusted $\mathrm{TT}_{4}$ and suppressed or undetectable serum TSH, in the absence of serum markers of thyroid autoimmunity" (70). It is diagnosed in about $1 \%-3 \%$ of pregnancies, depending on the geographic area and is secondary to elevated hCG levels $(70,71)$. It may be associated with hyperemesis gravidarum, defined as severe nausea and vomiting in early pregnancy, with more than $5 \%$ of weight loss, dehydration, and ketonuria. Hyperemesis gravidarum occurs in $0.5-10$ per 1000 pregnancies $(72,73)$. Other conditions associated with hCG-induced thyrotoxicosis include multiple gestation, hydatidiform mole or choriocarcinoma $(74,75)$. Most of the cases present with marked elevations of serum hCG (20). A TSH receptor mutation leading to functional hypersensitivity to hCG also has been recognized as a rare cause of gestational hyperthyroidism (76).

\section{Question 27: What is the appropriate initial evaluation of a suppressed serum TSH concentration during the first trimester of pregnancy?}

Serum TSH levels fall in the first trimester of normal pregnancies as a physiological response to the stimulating effect of hCG on the TSH receptor with a peak hCG level between 7 and 11 weeks gestation (77). Normal serum TSH values can be as low as $0.03 \mathrm{mIU} / \mathrm{mL}$ (or even undetectable) with upper limits of $2.5 \mathrm{mIU} / \mathrm{mL}$ in the first trimester and 3.0 $\mathrm{mIU} / \mathrm{mL}$ in the second and third trimesters. Any subnormal serum TSH value should be evaluated in conjunction with serum $\mathrm{FT}_{4}$. The diagnosis of clinical hyperthyroidism is confirmed in the presence of a suppressed or undetectable serum TSH and an elevated $\mathrm{FT}_{4}$.

\section{Question 28: How can gestational hyperthyroidism be differentiated from Graves' hyperthyroidism in pregnancy?}

In the presence of an undetectable or very low serum TSH and elevated $\mathrm{FT}_{4}$, the differential diagnosis in the majority of cases is between Graves' hyperthyroidism and gestational hyperthyroidism $(70,71)$. In both situations, common clinical manifestations include palpitations, anxiety, hand tremor, and heat intolerance. A careful history and physical examination are of utmost importance in establishing the etiology. The findings of no prior history of thyroid disease and no clinical signs of Graves' disease (goiter, endocrine ophthalmopathy) favor the diagnosis of gestational hyperthyroidism. In situations in which the clinical diagnosis is in doubt the determination of TSH receptor antibody (TRAb) is indicated. In the presence of a nodular goiter, a serum total $\mathrm{T}_{3}\left(\mathrm{TT}_{3}\right)$ determination is helpful in assessing the possibility of the " $\mathrm{T}_{3}$ toxicosis" syndrome. Total $\mathrm{T}_{3}$ determination may also be of benefit in diagnosing $\mathrm{T}_{3}$ thyrotoxicosis caused by Graves' disease.

\section{- RECOMMENDATION 22}

In the presence of a suppressed serum TSH in the first trimester (TSH $<0.1 \mathrm{mIU} / \mathrm{L}$ ), a history and physical examination are indicated. $\mathrm{FT}_{4}$ measurements should be obtained in all patients. Measurement of $\mathrm{TT}_{3}$ and $\mathrm{TRAb}$ may be helpful in establishing a diagnosis of hyperthyroidism. Level B-USPSTF

\section{- RECOMMENDATION 23}

There is not enough evidence to recommend for or against the use of thyroid ultrasound in differentiating the cause of hyperthyroidism in pregnancy. Level I-USPSTF

\section{- RECOMMENDATION 24}

Radioactive iodine (RAI) scanning or radioiodine uptake determination should not be performed in pregnancy. Level D-USPSTF

\section{Question 29: What is the appropriate management of gestational hyperthyroidism?}

The management of women with gestational hyperthyroidism depends on the severity of symptoms. In women with hyperemesis gravidarum, control of vomiting and treatment of dehydration with intravenous fluids compose the customary treatment. Women with severe hyperemesis gravidarum need frequent medical visits for management of dehydration and electrolyte abnormalities. In some cases hospitalization is required. Antithyroid drugs (ATDs) are not indicated, since the serum $\mathrm{T}_{4}$ returns to normal by 14-18 weeks gestation. The obstetrical outcome was not improved in isolated cases in which gestational hyperthyroidism was treated with ATDs (78). There are no studies reported in the literature comparing ATD therapy vs. supportive therapy. In 
situations in which it is difficult to arrive at a definite diagnosis, a short course of ATDs is reasonable. If the hyperthyroidism returns after discontinuation of ATDs, Graves' hyperthyroidism is the most likely diagnosis and may require further therapy.

\section{- RECOMMENDATION 25}

The appropriate management of women with gestational hyperthyroidism and hyperemesis gravidarum includes supportive therapy, management of dehydration, and hospitalization if needed. Level A-USPSTF

\section{- RECOMMENDATION 26}

ATDs are not recommended for the management of gestational hyperthyroidism. Level D-USPSTF

\section{Question 30: How should women with Graves' disease be counseled before pregnancy?}

The optimal time to conceive is once a euthyroid state is reached. Prepregnancy counseling for all patients with hyperthyroidism or a history of hyperthyroidism is imperative, and use of contraception until the disease is controlled is strongly recommended. Prior to conception, a hyperthyroid patient may be offered ablative therapy ( ${ }^{131} \mathrm{I}$ or surgery) or medical therapy.

Ablative therapy. If the patient opts for ablative therapy, the following recommendations should be given. First, surgery is a reasonable option in the presence of high TRAb titers if the mother is planning pregnancy in the following 2 years. $\mathrm{TRAb}$ titers tend to increase following ${ }^{131} \mathrm{I}$ therapy and remain elevated for many months (79). Second, a pregnancy test should be performed 48 hours before ${ }^{131}$ I ablation to avoid radiation exposure to the fetus. Third, conception should be delayed for 6 months post-ablation to allow time for the dose of $\mathrm{LT}_{4}$ to be adjusted to obtain target values for pregnancy (serum TSH between 0.3 and $2.5 \mathrm{mIU} / \mathrm{L}$ ).

Antithyroid drugs. If the patient chooses ATD therapy, the following recommendations should be given: 1) Risks associated with both propylthiouracil (PTU) and methimazole (MMI) should be discussed; 2) PTU should be used in the first trimester of pregnancy, because of the risk of MMI embryopathy; and 3) consideration should be given to discontinuing PTU after the first trimester and switching to MMI in order to decrease the incidence of liver disease.

\section{- RECOMMENDATION 27}

Thyrotoxic women should be rendered euthyroid before attempting pregnancy. Level A-USPSTF

\section{Question 31: What is the management of patients with Graves' hyperthyroidism in pregnancy?}

Several studies have shown that obstetrical and medical complications are directly related to control of hyperthyroidism and the duration of the euthyroid state in pregnancy (80-83). Poor control of thyrotoxicosis is associated with miscarriages, pregnancy-induced hypertension, prematurity, low birth weight, intrauterine growth restriction, stillbirth, thyroid storm, and maternal congestive heart failure (84).
ATDs are the mainstay of treatment for hyperthyroidism during pregnancy $(85,86)$. They reduce iodine organification and coupling of monoiodotyrosine and diiodotyrosine, thereby inhibiting thyroid hormone synthesis. Side effects occur in 3\%$5 \%$ of patients taking thioamide drugs, mostly allergic reactions such as skin rash (85). The greatest concern with the use of ATDs in pregnancy is related to teratogenic effects. Exposure to MMI may produce several congenital malformations, mainly aplasia cutis and the syndrome of "MMI embryopathy" that includes choanal or esophageal atresia and dysmorphic facies. Although very rare complications, they have not been reported with the use of PTU (87-89). Recently, a report from the Adverse Event Reporting System of the U.S. Food and Drug Administration (FDA) called attention to the risk of hepatotoxicity in patients exposed to PTU $(90,91)$; an advisory committee recommended limiting the use of PTU to the first trimester of pregnancy (92). Other exceptions to avoiding PTU are patients with MMI allergy and in the management of thyroid storm. Hepatotoxicity may occur at any time during PTU treatment. Monitoring hepatic enzymes during administration of PTU should be considered. However, no data exist that have demonstrated that the monitoring of liver enzymes is effective in preventing fulminant PTU hepatotoxicity.

Equivalent doses of PTU to MMI are 10:1 to 15:1 (100 mg of $\mathrm{PTU}=7.5$ to $10 \mathrm{mg}$ of $\mathrm{MMI}$ ) and those of carbimazole to MMI are 10:8 (85). The initial dose of ATDs depends on the severity of the symptoms and the degree of hyperthyroxinemia. In general, initial doses of ATDs are as follows: MMI, 5-15 mg daily; carbimazole, 10-15 mg daily; and PTU, 50-300 mg daily in divided doses.

Beta adrenergic blocking agents, such as propranolol 20$40 \mathrm{mg}$ every 6-8 hours may be used for controlling hypermetabolic symptoms. The dose should be reduced as clinically indicated. In the vast majority of cases the drug can be discontinued in 2-6 weeks. Long-term treatment with beta blockers has been associated with intrauterine growth restriction, fetal bradycardia and neonatal hypoglycemia (93). One study suggested a higher rate of spontaneous abortion when both drugs were taken together, as compared with patients receiving only MMI (94). However, it was not clear that this difference was due to the medication as opposed to the underlying condition. Beta blocking drugs may be used as preparation for thyroidectomy.

\section{- RECOMMENDATION 28}

PTU is preferred for the treatment of hyperthyroidism in the first trimester. Patients on MMI should be switched to PTU if pregnancy is confirmed in the first trimester. Following the first trimester, consideration should be given to switching to MMI. Level I-USPSTF

The combination of $\mathrm{LT}_{4}$ and ATDs has not been shown to decrease the recurrence rate of Graves' disease postpartum, results in a larger dose of ATDs in order to maintain the $\mathrm{FT}_{4}$ within the target range, and may lead to fetal hypothyroidism (95). The only indication for the combination of ATDs and $\mathrm{LT}_{4}$ is in the treatment of fetal hyperthyroidism.

\section{- RECOMMENDATION 29}

A combination regimen of $\mathrm{LT}_{4}$ and an ATD should not be used in pregnancy, except in the rare situation of fetal hyperthyroidism. Level D-USPSTF 


\section{Question 32: What tests should be performed in women treated with ATDs during pregnancy? What is the target value of $\mathrm{FT}_{4}$ ?}

MMI, PTU, and carbimazole all cross the placenta. Therefore, in order to avoid a deleterious fetal impact, the aim is to maintain $\mathrm{FT}_{4}$ values at, or just above the upper limit of normal, while utilizing the smallest possible dose of ATDs. Free $\mathrm{T}_{4}$ and TSH should be measured approximately every 2-4 weeks at initiation of therapy and every 4-6 weeks after achieving the target value $(68,96,97)$. When trimester-specific $\mathrm{FT}_{4}$ values are not available, the reference ranges for nonpregnant patients are recommended. Over-treatment should be avoided because of the possibility of inducing fetal goiter and or fetal hypothyroidism (98). Serum TSH may remain undetectable through pregnancy. Serum $\mathrm{TT}_{3}$ determination is not recommended in the management of Graves' hyperthyroidism because normalization of maternal serum $\mathrm{TT}_{3}$ has been reported to cause elevated serum TSH in the infants at birth (99). The exception is the woman with $\mathrm{T}_{3}$ thyrotoxicosis, such as in the presence of a nodular goiter.

In the first trimester of pregnancy some women with Graves' disease will experience an exacerbation of symptoms. Afterwards, the natural course of Graves' disease is for a gradual improvement in the second and third trimesters. Typically, this will result in a need to decrease the dose of ATDs. Discontinuation of all ATD therapy is feasible in $20 \%-$ $30 \%$ of patients in the last trimester of gestation (99). The exceptions are women with high levels of TRAb values, in which cases ATD therapy should be continued until delivery. Aggravation of symptoms often occurs after delivery (100).

\section{- RECOMMENDATION 30}

In women being treated with ATDs in pregnancy, $\mathrm{FT}_{4}$ and TSH should be monitored approximately every 2-6 weeks. The primary goal is a serum $\mathrm{FT}_{4}$ at or moderately above the normal reference range. Level B-USPSTF

\section{Question 33: What are the indications and timing for thyroidectomy in the management of Graves' disease during pregnancy?}

Thyroidectomy should be considered in cases of allergies/ contraindications to both ATDs, in women requiring large doses of ATDs, and for patients who are not compliant with drug therapy. If surgery is indicated, second trimester is the optimal time. A determination of serum TRAb titers is of value at the time of surgery in order to assess the potential risk of fetal hyperthyroidism (101). Preparation with betablocking agents and a short course of potassium iodine solution (50-100 mg/d) are recommended (102).

\section{- RECOMMENDATION 31}

Thyroidectomy in pregnancy is rarely indicated. If required, the optimal time for thyroidectomy is in the second trimester. Level A-USPSTF

\section{Question 34: What is the value of TRAb measurement in the evaluation of a pregnant woman with Graves' hyperthyroidism?}

Fetal risks for women with active Graves' hyperthyroidism and those who received ablation therapy are 1) fetal hyper- thyroidism, 2) neonatal hyperthyroidism, 3) fetal hypothyroidism, 4) neonatal hypothyroidism, and 5) central hypothyroidism. The above potential complications depend on several factors: 1) poor control of hyperthyroidism throughout pregnancy may induce transient central hypothyroidism $(103,104) ; 2)$ excessive amounts of ATDs are responsible for fetal and neonatal hypothyroidism (105), and 3) high titers of serum TRAb between 22 and 26 weeks gestation are risk factors for fetal or neonatal hyperthyroidism (106109). TRAb are present in over $95 \%$ of patients with active Graves' hyperthyroidism and high titers may remain still elevated following ablation therapy (79). Indications for ordering a TRAb test in Graves' disease include: 1) mother with active hyperthyroidism, 2) previous history of treatment with radioiodine, 3) previous history of delivering an infant with hyperthyroidism, and 4) thyroidectomy for treatment of hyperthyroidism in pregnancy (101). The titers of antibodies decrease with the progression of the pregnancy. The prevalence of fetal and neonatal hyperthyroidism is between $1 \%$ and $5 \%$ of all women with active or past history of Graves' hyperthyroidism and is associated with increased fetal and neonatal morbidity and mortality if unrecognized and untreated (110).

A determination of serum TRAb by 24-28 weeks gestation is helpful in detecting pregnancies at risk. A value over three times the upper limit of normal is an indication for close follow-up of the fetus, optimally with the collaboration of a maternal-fetal medicine physician. Some clinicians recommend to perform the test in the first trimester (106) and if elevated repeat the determination at 22-26 weeks gestation, while others prefer a single determination at 24-28 weeks gestation (68) because of the normal decline in antibody concentration, which starts at approximately 20 weeks gestation.

\section{- RECOMMENDATION 32}

If the patient has a past or present history of Graves' disease, a maternal serum determination of TRAb should be obtained at 20-24 weeks gestation. Level B-USPSTF

\section{Question 35: Under what circumstances should additional fetal ultrasound monitoring for growth, heart rate, and goiter be performed in women with Graves' hyperthyroidism in pregnancy?}

Serial ultrasound examinations may be performed for the assessment of gestational age, fetal viability, amniotic fluid volume, fetal anatomy, and detection of malformations. Fetal well-being may be compromised in the presence of elevated $\mathrm{TRAb}$, uncontrolled hyperthyroidism, and pre-eclampsia $(80,83,111,112)$. Signs of potential fetal hyperthyroidism that may be detected by ultrasonography include fetal tachycardia (bpm >170, persistent for over 10 minutes), intrauterine growth restriction, presence of fetal goiter (the earliest sonographic sign of fetal thyroid dysfunction), accelerated bone maturation, signs of congestive heart failure, and fetal hydrops (106,111-114). A team approach to the management of these patients is required including an experienced obstetrician or maternal-fetal medicine specialist, neonatologist, and anesthesiologist. In most cases, the diagnosis of fetal hyperthyroidism should be made on clinical grounds based on maternal history, interpretation of serum TRAb levels, and fetal ultrasonography $(68,106,112,113)$. 


\section{- RECOMMENDATION 33}

Fetal surveillance with serial ultrasounds should be performed in women who have uncontrolled hyperthyroidism and/or women with high TRAb levels (greater than three times the upper limit of normal). A consultation with an experienced obstetrician or maternal-fetal medicine specialist is optimal. Such monitoring may include ultrasound for heart rate, growth, amniotic fluid volume, and fetal goiter. Level I-USPSTF

\section{Question 36: When should umbilical blood sampling be considered in women with Graves' disease in pregnancy?}

Umbilical cord blood sampling (cordocentesis) is associated with both fetal mortality and morbidity $(114,115)$. It has been utilized when a mother is TRAb + and treated with ATDs, a fetal goiter is present, and the thyroid status of the fetus is unclear $(106,116)$. The presence of TRAb is not an indication for cordocentesis (117).

\section{- RECOMMENDATION 34}

Cordocentesis should be used in extremely rare circumstances and performed in an appropriate setting. It may occasionally be of use when fetal goiter is detected in women taking ATDs to help determine whether the fetus is hyperthyroid or hypothyroid. Level I-USPSTF

\section{Question 37: What are the etiologies of thyrotoxicosis in the postpartum period?}

The most common cause of thyrotoxicosis in the postpartum period is postpartum thyroiditis (PPT). Specifically, the prevalence of PPT thyrotoxicosis is $4.1 \%$ vs. $0.2 \%$ for thyrotoxicosis related to Graves' disease (118). PPT may manifest as a hyperthyroid phase, occurring within the first 6 months after delivery, with a spontaneous remission. This is frequently followed by a hypothyroid phase before a return to euthyroidism in the majority of women by 1 year postpartum $(118,119)$. Some women will present with mild hypermetabolic symptoms and may need a short course of beta blockers. Women with a past history of Graves' disease treated with ATDs or women who had a thyrotoxic phase in early pregnancy are at increased risk of developing (Graves') hyperthyroidism postpartum (120). In one study the overall relapse rate of Graves disease following a pregnancy was $84 \%$ as compared with a relapse rate of $56 \%$ in women who did not become pregnant (120). It should also be noted that an increased prevalence of de novo Graves' disease has been reported in the postpartum period (121), although this association has been questioned (122).

\section{Question 38: How should the etiology of new thyrotoxicosis be determined in the postpartum period?}

The major challenge is to differentiate thyrotoxicosis caused by PPT from thyrotoxicosis caused by Graves' disease. This is an important differentiation as the two disease entities require different treatments and a have a markedly different clinical course. TRAb is positive in Graves' disease in the vast majority of cases and negative in PPT in the majority of cases $(118,119)$. An elevated $T_{4}: T_{3}$ ratio suggests the presence of PPT. Physical stigmata of Graves' disease may be diagnostic (goiter with a bruit, endocrine ophthalmopathy). The radioiodine uptake is elevated or normal in Graves' disease and low in PPT. Due to their shorter half-life ${ }^{123} \mathrm{I}$ or technetium scans are preferred to ${ }^{131} \mathrm{I}$ in women who are breastfeeding. Nursing can resume several days after $\mathrm{a}^{123}$ I or technetium scan.

\section{Question 39: How should Graves' hyperthyroidism be treated in lactating women?}

The use of moderate doses of ATDs during breastfeeding is safe. In one study, breastfed infants of mothers with elevated TSH levels after administration of high doses of MMI had normal $\mathrm{T}_{4}$ and TSH levels (123). Furthermore, the physical and intellectual development of children, aged 48-86 months, remained unchanged in comparison with controls when assessed by the Wechsler and Goodenough tests (124). The conclusion drawn from these studies is that breastfeeding is safe in mothers on ATDs at moderate doses (PTU less than $300 \mathrm{mg} / \mathrm{d}$ or methimazole $20-30 \mathrm{mg} / \mathrm{d}$ ). It is currently recommended that breast-feeding infants of mothers taking ATDs be screened with thyroid function tests and that the mothers take their ATDs in divided doses immediately following each feeding.

\section{- RECOMMENDATION 35}

MMI in doses up to $20-30 \mathrm{mg} / \mathrm{d}$ is safe for lactating mothers and their infants. PTU at doses up to $300 \mathrm{mg} / \mathrm{d}$ is a second-line agent due to concerns about severe hepatotoxicity. ATDs should be administered following a feeding and in divided doses. Level A-USPSTF

\section{Clinical Guidelines for lodine Nutrition}

\section{Question 40: Why is increased iodine intake required in pregnancy and lactation, and how is iodine intake assessed?}

Because of increased thyroid hormone production, increased renal iodine excretion, and fetal iodine requirements, dietary iodine requirements are higher in pregnancy than they are for nonpregnant adults (125). Women with adequate iodine intake before and during pregnancy have adequate intrathyroidal iodine stores and have no difficulty adapting to the increased demand for thyroid hormone during gestation. In these women, total body iodine levels remain stable throughout pregnancy (126). However, in areas of even mild to moderate iodine deficiency, total body iodine stores, as reflected by urinary iodine values, decline gradually from the first to the third trimester of pregnancy (127). Iodine, required for infant nutrition, is secreted into breast milk. Therefore, lactating women also have increased dietary iodine requirements $(128,129)$.

Spot urinary iodine values are used most frequently for determination of iodine status in general populations. A limitation of urinary iodine testing is that identifying particular individuals at risk for iodine deficiency is problematic because there is substantial diurnal and day-to-day variation in urinary iodine excretion (129).

\section{Question 41: What is the impact of severe iodine deficiency on the mother, fetus, and child?}

Maternal dietary iodine deficiency results in impaired maternal and fetal thyroid hormone synthesis. Low thyroid 
hormone values stimulate increased pituitary TSH production, and the increased TSH stimulates thyroid growth, resulting in maternal and fetal goiter (130). Severe iodine deficiency in pregnant women has been associated with increased rates of miscarriage, stillbirth, and increased perinatal and infant mortality (131).

Normal levels of thyroid hormone are essential for neuronal migration and myelination of the fetal brain. Thyroid hormones are needed throughout pregnancy and in particular between the third and fifth months of intrauterine life. As iodine deficiency affects both maternal and fetal thyroid, both sources of thyroid hormone production may be affected. Maternal and fetal iodine deficiency in pregnancy and neonatal iodine deficiency have adverse effects on the cognitive function of offspring (132-135). Children whose mothers were severely iodine deficient during pregnancy may exhibit cretinism, characterized by profound mental retardation, deaf-mutism, and motor rigidity. Iodine deficiency is the leading cause of preventable mental retardation worldwide (136).

\section{Question 42: What is the impact of mild to moderate iodine deficiency on the mother, fetus, and child?}

Groups of pregnant women whose median urinary iodine concentrations are $50-150 \mu \mathrm{g} / \mathrm{L}$ are defined as mildly to moderately iodine deficient. Women with mild to moderate iodine deficiency during pregnancy are at increased risk for the development of goiter (130). In addition, decreased thyroid hormone associated with even mild to moderate iodine deficiency may have adverse effects on the cognitive function of the offspring (132-134). Mild to moderate maternal iodine deficiency has also been associated with attention deficit and hyperactivity disorders (137).

\section{Question 43: What is the iodine status of pregnant and breastfeeding women in the United States?}

Surveillance of urinary iodine values of the U.S. population has been carried out at intervals since 1971. Following a precipitous drop in urinary iodine values between 1971 and 1994, U.S. dietary iodine intake has stabilized (138-142). The U.S. population overall remains iodine sufficient. However, U.S. women of reproductive age are the most likely group to have low urinary iodine values.

According to the World Health Organization (WHO) guidelines, median urinary iodine values for pregnant women between 149 and $249 \mu \mathrm{g} / \mathrm{L}$ are consistent with optimal iodine intake (132). In the 2001-2006 National Health and Nutrition Examination Survey (NHANES) surveys, the median urinary iodine concentration among 326 pregnant women was marginal at $153 \mu \mathrm{g} / \mathrm{L}$ and $17 \%$ of pregnant women had urinary iodine concentrations $<50 \mu \mathrm{g} / \mathrm{L}$ (143). It is not clear whether these women were truly iodine deficient or whether their low values just represented random fluctuation. Current data regarding iodine sufficiency among lactating U.S. women are very limited. It is possible that a subset of pregnant and lactating U.S. women may have mildly to moderately inadequate dietary iodine intake resulting in insufficient amounts of iodine in the breast milk to meet infants' dietary requirements $(144,145)$.

\section{Question 44: What is the iodine status of pregnant and breastfeeding women worldwide?}

Since 1990, the number of households worldwide using iodized salt has risen from less than $20 \%$ to more than $70 \%$ (146). Despite these advances, however, iodine deficiency affects over 2.2 billion individuals globally, especially in South Asian, East Asia Pacific, and East and South African regions, and remains the leading cause of preventable intellectual deficits (134).

\section{Question 45: Does iodine supplementation in pregnancy and lactation improve outcomes in severe iodine deficiency?}

In areas of severe iodine deficiency, iodine supplementation of mothers prior to conception or in early pregnancy results in children with improved cognitive performance relative to those given a placebo (147-149). The prevalence of cretinisim and other severe neurological abnormalities is significantly reduced (150). Maternal iodine supplementation in severely iodine-deficient areas also decreases rates of stillbirth and neonatal and infant mortality $(151,152)$.

\section{Question 46: Does iodine supplementation in pregnancy and lactation improve outcomes in mildly to moderately iodine-deficient women?}

Eight controlled trials of iodine supplementation in mildly to moderately iodine-deficient pregnant European women have been published (153-160), although doses and timing of iodine supplementation varied and only two trials examined effects on offspring development. Iodine supplementation of moderately deficient pregnant women appears to consistently decrease maternal and neonatal thyroid volumes and Tg levels. Effects on maternal thyroid function have been mixed, with significant maternal TSH decreases with supplementation described in four $(149,151,152,154)$ of the eight published trials, and increases in maternal $\mathrm{T}_{4}$ or $\mathrm{FT}_{4}$ noted in just two $(151,154)$.

In both studies where assessed, neurodevelopmental outcomes were improved in children from mildly to moderately iodine-deficient areas whose mothers received iodine supplementation early in pregnancy $(148,154)$. The timing of supplementation is likely to be critical because the beneficial effects of iodine on offspring development appeared to be lost if supplementation is started after 10-20 weeks gestation.

No trials to date have specifically examined the effects of iodine supplementation in lactation.

\section{Question 47: What is the recommended daily iodine intake in women planning pregnancy, women who are pregnant, and women who are breastfeeding?}

Iodine is an essential nutrient required for thyroid hormone production and is primarily derived from the diet and from vitamin/mineral preparations. The Institute of Medicine recommended dietary allowances to be used as goals for individual total daily iodine intake (dietary and supplement) are $150 \mu \mathrm{g} / \mathrm{d}$ for women planning a pregnancy, $220 \mu \mathrm{g} / \mathrm{d}$ for pregnant women, and $290 \mu \mathrm{g} / \mathrm{d}$ for women who are breastfeeding (161). WHO recommends $250 \mu \mathrm{g} / \mathrm{d}$ for pregnant women and for lactating women (130).

Dietary iodine sources vary regionally. Sources of iodine in the U.S. diet have been difficult to identify, in part because there are a wide variety of potential sources and food iodine 
content is not listed on packaging. Iodized salt remains the mainstay of iodine deficiency disorder eradication efforts worldwide. However, salt iodization has never been mandated in the United States and only approximately $70 \%$ of salt sold for household use in the United States is iodized (162). In the U.S. dairy foods are another important source of dietary iodine due to the use of iodophor disinfectants by the dairy industry (163-165). Commercially baked breads have been another major source of iodine in the United States due to the use of iodate bread conditioners (165). However, the use of iodate bread conditioners has decreased over the past several decades. Other sources of iodine in the U.S. diet are seafood, eggs, meat, and poultry (166). Foods of marine origin have higher concentrations of iodine because marine animals concentrate iodine from seawater (155-157).

In the United States, the dietary iodine intake of individuals cannot be reliably ascertained either by patient history or by any laboratory measure. Due to concerns that a subset of pregnant U.S. women may be mildly to moderately iodine deficient and an inability to identify individual women who may be at risk, the ATA has previously recommended $150 \mu \mathrm{g}$ daily as iodine supplementation for all North American women who are pregnant or breastfeeding (167). The goal is supplementation of, rather than replacement for, dietary iodine intake.

Recommendations regarding iodine supplementation in North America have not been widely adopted. In the NHANES 2001-2006 dataset, only 20\% of pregnant women and $15 \%$ of lactating women reported ingesting iodinecontaining supplements (168). Of the 223 types of prenatal multivitamins available in the United States, only 51\% contain any iodine (169). Iodine in U.S. prenatal multivitamins is typically derived either from potassium iodide (KI) or from kelp. The iodine content in prenatal multivitamin brands containing kelp may be inconsistent due to variability in kelp iodine content (162).

\section{- RECOMMENDATION 36}

All pregnant and lactating women should ingest a minimum of $250 \mu \mathrm{g}$ iodine daily. Level A-USPSTF

\section{- RECOMMENDATION 37}

To achieve a total of $250 \mu \mathrm{g}$ iodine ingestion daily in North America all women who are planning to be pregnant or are pregnant or breastfeeding should supplement their diet with a daily oral supplement that contains $150 \mu \mathrm{g}$ of iodine. This is optimally delivered in the form of potassium iodide because kelp and other forms of seaweed do not provide a consistent delivery of daily iodide. Level B-USPSTF

\section{- RECOMMENDATION 38}

In areas of the world outside of North America, strategies for ensuring adequate iodine intake during preconception, pregnancy, and lactation should vary according to regional dietary patterns and availability of iodized salt. Level A-USPSTF

\section{Question 48: What is the safe upper limit for iodine consumption in pregnant and breastfeeding women?}

Most people are tolerant of chronic excess dietary iodine intake due to a homeostatic mechanism known as the WolffChaikoff effect $(170,171)$. In response to a large iodine load, there is a transient inhibition of thyroid hormone synthesis. Following several days of continued exposure to high iodine levels, escape from the acute Wolff-Chaikoff effect is mediated by a decrease in the active transport of iodine into the thyroid gland, and thyroid hormone production resumes at normal levels (172).

Some individuals do not appropriately escape from the acute Wolff-Chaikoff effect, making them susceptible to hypothyroidism in the setting of high iodine intake. The fetus may be particularly susceptible, since the ability to escape from the acute Wolff-Chaikoff effect does not fully mature until about week 36 of gestation $(173,174)$.

Tolerable upper intake levels for iodine have been established to determine the highest level of daily nutrient intake that is likely to be tolerated biologically and to pose no risk of adverse health effects for almost all individuals in the general population. The upper intake levels are based on total intake of a nutrient from food, water, and supplements and apply to chronic daily use. The U.S. Institute of Medicine has defined the tolerable upper limit for daily iodine intake as $1100 \mu \mathrm{g} / \mathrm{d}$ in all adults, including pregnant women $(1.1 \mathrm{mg} / \mathrm{d})(155)$ and WHO has stated that daily iodine intake $>500 \mu \mathrm{g}$ may be excessive in pregnancy, but these maximal values are based on limited data.

Medications may be a source of excessive iodine intake for some individuals. Amiodarone, an antiarrythmic agent (175), contains $75 \mathrm{mg}$ iodine per $200 \mathrm{mg}$ tablet. Iodinated intravenous radiographic contrast agents contain up to $380 \mathrm{mg}$ of iodine per milliliter. Some topical antiseptics contain iodine, although systemic absorption is generally not clinically significant in adults except in patients with severe burns (176). Iodine-containing anti-asthmatic medications and expectorants are occasionally used. In addition, some dietary supplements may contain large amounts of iodine.

\section{- RECOMMENDATION 39}

Pharmacologic doses of iodine exposure during pregnancy should be avoided, except in preparation for thyroid surgery for Graves' disease. Clinicians should carefully weigh the risks and benefits when ordering medications or diagnostic tests that will result in high iodine exposure. Level C-USPSTF

\section{- RECOMMENDATION 40}

Sustained iodine intake from diet and dietary supplements exceeding 500-1100 $\mu \mathrm{g}$ daily should be avoided due to concerns about the potential for fetal hypothyroidism. Level C-USPSTF

\section{Spontaneous Pregnancy Loss, Preterm Delivery, and Thyroid Antibodies}

Thyroid antibodies and pregnancy loss. Spontaneous pregnancy loss, or miscarriage, has been reported to occur in between $17 \%$ and $31 \%$ of all gestations $(172,177)$. A spontaneous pregnancy loss is defined as one occurring at less than 20 weeks of gestation. The individual risk varies by a number of clinical factors including maternal age, family history, environmental exposures, and medical comorbidities (178). Pregnancy losses are a significant emotional burden to patients and may also result in bleeding, infections, pain, and surgical procedures. 


\section{Question 49: Is there an association between thyroid antibody positivity and sporadic spontaneous abortion in euthyroid women?}

Endocrine disorders have been previously recognized as risk factors for spontaneous pregnancy loss. Patients with poorly controlled diabetes mellitus may have up to a 50\% risk of loss (179). Thyroid dysfunction has also been associated with increased rates of pregnancy loss $(25,180)$. Stagnaro-Green and colleagues (181) published the first paper that demonstrated an association between pregnancy loss and thyroid antibodies. In that prospective observational study, patients who were positive for thyroid antibodies (TPO and Tg) had a twofold increase in the risk of a pregnancy loss (17\% vs. $8.4 \%, p=0.011)$. Iijima and colleagues (182) also reported a nearly twofold increase in spontaneous pregnancy loss in patients who were positive for anti-microsomal antibodies. Glinoer and colleagues (183) reported a fourfold increase in pregnancy loss (13.3 vs. $3.3 \%$, $p<.001)$ with the presence of TPOAb. Other authors have reported similar findings $(184,185)$. Sezer and colleagues $(186)$, in a small prospective study, reported no increase in pregnancy loss in women with thyroid auto-antibodies ( $28.6 \%$ vs. $20 \%$, $p=n s)$. However, they did find a higher titer of anti-Tg antibody in pregnancies that ended in abortion compared with those that went to term.

A meta-analysis of 8 case-control and 10 longitudinal studies demonstrated a clear association between thyroid antibodies and spontaneous abortion (OR 2.30, 95\% CI 1.802.95) (187). The meta-analysis also reported that $\mathrm{TAb}+$ women were slightly older ( 0.7 years) and had a slightly higher TSH (0.81) than antibody-negative women. A review of the studies also reveals that there was an unusually low rate of pregnancy loss in the control groups. Although a clear association has been made between thyroid antibodies and abortion, it does not prove causality. Three research groups have demonstrated a possible mechanism through increased fetal resorption in an active immunization murine model with either Tg or TPO antibodies (188-190).

\section{Question 50: Should women be screened for TPO antibodies before or during pregnancy with the goal of treating TPOAb+ euthyroid women with $L T_{4}$ to decrease the rate of spontaneous miscarriage?}

Negro and colleagues (28) reported a prospective, randomized interventional trial of $\mathrm{LT}_{4}$ in euthyroid patients who were $\mathrm{TPOAb}+$. They reported a significantly decreased rate of pregnancy loss in the treated group (3.5\% vs. $13.8 \%, p<.05)$. A limitation of the study is that the mean gestational age of starting $\mathrm{LT}_{4}$ was 10 weeks estimated gestational age, and all but one of the losses had occurred at less than 11 weeks.

\section{- RECOMMENDATION 41}

There is insufficient evidence to recommend for or against screening all women for thyroid antibodies in the first trimester of pregnancy. Level I-USPSTF

\section{Question 51: Is there an association between thyroid antibodies and recurrent spontaneous abortion in euthyroid women?}

Recurrent pregnancy loss is defined as either two consecutive losses or three total spontaneous losses and may occur in up to $1 \%$ of all women (191). Several causes have been reported, including parental chromosomal anomalies, immunologic derangements, uterine pathology, and endocrine dysfunction (192). In a case-control study, Irivani and colleagues (193) reported that patients with primary recurrent pregnancy losses (three or more) had a higher prevalence of thyroid antibody positivity (OR 2.24, 95\% CL 1.5-3.3). Kutteh et al. (194) reported similar findings with an increased rate of thyroid antibody positivity in 700 women with recurrent abortion as compared with 200 healthy controls $(22.5 \%$ vs. $14.5 \%, p=0.01)$. On the other hand, in a prospective observational study, Esplin and colleagues (195) demonstrated no difference in thyroid antibody positivity between patients with recurrent pregnancy loss and healthy controls. Pratt and colleagues reported a higher rate of subsequent pregnancy loss in patients with recurrent losses and thyroid antibody positivity (196). In a larger trial with a similar population, Rushworth and colleagues (197) reported no significant difference in live birth rates between women with recurrent losses who were positive for thyroid antibodies and those who were not.

The data for an association between thyroid antibodies and recurrent pregnancy loss are less robust than for sporadic loss and somewhat contradictory. This may be because recurrent pregnancy loss has many potential causes, and endocrine dysfunction may only account for $15 \%-20 \%$ of all cases (192). Many of the previously mentioned trials did not control for other potential causes of recurrent losses. One intriguing study reported an apparent interaction of anti-phospholipid antibodies and thyroid antibodies in the risk of recurrent pregnancy loss (198).

\section{Question 52: Should women with recurrent abortion be screened for thyroid antibodies before or during pregnancy with the goal of treating TAb+ euthyroid women with $L T_{4}$ or intravenous immunoglobulin therapy (IVIG) to decrease the rate of recurrent spontaneous abortion?}

Three small nonrandomized case series have been published on the use of intravenous immunoglobulin (IVIG) therapy for the prevention of recurrent pregnancy loss in women with thyroid antibodies (199-201). The live birth rates ranged from $80 \%$ to $95 \%$, and the one study with a control group (consisting of women who refused IVIG therapy) reported a highly significant improvement in live births in the IVIG-treated cohort (95\% vs. 0\% $p=.001$ ) (200). Comparison of $\mathrm{LT}_{4}$ intervention with IVIG in one study resulted in a higher rate of term delivery in the $\mathrm{LT}_{4}$-treated group (201). However, all three studies had serious design flaws including small sample size, heterogeneous patient populations, lack of or limited randomization, and differences when treatment was initiated. In summary, intervention trials with IVIG or $\mathrm{LT}_{4}$ in $\mathrm{TAb}+$ women with recurrent abortion have shown a decrease in the recurrent abortion rate but are limited by methodological problems.

\section{- RECOMMENDATION 42}

There is insufficient evidence to recommend for or against screening for thyroid antibodies, or treating in the first trimester of pregnancy with $\mathrm{LT}_{4}$ or IVIG, in euthyroid women with sporadic or recurrent abortion or in women undergoing in vitro fertilization (IVF). Level I-USPSTF 
Question 53: Should euthyroid women who are known to be positive for thyroid antibodies either before or during pregnancy be treated with $L T_{4}$ in order to decrease the chance of sporadic or recurrent miscarriage?

\section{- RECOMMENDATION $\mathbf{4 3}$}

There is insufficient evidence to recommend for or against $\mathrm{LT}_{4}$ therapy in $\mathrm{TAb}+$ euthyroid women during pregnancy. Level I-USPSTF

\section{Question 54: Is there an association between thyroid antibody positivity and pregnancy loss in euthyroid women undergoing IVF?}

Several authors have reported an increased risk of pregnancy loss after assisted reproductive procedures in women who are positive for thyroid antibodies (202-204). Other authors have found no association $(205,206)$. A meta-analysis of four trials of patients undergoing IVF found an increased risk of pregnancy loss with the presence of thyroid antibodies (RR 1.99, 95\% CI 1.42-2.79) (207).

\section{Question 55: Should women undergoing IVF be screened for TPO antibodies before or during pregnancy?}

Negro et al. (208) performed a prospective placebocontrolled intervention trial of $\mathrm{LT}_{4}$ in $\mathrm{TPOAb}+$ women undergoing assisted reproduction technologies. Though underpowered for its proposed endpoint, no difference in pregnancy loss was observed. Patients undergoing assisted reproductive procedures for infertility may have a number of reasons for infertility or subfertility, and this may explain the conflicting data.

\section{- RECOMMENDATION 44}

There is insufficient evidence to recommend for or against $\mathrm{LT}_{4}$ therapy in euthyroid $\mathrm{TAb}+$ women undergoing assisted reproduction technologies. Level I-USPSTF

\section{Question 56: Is there an association between thyroid antibodies and preterm delivery in euthyroid women?}

Preterm delivery, or birth prior to 37 weeks, affects $12.3 \%$ of pregnancies in the United States (209). It remains one of the most prevalent and morbid perinatal complications. It is the leading cause of neonatal death and the second leading cause of infant death (210). The cost of preterm delivery to the health care system is enormous (211). Preterm birth has remained difficult to predict, prevent, and treat primarily because there are multiple potential causes and pathways that end in premature labor (212). Examples include infection, trauma, cervical insufficiency, premature rupture of membranes, and maternal medical conditions.

Medical conditions such as hypertension and diabetes have been associated with a risk of preterm delivery, either due to the spontaneous onset of labor or from complications prompting medically indicated delivery. Patients with uncontrolled hyperthyroidism also have higher rates of preterm delivery, most commonly due to medical intervention $(80,213)$. The most severe example of uncontrolled hyper- thyroidism, thyroid storm, results in high rates of preterm labor and delivery (214).

The relationship of thyroid antibodies and preterm delivery has also been investigated. Glinoer et al. (183) reported in a prospective cohort that women who were positive for either $\mathrm{TPOAb}$ or $\mathrm{TgAb}$ had a significantly increased prevalence of preterm birth $(16 \%$ vs. $8 \%, p<0.005)$. Ghafoor et al. (215) evaluated 1500 euthyroid women and found an increase in preterm delivery in TPOAb + women as compared with women who were TPOAb- $(26.8 \%$ vs. $8.0 \%, p<0.01)$. In contrast, Iijima et al. (182) did not find an increased risk for preterm birth in women positive for seven different autoantibodies and thyroid antibodies. This study had an unusually low rate of preterm birth in both study and control groups (3\% vs. $3.1 \%$ ). Interestingly, Haddow et al. (216) reported a significant increase in preterm premature rupture of the membranes in $\mathrm{TAb}+$ women but not in preterm birth among women who were positive for TPOAb and $\mathrm{TgAb}$ in the first trimester. Their data revealed a positive association between very preterm delivery $(<32$ weeks) and thyroid antibody positivity (OR 1.73, 95\% CI 1.00-2.97). However, the adjusted odds ratio for very preterm delivery and thyroid antibody positivity failed to reach statistical significance (adjusted OR 1.70, 95\% CI 0.98-2.94).

\section{Question 57: Should women be screened for thyroid antibodies before or during pregnancy with the goal of treating TAb+ euthyroid women with $L T_{4}$ to decrease the rate of preterm delivery?}

Negro et al. (28) reported an increased risk of preterm delivery among euthyroid $\mathrm{TPOAb}+$ women compared with euthyroid TPOAb- women in the only published prospective interventional trial to date $(22.4 \%$ vs. $8.2 \%, p<.01)$. The TPOAb + subjects were then randomized to either treatment with $\mathrm{LT}_{4}$ or no treatment, with the dose based on TSH level. The treated group had a significantly lower rate of preterm delivery than did the untreated group (7\% vs. $22.4 \%$, $p<.05)$

\section{- RECOMMENDATION 45}

There is insufficient evidence to recommend for or against screening for thyroid antibodies in the first trimester of pregnancy, or treating $\mathrm{TAb}+$ euthyroid women with $\mathrm{LT}_{4}$, to prevent preterm delivery. Level I-USPSTF

\section{Thyroid Nodules and Thyroid Cancer}

Thyroid nodules and thyroid cancer discovered during pregnancy present unique challenges to both the clinician and the mother. A careful balance is required between making a definitive diagnosis and instituting treatment, while avoiding interventions that may adversely impact the mother, the health of the fetus, or the maintenance of the pregnancy.

\section{Question 58: What is the frequency of thyroid nodules during pregnancy?}

Three studies have evaluated the prevalence of thyroid nodules during pregnancy, the impact of pregnancy on nodular size, and the percentage of women who have new nodules detected during pregnancy. All three studies were performed in areas with mild to moderate iodine deficiency 
(Brussels, China, and Germany). The prevalence of thyroid nodules varied between $3 \%$ and $21 \%(183,217,218)$ and increased with increasing parity $(9.4 \%$ without a prior pregnancy, $20.7 \%$ with one prior pregnancy, $20.7 \%$ with two prior pregnancies, and $33.9 \%$ with three or more prior pregnancies) (217). In the Belgian study, $60 \%$ of the nodules doubled in size during pregnancy yet remained between 5 and $12 \mathrm{~mm}$ (183). No increase throughout pregnancy was noted in the maximum diameter of the dominant nodule in the Chinese study (mean diameter was 5.1, 5.1, and $5.5 \mathrm{~mm}$, in the first, second, and third trimesters, respectively). However, an increase in nodular volume was reported during pregnancy with a return to first trimester volumes by the third postpartum month (218). The studies in Belgium and Germany reported that $11 \%-20 \%$ of women with a nodule detected in the first trimester of pregnancy developed a second nodule through the course of pregnancy $(183,218)$. Increasing age is associated with an increase in the percentage of women who have thyroid nodules present during pregnancy $(183,218)$.

\section{Question 59: What is the frequency of thyroid cancer in women with thyroid nodules discovered during pregnancy?}

Data regarding the prevalence of thyroid cancer derive from three retrospective studies performed at three tertiary referral centers (Mayo Clinic, George Washington University Hospital, and Mount Sinai Hospital-Toronto), one prospective study, and a retrospective study of the California Cancer Registry. The research performed at the referral centers revealed a 15\% (6/40, Mayo Clinic) (219), 12\% (7/57, George Washington Hospital) (220), and 43\% (7/16, Mount Sinai Hospital-Toronto) (221) rate of thyroid malignancy. All three studies are limited by two major methodological flaws. The first, and most problematic, is selection bias. The population study consisted of women referred for diagnosis and treatment at major referral centers. As such they are not representative of the population of pregnant women with thyroid nodules detected during pregnancy. Instead, they represent a select group of women referred to a tertiary medical center due to physician concern of thyroid malignancy. Consequently, they overrepresent the prevalence of thyroid malignancy during pregnancy. Secondly, each study was retrospective in nature; therefore, neither the accuracy of the diagnosis nor the completeness of case identification within the database could be verified. The lone prospective study investigated the prevalence of thyroid cancer during pregnancy in 212 Chinese women. The study found a $15.3 \%(34 / 221)$ rate of thyroid nodules and a $0 \%$ rate of malignancy. Interpreting these data is hampered by the limited number of women enrolled in the study (218). The final study consisted of a population-based retrospective analysis of all obstetrical deliveries in California between the years 1991 through 1999 identified by cross-referencing maternal/neonatal hospital discharges in California and the California Cancer Registry ( $n=4,846,505$ women). A prevalence of thyroid cancer in pregnancy of $14.4 / 100,000$ was reported, with papillary cancer being the most frequent pathological type (222). Timing of diagnosis of the thyroid malignancy was as follows: $3.3 / 100,000$ cases diagnosed before delivery, $0.3 / 100,000$ at delivery, and 10.8/100,000 within 1 year postpartum.

\section{Question 60: What is the optimal diagnostic strategy for thyroid nodules detected during pregnancy?}

History and physical examination. The patient with a thyroid nodule should be asked about a family history of benign or malignant thyroid disease, familial medullary thyroid carcinoma, multiple endocrine neoplasia type 2 (MEN 2), familial papillary thyroid carcinoma, and familial polyposis coli $(223,224)$. Previous disease or treatment involving the neck (history of head and neck irradiation during childhood), rapidity of onset, and rate of nodule growth should be documented (225). A progressive nodule growth warrants a fine-needle aspiration (FNA), while persistent cough or dysphonia may suggest a malignant lesion (224). Thorough palpation of the thyroid and neck inspection for cervical nodes are essential (226).

Ultrasound. Thyroid ultrasound is the most accurate tool for detecting thyroid nodules, determining their features, monitoring their growth, and evaluating cervical lymph nodes. Nodules smaller than $10 \mathrm{~mm}$ do not require a FNA unless suspicious for malignancy on ultrasound or clinical grounds (227). Ultrasonographic features suggestive of malignancy include a hypoechoic pattern, irregular margins, chaotic intranodular vascular spots, nodules that are taller than they are wide, and microcalcifications (228). The presence of two or more suspicious sonographic criteria reliably identifies most neoplastic lesions of the thyroid gland $(87 \%-$ $93 \%$ of cases) (229). Ultrasonographic features suggestive of malignancy or with extracapsular growth or metastatic lymph nodes warrant FNA evaluation. FNA of nodules that appear benign on ultrasound can be deferred until postpartum.

Thyroid function tests. All women with a thyroid nodule should have a TSH and $\mathrm{FT}_{4}$ performed $(6,230,231)$. Thyroid function tests are usually normal in women with thyroid cancer.

\section{- RECOMMENDATION 46}

The optimal diagnostic strategy for thyroid nodules detected during pregnancy is based on risk stratification. All women should have the following: a complete history and clinical examination, serum TSH testing, and ultrasound of the neck. Level A-USPSTF

As with the general population, the routine measurement of calcitonin remains controversial (232). Calcitonin measurement should be performed in pregnant women with a family history of medullary thyroid carcinoma or MEN 2. However, the utility of measuring calcitonin in all pregnant women with thyroid nodules has not been evaluated in the literature. The pentagastrin stimulation test is contraindicated in pregnancy (233).

\section{- RECOMMENDATION 47}

The utility of measuring calcitonin in pregnant women with thyroid nodules is unknown. Level I-USPSTF

Fine-needle aspiration. FNA is a safe diagnostic tool in pregnancy and may be performed in any trimester $(229,234-$ 242). Two retrospective case series of FNAs performed during pregnancy, involving a total of 94 patients, have been 
published. In the cases in which surgery was performed, pathological examination of the specimens confirmed the diagnosis of all FNAs classified by cytology as either benign or malignant. Six of the $16(37.5 \%)$ cases reported by cytology as suspicious for malignancy were found to be malignant at pathological examination $(219,220)$. Pregnancy does not appear to increase the difficulty of making a cytological diagnosis of thyroid tissue obtained by FNA. There have been no prospective studies which have evaluated the reliability of FNA in pregnancy.

\section{- RECOMMENDATION 48}

Thyroid or lymph node FNA confers no additional risks to a pregnancy. Level A-USPSTF

\section{- RECOMMENDATION 49}

Thyroid nodules discovered during pregnancy that have suspicious ultrasound features, as delineated by the 2009 ATA guidelines, should be considered for FNA. In instances in which nodules are likely benign, FNA may be deferred until after delivery based on patients' preference. Level I-USPSTF

Radionuclide scanning. The use of radionuclide scanning is contraindicated during pregnancy (243-245). Inadvertent scanning performed prior to 12 weeks gestation does not appear to damage the fetal thyroid.

\section{- RECOMMENDATION 50}

The use of radioiodine imaging and/or uptake determination or therapeutic dosing is contraindicated during pregnancy. Inadvertent use of radioiodine prior to 12 weeks of gestation does not appear to damage the fetal thyroid. Level A-USPSTF

\section{Question 61: Does pregnancy impact the prognosis of thyroid carcinoma?}

Seven studies have compared the prognosis of women with differentiated thyroid cancer (DTC) diagnosed either during pregnancy or within the first postpartum year to women diagnosed with thyroid carcinoma at another time period (controls) (246-252). In six of the studies the prognosis, defined as either tumor recurrence or death, of women diagnosed during pregnancy/postpartum did not differ from controls. The studies ranged in size from 9 to 595 thyroid cancer cases diagnosed during pregnancy/postpartum and 462 to 2270 controls. Prognosis in women diagnosed with thyroid carcinoma while pregnant did not differ based on whether surgery was performed during pregnancy or deferred until postpartum. In contrast with these studies, a 2010 publication reported that women diagnosed with DTC during pregnancy or within 1 year following delivery $(n=15)$, had a poorer prognosis in terms of persistence and relapse of disease compared with women diagnosed with welldifferentiated thyroid cancer either prior to pregnancy $(n=61)$ or 1 year following delivery $(n=47)$ (252). Estrogen receptor $\alpha$ was present in the tumors of the majority of women diagnosed during pregnancy/postpartum as compared with the other two groups, which may indicate that the poorer prognosis is related to estrogen-mediated growth.
In conclusion, the majority of studies indicate that pregnancy does not worsen the prognosis in women diagnosed with DTC. Surgery for DTC diagnosed during pregnancy can be postponed until postpartum without impacting tumor recurrence or mortality. It should be noted that none of the studies were randomized controlled trials, all were retrospective, and the size of many of the studies was limited. The impact on prognosis of estrogen receptor $\alpha$ positivity requires further evaluation. The impact of pregnancy on women with medullary or anaplastic carcinoma is unknown.

\section{- RECOMMENDATION $\mathbf{5 1}$}

Because the prognosis of women with well-differentiated thyroid cancer identified but not treated during pregnancy is similar to that of nonpregnant patients, surgery may be generally deferred until postpartum. Level B-USPSTF

\section{- RECOMMENDATION 52}

The impact of pregnancy on women with medullary carcinoma is unknown. Surgery is recommended during pregnancy in the presence of a large primary tumor or extensive lymph node metastases. Level I-USPSTF

\section{Question 62: What are the perioperative risks to mother and fetus of surgery for thyroid cancer during pregnancy?}

Surgery is the treatment of choice for DTC. Deferring surgery until postpartum has not been associated with a worse prognosis, so it is imperative to assess maternal and neonatal complications before advising an operation during pregnancy. Between 1986 and 2008 nine studies evaluated the impact of thyroidectomy during pregnancy on a total of 113 patients (study size ranged from 1 to 96$)(219,223-227,253-255)$. The majority, but not all, of the operations were performed in the second trimester. There were no maternal or fetal complications in any of the studies. Recently (2009), a population-based study compared 201 pregnant women who underwent thyroid and parathyroid surgery during pregnancy with 31,155 similarly treated nonpregnant women (256). One hundred sixty-five operations were thyroid related and $46 \%$ of the women had thyroid cancer. Pregnant patients had a higher rate of endocrine and general complications, longer lengths of stay, and higher hospital costs. The fetal and maternal complication rates were $5.5 \%$ and $4.5 \%$, respectively. Interpretation of the results of this study is difficult because there were substantial baseline differences between the two groups. Pregnant women were more likely to have either urgent or emergent admissions and had a higher percentage of government insurance. In situations in which surgery during pregnancy is indicated or desired, it should be performed in the second trimester in order to minimize complications to both the mother and fetus (altered organogenesis and spontaneous abortion in the first trimester; preterm labor and delivery in the third trimester) (257). The risk of post-thyroidectomy maternal hypothyroidism and hypoparathyroidism should also be considered.

\section{- RECOMMENDATION 53}

Surgery for thyroid carcinoma during the second trimester of pregnancy has not been demonstrated to be associated with increased maternal or fetal risk. Level B-USPSTF 


\section{Question 63: How should benign thyroid nodules be managed during pregnancy?}

Although pregnancy is a risk factor for progression of nodular thyroid disease, there is no evidence demonstrating that $\mathrm{LT}_{4}$ is effective in decreasing the size or arresting the growth of thyroid nodules during pregnancy. Hence, $\mathrm{LT}_{4}$ suppressive therapy for thyroid nodules is not recommended during pregnancy. Nodules that on FNA were benign but show rapid growth or ultrasound changes suspicious for malignancy should have a repeat FNA and be considered for surgical intervention. In the absence of rapid growth, nodules with biopsies that are either benign or indeterminate do not require surgery during pregnancy (258).

Surgery for benign nodules must be considered in cases of large nodules with tracheal or esophageal compression.

\section{- RECOMMENDATION 54}

Pregnant women with thyroid nodules that are read as benign on FNA cytology do not require surgery during pregnancy except in cases of rapid nodule growth and/or if severe compressive symptoms develop. Postpartum, nodules should be managed according to the 2009 ATA guidelines. Level B-USPSTF

\section{Question 64: How should DTC be managed during pregnancy?}

Recently published ATA Guidelines (258) recommend that a nodule with cytology indicating papillary thyroid carcinoma discovered early in pregnancy should be monitored sonographically. If it grows substantially by 24 weeks gestation (50\% in volume and $20 \%$ in diameter in two dimensions), surgery should be performed. However, if it remains stable by midgestation or if it is diagnosed in the second half of pregnancy, surgery may be performed after delivery. In patients with more advanced disease, surgery in the second trimester is a viable option.

If surgery is deferred until postpartum, thyroid hormone suppression therapy may be considered for patients with an FNA biopsy diagnostic of a DTC (258). The goal of $\mathrm{LT}_{4}$ therapy is to keep TSH in the low-normal range of $0.1-1.5 \mathrm{mU} / \mathrm{L}$.

\section{- RECOMMENDATION 55}

When a decision has been made to defer surgery for welldifferentiated thyroid carcinoma until after delivery, neck ultrasounds should be performed during each trimester to assess for rapid tumor growth, which may indicate the need for surgery. Level I-USPSTF

\section{- RECOMMENDATION 56}

Surgery in women with well-differentiated thyroid carcinoma may be deferred until postpartum without adversely affecting the patient's prognosis. However, if substantial growth of the well-differentiated thyroid carcinoma occurs or the emergence of lymph node metastases prior to midgestation occurs, then surgery is recommended. Level B-USPSTF

\section{- RECOMMENDATION 57}

Thyroid hormone therapy may be considered in pregnant women who have deferred surgery for welldifferentiated thyroid carcinoma until postpartum. The goal of $\mathrm{LT}_{4}$ therapy is a serum TSH level of $0.1-1.5 \mathrm{mIU} / \mathrm{L}$. Level I-USPSTF

\section{Question 65: How should suspicious thyroid nodules be managed during pregnancy?}

There have been no prospective studies evaluating the outcome and prognosis of women with an FNA biopsy that is interpreted as being suspicious for thyroid cancer. Because $30 \%$ of suspicious thyroid nodules are malignant and the prognosis for DTC diagnosed during pregnancy is not adversely impacted by performing surgery postpartum, it is reasonable to defer surgery until after delivery. Because the majority of these women will have benign nodules, $\mathrm{LT}_{4}$ therapy during pregnancy is not recommended.

\section{- RECOMMENDATION 58}

Pregnant patients with an FNA sample that is suspicious for thyroid cancer do not require surgery while pregnant except in cases of rapid nodular growth and/or the appearance of lymph node metastases. Thyroid hormone therapy is not recommended. Level I-USPSTF

Figure 1 presents an algorithm for the work-up and treatment of a thyroid nodule detected during pregnancy.

\section{Question 66: What are the TSH goals during pregnancy for women with previously treated thyroid cancer and who are on $L T_{4}$ therapy?}

Based on studies that have demonstrated a lack of maternal or neonatal complications with subclinical hyperthyroidism it is reasonable to assume that the preconception degree of TSH suppression can be safely maintained throughout pregnancy. The appropriate level of TSH suppression depends upon preconception evidence of residual or recurrent disease. According to the ATA management guidelines for DTC (258) and the European Thyroid Association (ETA) consensus (259), serum TSH should be maintained indefinitely below $0.1 \mathrm{mU} /$ $\mathrm{L}$ in patients with persistent disease. In patients who are clinically and biochemically free of disease but who presented with a high risk tumor, TSH suppression should be maintained with serum TSH levels between 0.1 and $0.5 \mathrm{mU} / \mathrm{L}$. In low-risk patients free of disease, TSH may be kept within the low normal range $(0.3-1.5 \mathrm{mU} / \mathrm{L})$. Finally, in patients who have not undergone remnant ablation, who are clinically free of disease and have undetectable suppressed serum $\mathrm{Tg}$ and normal neck ultrasound, serum TSH may be allowed to remain in the low normal range $(0.3-1.5 \mathrm{mU} / \mathrm{L})$.

The main challenge in caring for women with previously treated DTC is maintaining the TSH level within the preconception range. In a recent report (56) thyroid cancer patients required smaller dose increases than patients who had undergone thyroid ablation for benign thyroid disorders or patients with primary hypothyroidism. On average, the cumulative $\mathrm{LT}_{4}$ dose increased by $9 \%$ in the first trimester, $21 \%$ in the second trimester, and $26 \%$ in the third trimester, with the majority of patients (65\%) requiring $\mathrm{LT}_{4}$ adjustments during the second trimester. Patients require careful monitoring of thyroid function tests in order to avoid hypothyroidism.

Thyroid function should be evaluated as soon as pregnancy is confirmed. The adequacy of $\mathrm{LT}_{4}$ treatment should be checked 4 weeks after any $\mathrm{LT}_{4}$ dose change. The same 
Work-up and treatment of thyroid nodule detected during pregnancy

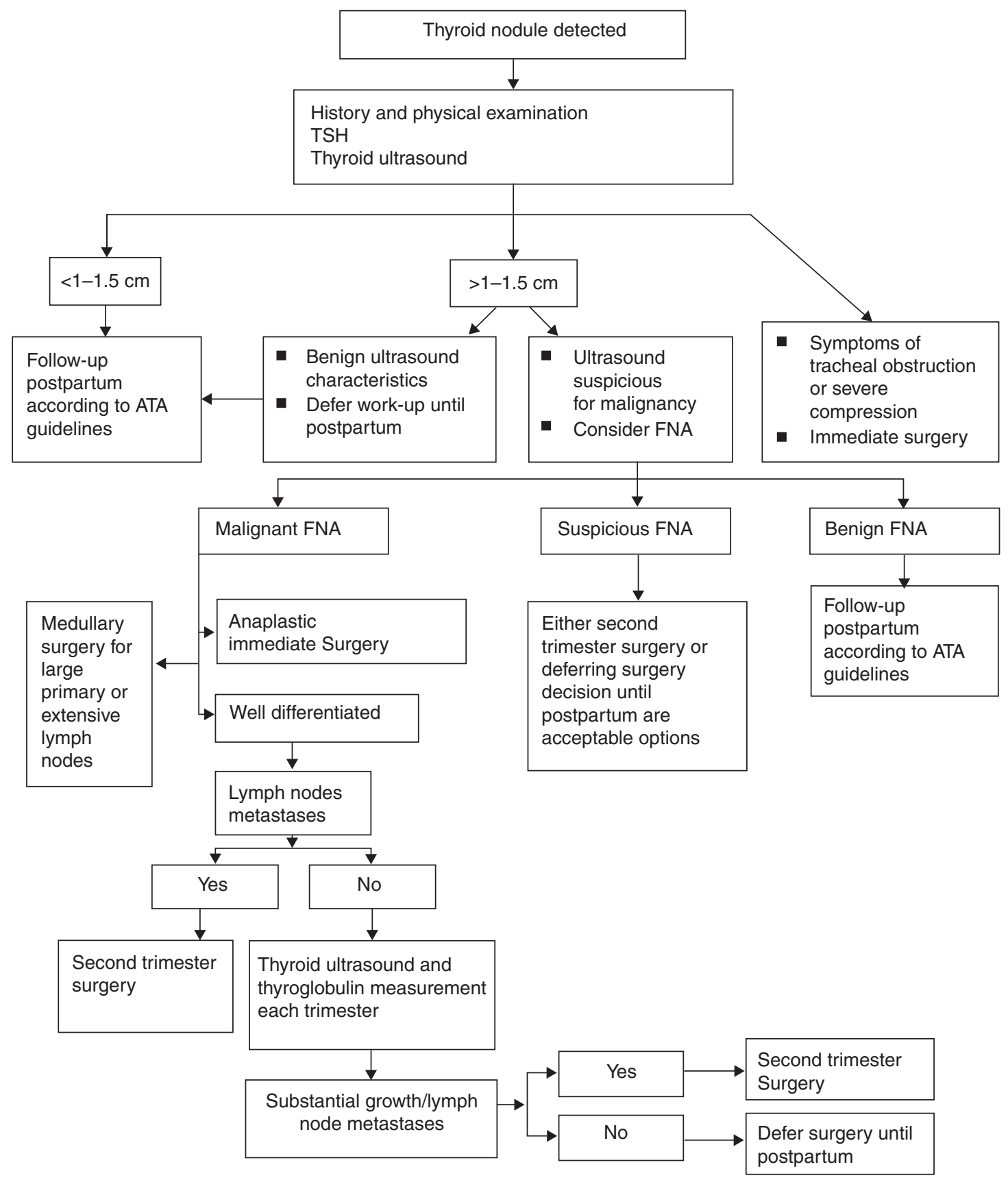

FIG. 1. An algorithm for the work-up and treatment of a thyroid nodule detected during pregnancy.

laboratory should be utilized to monitor TSH and Tg levels before, during, and after pregnancy.

\section{- RECOMMENDATION 59}

The preconception TSH goal in women with DTC, which is determined by risk stratification, should be maintained during pregnancy. TSH should be monitored approximately every 4 weeks until 16-20 weeks of ges- tation and once between 26 and 32 weeks of gestation. Level B-USPSTF

\section{Question 67: What is the effect of RAI treatment for DTC on subsequent pregnancies?}

Following surgery for DTC the majority of patients will receive an ablative dose of RAI. The possible deleterious effect of radiation on gonadal function and the outcome of 
subsequent pregnancies has been evaluated by Sawka et al. (260) and Garsi et al. (261) (the latter collected 2673 pregnancies, 483 of which occurred after RAI treatment). Neither study found an increased risk of infertility, miscarriage, stillbirth, neonatal mortality, congenital malformations, preterm birth, low birth weight, death during the first year of life, or cancer in the offspring.

The potential for an increased risk of miscarriage in the months following RAI administration may derive from suboptimal thyroid hormonal control. Therefore it seems reasonable to wait a minimum of 6 months following RAI ablative therapy before conceiving. This would help ensure that $\mathrm{LT}_{4}$ replacement therapy is optimal at the time of conception.

\section{- RECOMMENDATION 60}

There is no evidence that previous exposure to radioiodine affects the outcomes of subsequent pregnancies and offspring. Pregnancy should be deferred for 6 months following RAI treatment. $\mathrm{LT}_{4}$ dosing should be stabilized following RAI treatment before pregnancy is attempted. Level B-USPSTF

\section{Question 68: Does pregnancy increase the risk of DTC recurrence?}

Five studies have evaluated the impact of pregnancy after a woman has been treated for DTC. Rosvoll and Winship (262) evaluated 60 women with a history of DTC who had subsequent pregnancies. No tumor recurrence was seen in the 38 women who had been disease free for between 2 and 15 years, and pregnancy did not accelerate tumor growth in the 22 women who had stable or slowly progressive disease. Hill et al. (263) found no difference in thyroid cancer recurrence rate in 70 women who had one or more pregnancies following initial diagnosis of DTC and 109 women who had no subsequent pregnancies. Leboeuf et al. (264) reported on 36 women who became pregnant a median of 4.3 years after initial treatment for DTC (264). The mean suppressed Tg after delivery was not significantly different than the prepartum value. However, eight women had Tg values after delivery more than $20 \%$ higher than before pregnancy (three with known disease, five with no clinical evidence of disease). No evidence of recurrence was detected in the early postpartum period in women with negative prepregnancy neck ultrasound and serum $\mathrm{Tg}<3.2 \mathrm{ng} / \mathrm{mL}$. Disease progression was documented by the enlargement of a previously stable cervical node in one patient and by a marked rise in serum Tg without evidence of structural disease progression in another patient with previously stable lung metastasis. Rosario et al. (265) reported that pregnancy did not result in cancer recurrence in any of 64 women previously treated for DTC who were thyroid cancer free at the time of pregnancy (as determined by $\mathrm{Tg}$ levels, ultrasound, and physical examination). Hirsch and colleagues (266) evaluated 63 women who had given birth after receiving treatment for DTC. Twenty-three of 63 had more than one pregnancy, for a total of 90 births. The mean time to the first delivery after completion of thyroid cancer treatment was $5.1 \pm 4.4$ years; mean duration of follow-up after the first delivery was $4.8 \pm 3.8$ years. Six women had evidence of thyroid cancer progression that was independent of pathological staging, interval from diagnosis to pregnancy, TSH level during pregnancy, or Tg level before conception. The authors did, however, find a positive correlation of cancer progression with persistence of thyroid cancer before pregnancy.

Pregnancy does not pose a risk for tumor recurrence in women without structural or biochemical disease present prior to the pregnancy. However, pregnancy may represent a stimulus to thyroid cancer growth in patients with known structural or biochemical disease present at the time of conception.

\section{Question 69: What type of monitoring should be performed during pregnancy in a patient who has already been treated for DTC prior to pregnancy?}

\section{- RECOMMENDATION 61}

Ultrasound and Tg monitoring during pregnancy in patients with a history of previously treated DTC is not required for low-risk patients with no $\mathrm{Tg}$ or structural evidence of disease prior to pregnancy. Level B-USPSTF

\section{- RECOMMENDATION 62}

Ultrasound monitoring should be performed each trimester during pregnancy in patients with previously treated DTC and who have high levels of $\mathrm{Tg}$ or evidence of persistent structural disease prior to pregnancy. Level B-USPSTF

\section{Postpartum Thyroiditis}

\section{Question 70: What is the definition of PPT and what are its clinical implications?}

PPT is the occurrence of thyroid dysfunction in the first postpartum year in women who were euthyroid prior to pregnancy (267). In its classical form, transient thyrotoxicosis is followed by transient hypothyroidism with a return to the euthyroid state by the end of the initial postpartum year (118). The clinical course of PPT varies, with $25 \%$ of cases presenting in the classical form, $32 \%$ with isolated thyrotoxicosis, and $43 \%$ with isolated hypothyroidism (268). The thyrotoxic phase of PPT typically occurs between 2 and 6 months postpartum, but episodes have been reported as late as 1 year following delivery. All episodes of thyrotoxicosis resolve spontaneously. The hypothyroid phase of PPT occurs from 3 to 12 months postpartum with $10 \%-20 \%$ of cases resulting in permanent hypothyroidism. It should be noted, however, that a recently published article reported that $50 \%$ of women with PPT remained hypothyroid at the end of the first postpartum year (269).

\section{Question 71: What is the etiology of PPT?}

PPT is an autoimmune disorder associated with the presence of thyroid antibodies (TPO and Tg antibodies), lymphocyte abnormalities, complement activation, increased levels of IgG1, increased natural killer cell activity, and specific HLA haplotypes (270-272). The occurrence of PPT postpartum reflects the immune suppression that occurs during pregnancy followed by the rebound of the immune system in the postpartum period.

\section{Question 72: Are there predictors of PPT?}

PPT will develop in 33\%-50\% of women who present with thyroid antibodies in the first trimester, conferring a relative risk of PPT of between 10 and 59 compared with women who are negative for thyroid antibodies (273). The risk of PPT 
increases as the titer of thyroid antibodies in the first trimester increases. Although thyroid hypoechogenecity predates the hormonal changes of PPT, it is not of clinical utility in predicting or diagnosing PPT (274).

\section{Question 73: What is the prevalence of PPT?}

The prevalence of PPT is approximately $8.1 \%$ and varies markedly in different studies (the range is between $1.1 \%$ and $16.7 \%$ ) (275). Women with other autoimmune disorders have an increased risk of PPT. Specifically, the prevalence of PPT is $25 \%$ with Type 1 diabetes mellitus $(276,277), 25 \%$ with chronic viral hepatitis (278), 14\% with systemic lupus erythematosus (279), and $44 \%$ with a prior history of Graves' disease (280). Individuals who had PPT in a prior episode and who returned to the euthyroid state have a $70 \%$ chance of developing PPT in a subsequent pregnancy (281). Women on $\mathrm{LT}_{4}$ therapy secondary to Hashimoto's thyroiditis predating pregnancy may develop PPT if their thyroid gland is not completely atrophic (282). Cases of PPT have been reported following miscarriage, but the prevalence of thyroid dysfunction following pregnancy loss is unknown (283).

\section{Question 74: What symptoms are associated with PPT?}

Most women are asymptomatic during the thyrotoxic phase of PPT. This reflects the degree of increase in thyroid hormone, which is typically mild. Nevertheless, in prospective studies symptoms more common in women during the hyperthyroid phase of PPT, compared with euthyroid postpartum controls, include irritability, heat intolerance, fatigue, and palpitations $(267,284-286)$. It is more common for women in the hypothyroid phase of PPT to be symptomatic. Symptoms experienced more frequently during the hypothyroid phase of PPT, compared with euthyroid postpartum controls, include cold intolerance, dry skin, lack of energy, impaired concentration, and aches and pains $(267,284-286)$.

\section{Question 75: Is PPT associated with depression?}

Studies evaluating the relationship of PPT to postpartum depression have yielded mixed results, with some (287) but not all (288) studies reporting a significant association. Two studies have reported a significant association between thyroid antibodies and depression $(289,290)$, irrespective of thyroid function, whereas one study showed no association between the presence of microsomal antibodies and postpartum depression (291). A prospective trial of $\mathrm{LT}_{4}$ intervention postpartum versus placebo, in TPOAb + women, resulted in no difference in rates of postpartum depression between the two groups (292).

\section{- RECOMMENDATION 63}

Women with postpartum depression should have TSH, $\mathrm{FT}_{4}$, and TPOAb tests performed. Level B-USPSTF

\section{Question 76: What is the treatment for the thyrotoxic phase of PPT?}

There have been no prospective studies evaluating when and how to treat PPT. Treatment of the thyrotoxic phase is guided by its transitory nature. ATDs (PTU and MMI) are ineffective in treating the thyrotoxic phase of PPT because it is a destructive thyroiditis. Clinical symptoms increased in the thyrotoxic phase, as compared with controls, are palpitations, heat intolerance, and nervousness $(284,286)$. Symptoms are typically mild and frequently do not require intervention. The thyrotoxic phase of PPT must be differentiated from recurrent or de novo Graves' disease.

\section{- RECOMMENDATION 64}

During the thyrotoxic phase of PPT, symptomatic women may be treated with beta blockers. Propranolol at the lowest possible dose to alleviate symptoms is the treatment of choice. Therapy is typically required for a few months. Level B-USPSTF

\section{- RECOMMENDATION 65}

ATDs are not recommended for the treatment of the thyrotoxic phase of PPT. Level D-USPSTF

\section{Question 77: Once the thyrotoxic phase of PPT resolves, how often should TSH be measured to screen for the hypothyroid phase?}

\section{- RECOMMENDATION 66}

Following the resolution of the thyrotoxic phase of PPT, TSH should be tested every 2 months (or if symptoms are present) until 1 year postpartum to screen for the hypothyroid phase. Level B-USPSTF

\section{Question 78: What is the treatment for the hypothyroid phase of PPT?}

The hypothyroid phase of PPT is associated with increased symptoms including impaired concentration, carelessness, and an increase in total complaints when compared with postpartum euthyroid women (285).

\section{- RECOMMENDATION 67}

Women who are symptomatic with hypothyroidism in PPT should either have their TSH level retested in 4-8 weeks or be started on $\mathrm{LT}_{4}$ (if symptoms are severe, if conception is being attempted, or if the patient desires therapy). Women who are asymptomatic with hypothyroidism in PPT should have their TSH level retested in 4-8 weeks. Level B-USPSTF

\section{- RECOMMENDATION 68}

Women who are hypothyroid with PPT and attempting pregnancy should be treated with $\mathrm{LT}_{4}$. Level A-USPSTF

\section{Question 79: How long should $L T_{4}$ be continued in women with PPT?}

The length of time that $\mathrm{LT}_{4}$ should be continued once initiated has not been systematically evaluated. Guiding principles are to maintain a euthyroid state while a woman is attempting pregnancy, pregnant, or breastfeeding, and eventually to determine if the hypothyroid phase of PPT was transitory or permanent.

\section{- RECOMMENDATION 69}

If $\mathrm{LT}_{4}$ is initiated for PPT, future discontinuation of therapy should be attempted. Tapering of treatment can be begun 6-12 months after the initiation of treatment. Tapering of $\mathrm{LT}_{4}$ should be avoided when a woman is actively attempting pregnancy, is breastfeeding, or is pregnant. Level C-USPSTF 


\section{Question 80: How often should screening be performed after the hypothyroid phase of PPT resolves?}

The impact of PPT on long-term thyroid function has been evaluated in six studies $(284,293-297)$. The data demonstrate that within 1 year, $10 \%-20 \%$ of women who were euthyroid following their initial hypothyroid phase of PPT develop permanent hypothyroidism. Recent data from a large-scale prospective study of 169 women with PPT demonstrated that $82 \%$ of the women had a hypothyroid phase at some point during the first year and, at the end of the first year, $54 \%$ of the 169 women were persistently hypothyroid (269). Factors associated with an increased risk of developing permanent hypothyroidism are mulitparity, hypoechogenecity on ultrasound, the severity of the initial hypothyroidism, TPO antibody titer, maternal age, and a history of miscarriage.

\section{- RECOMMENDATION 70}

Women with a prior history of PPT should have an annual TSH test performed to evaluate for permanent hypothyroidism. Level A-USPSTF

Figure 2 presents an algorithm for the treatment and monitoring of PPT.

\section{Question 81: Does treatment of TAb+ euthyroid women with $L T_{4}$ or iodine during pregnancy prevent PPT?}

Two prospective randomized placebo-controlled controlled trials have evaluated the efficacy of iodine or $\mathrm{LT}_{4}$ treatment during pregnancy to prevent the development of $\mathrm{PPT}$ in $\mathrm{TAb}+$ women. Neither intervention decreased the prevalence of PPT $(298,299)$. Levothyroxine diminished the degree of hypothyroidism during the hypothyroid phase of PPT and iodine appeared to enhance thyroid dysfunction.

\section{- RECOMMENDATION 71}

Treatment of $\mathrm{TAb}+$ euthyroid pregnant woman with either $\mathrm{LT}_{4}$ or iodine to prevent PPT is ineffective and is not recommended. Level D-USPSTF

\section{Question 82: Does treatment of TAb+ euthyroid women with selenium during pregnancy prevent PPT?}

In 2007 Negro et al. (65) evaluated the impact of selenium administration in preventing PPT in 151 Italian women who were positive for thyroid antibodies during pregnancy. Seventy-seven women received $200 \mu \mathrm{g}$ /day of selenium during pregnancy and the postpartum period and 74 women received a placebo. The prevalence of PPT was significantly decreased in women receiving selenium as compared with women in the placebo group $(28.6 \%$ vs. $48.6 \% p<0.01)$. Because only a single trial has documented a benefit of selenium supplementation to prevent PPT, there is insufficient evidence to recommend selenium supplementation during pregnancy in $\mathrm{TAb}+$ women (see Recommendation 21).

\section{Thyroid Function Screening in Pregnancy}

\section{Question 83: Should all pregnant women be screened for serum TSH level in the first trimester of pregnancy?}

The question of whether all pregnant women should be screened in order to identify and treat thyroid dysfunction has been extremely controversial. In order for any screening program to be worthwhile, the condition of interest must be prevalent in asymptomatic individuals, there must be a reliable and readily available test to identify the condition, and identification of the condition must result in a beneficial intervention. Finally, the screening and intervention strategy must be shown to be cost-effective.

U.S. data suggest that approximately $2 \%-3 \%$ of pregnant women will have an elevated serum TSH level at the time of routine screening. Of the screened women, $0.3 \%-0.5 \%$ will have $\mathrm{OH}$ and $2 \%-2.5 \%$ will have $\mathrm{SCH}(36,300)$. The prevalence of both $\mathrm{OH}$ and $\mathrm{SCH}$ increases with patient age and is also likely to be higher in iodine-deficient regions. Hyperthyroidism is less common, occurring in approximately $0.1 \%-0.4 \%$ of pregnant women (96). The prevalence of thyroid dysfunction in pregnant women is similar to the prevalence of other disorders for which universal screening has been advocated.

Serum TSH testing is relatively inexpensive, is widely available, and is a reliable test in pregnancy, assuming that trimester-specific reference ranges are applied.

The adverse maternal and fetal effects associated with undiagnosed and untreated overt thyroid dysfunction (both overt hypothyroidism and overt hyperthyroidism) in pregnant women have been clearly delineated as described in previous sections. Subclinical maternal hyperthyroidism has not been associated with adverse maternal or fetal outcomes (25).

The maternal and fetal consequences of SCH in pregnancy are less well defined, although the majority of studies report an association between SCH and adverse pregnancy outcomes. A retrospective study by Casey et al. described a twoto threefold increased risk of placental abruption and preterm delivery before 34 weeks in untreated women with $\mathrm{SCH}$ compared with euthyroid controls (35). Abalovich et al. (38) reported that inadequate $\mathrm{LT}_{4}$ treatment in women with either $\mathrm{OH}$ or $\mathrm{SCH}$ was associated with significant increases in the risks for miscarriage and preterm delivery. Allan et al. (36) described a fourfold increased rate of fetal death in mothers with hypothyroidism compared with a euthyroid control population. Negro et al. (41) recently noted an increased miscarriage rate in TPOAb- women with serum TSH values between 2.5 and $5.0 \mathrm{mIU} / \mathrm{L}$. However, studies have not consistently demonstrated adverse obstetrical outcomes in pregnant women with SCH. Cleary-Goldman et al. (43) did not find any association between maternal SCH and adverse pregnancy outcomes in a secondary analysis of a cohort of 10,990 women. Similarly, Mannisto et al. $(44,45)$ found no association between SCH and adverse pregnancy outcomes in a large retrospective cohort.

Several studies suggest that mild maternal hypothyroidism is associated with adverse fetal neurocognitive outcomes. In a large case-control study Haddow et al. (37) demonstrated that at age 7-9 years children of mothers with untreated TSH elevations in pregnancy had IQ scores 7 points lower than children of euthyroid mothers. Li et al. (51) noted decreased IQ not only in the offspring of mothers with hypothyroidism or hypothyroxinemia during the first trimester, but also in those mothers who had detectable thyroid antibodies without thyroid dysfunction. Pop et al. (301) reported a decrease in psychomotor testing among offspring born to women with serum $\mathrm{FT}_{4}$ in the lowest 10th percentile, most of whom had normal serum TSH values. Finally, it was recently reported that maternal TSH in the Generation R Study was not related to 


\section{Treatment and monitoring of postpartum thyroiditis}

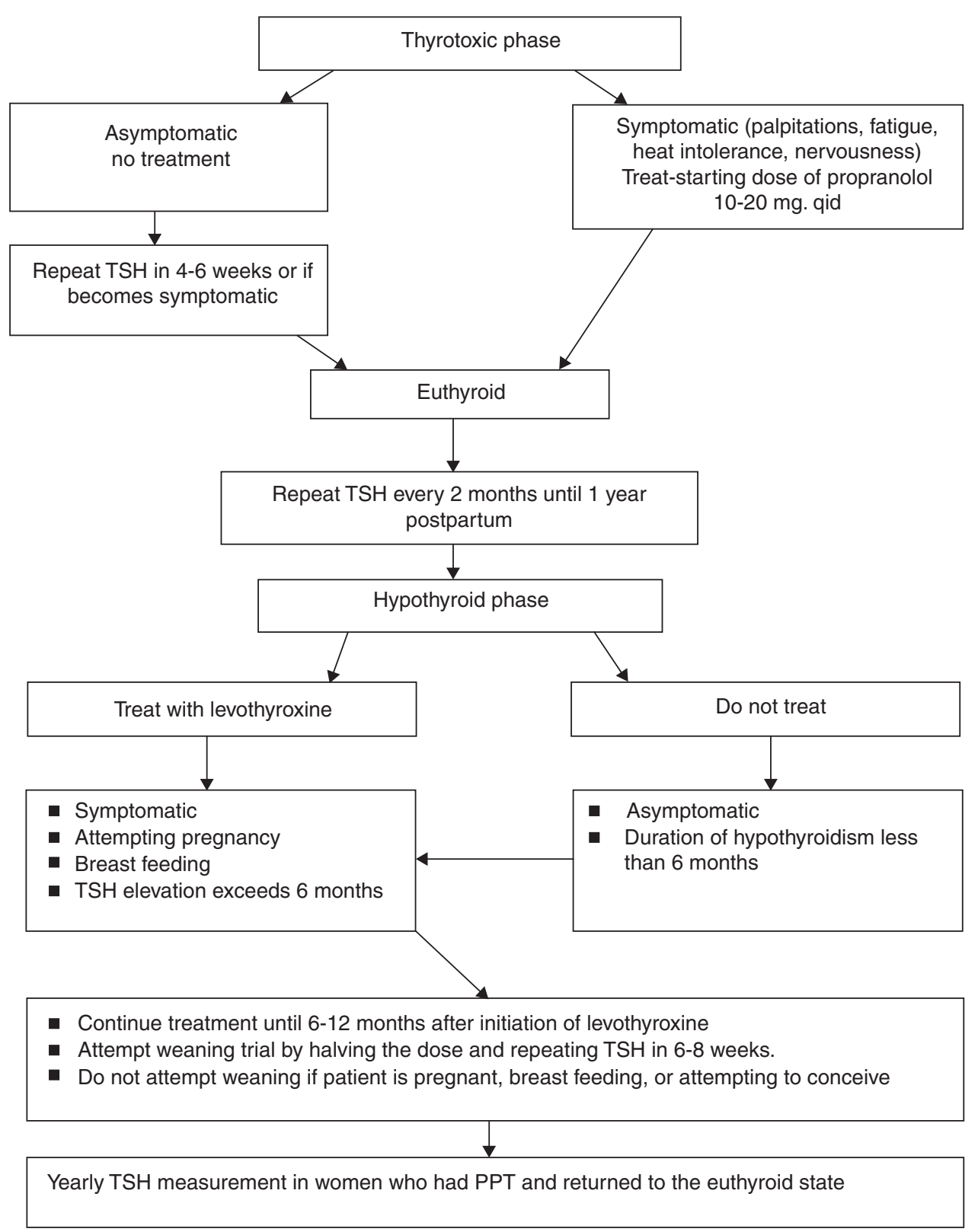

FIG. 2. An algorithm for the treatment and monitoring of postpartum thyroiditis.

cognitive outcomes in offspring, but that maternal hypothyroxinemia was associated with a higher risk of expressive language and nonverbal cognitive delays (52).

Only one prospective trial to date has demonstrated that $\mathrm{LT}_{4}$ treatment of subclinically hypothyroid women who were $\mathrm{TPOAb}+$ resulted in improved obstetric outcomes. Negro et al. (40) randomized 4562 first-trimester pregnant women to a casefinding vs. universal thyroid screening strategy. Women from the case-finding group considered to be at high risk for thyroid dysfunction and all women from the universal screening group had thyroid function tests ascertained during the first trimester, and those who were $\mathrm{TPOAb}+$ with $\mathrm{TSH}>2.5 \mathrm{mIU} / \mathrm{L}$ were treated with $\mathrm{LT}_{4}$. Women in the case-finding group who were considered low-risk had serum samples drawn in early pregnancy, but measurement of TSH in these samples was delayed until after delivery, and thus no $\mathrm{LT}_{4}$ was provided for women of this group. Women who were TPOAb- with TSH levels between 2.5 and $5.0 \mathrm{mIU} / \mathrm{L}$ were not treated in this investigation, and therefore no conclusions can be drawn about this subgroup. While the universal screening approach did not result in an overall decrease in adverse outcomes, treatment of thyroid dysfunction, as defined as a TSH $>2.5 \mathrm{mIU} / \mathrm{L}$ in TPOAb+ women, was associated with a significantly lower risk of at least one of the following adverse obstetrical outcomes: miscarriage, hypertension, preeclampsia, gestational diabetes, placental abruption, cesarean delivery, congestive heart failure, preterm 
labor, respiratory distress, neonatal intensive care unit admission, low birth weight, high birth weight, preterm or very preterm delivery, low Apgar score, and perinatal death.

The Controlled Antenatal Thyroid Screening Study was designed to determine whether $\mathrm{LT}_{4}$ treatment for hypothyroid or hypothyroxinemic pregnant women improves child intellectual development. A total of 22,000 women with singleton pregnancies were enrolled at $<16$ weeks gestation (mean gestational age 12.5 weeks) and were randomized to immediate assay of thyroid function, with $\mathrm{LT}_{4}$ treatment for elevated serum TSH ( $>97.5$ th percentile) and/or low serum $\mathrm{FT}_{4}$ ( $<2.5$ th percentile), versus storage of blood samples for measurement of thyroid function only after completion of pregnancy. Preliminary results were given as an oral presentation at the International Thyroid Congress in Paris, France, in September 2010 (302). At age 3 years, there was no difference in IQ between the children of 390 treated mothers compared with 404 untreated mothers. Fifteen percent of children in the control group had an IQ $<85$ compared with $11.5 \%$ in the screened and treated group, but this difference was not significant $(p=0.09)$.

A multicenter randomized placebo-controlled clinical trial to evaluate the effects of $\mathrm{LT}_{4}$ treatment for pregnant women with subclinical hypothyroidism or hypothyroxinemia is currently being conducted by the Maternal Fetal Medicine Unit of the National Institutes of Health. The primary outcome will be child IQ at 5 years of age. It is anticipated that results of this study will be available in 2015 .

Universal screening for thyroid dysfunction in pregnancy has been found to be cost-effective in one study (303). However, this was based on the assumption that treatment of subclinically hypothyroid pregnant women would increase offspring IQ. Another cost-effectiveness study by Thung et al. (304) concluded that screening for SCH in pregnancy would be cost-effective if future RCTs were to demonstrate that $\mathrm{LT}_{4}$ treatment of pregnant women with $\mathrm{SCH}$ decreased the incidence of offspring with an IQ of less than 85.

\section{- RECOMMENDATION 72}

There is insufficient evidence to recommend for or against universal TSH screening at the first trimester visit. Level I-USPSTF

\section{- RECOMMENDATION 73}

Because no studies to date have demonstrated a benefit to treatment of isolated maternal hypothyroximenia, universal $\mathrm{FT}_{4}$ screening of pregnant women is not recommended. Level D-USPSTF

\section{Question 84: Should serum TSH testing be carried out in a targeted population of pregnant women?}

In the absence of strong evidence favoring universal thyroid screening in pregnant women, a case-finding approach targeting thyroid function testing in high-risk groups has previously been advocated (1). However, this approach has been questioned. Vaidya et al. (305) obtained thyroid function tests in 1560 consecutive pregnancies to evaluate the effectiveness of a targeted case-finding strategy vs. universal screening to identify patients with hypothyroidism. In this cohort, $30 \%$ of hypothyroid women would not have been identified using the case-finding approach. In a separate study of 400 pregnant women, the authors estimated that $55 \%$ of women with thyroid abnormalities (including thyroid antibody positivity and hypothyroxinemia as well as hypothyroidism) would have been missed using a case-finding rather than a universal screening approach (306). To date, universal screening has not been demonstrated to result in improved population outcomes (40).

Women who are at high risk for thyroid dysfunction and may benefit from selected screening during pregnancy include those with the following attributes:

1) Women with a history of thyroid dysfunction and/or thyroid surgery. The prevalence of hypothyroidism following thyroid lobectomy has been reported as high as 33\% (307).

2) Women with a family history of thyroid disease.

3) Women with a goiter.

4) Women with thyroid antibodies. Based on NHANES data, the odds ratio for $\mathrm{OH}$ is approximately 40 in individuals with TPOAb compared with women who are $\mathrm{TPOAb}-(308)$.

5) Women with symptoms or clinical signs suggestive of hypothyroidism. It is important to note that women with $\mathrm{OH}$ are not invariably symptomatic. In a casecontrol study, although $\mathrm{OH}$ patients were more likely than euthyroid controls to report hypothyroid symptoms, only $30 \%$ of patients were symptomatic and $17 \%$ of the controls complained of hypothyroid symptoms (309).

6) Women with type I diabetes, in whom the rate of development of new onset hypothyroidism in pregnancy was $16 \%$ in one series (310).

7) Women with a history of either miscarriage or preterm delivery.

8) Women with other autoimmune disorders that are frequently associated with autoimmune thyroid dysfunction, including vitiligo, adrenal insufficiency, hypoparathyroidism, atrophic gastritis, pernicious anemia, systemic sclerosis, systemic lupus erythematosus, and Sjögren's syndrome (311).

9) Women with infertility should have screening with TSH as part of their infertility work-up. In one study $2 \%$ of women presenting for infertility treatment were found to have hyperthyroidism (312). The prevalence of hypothyroidism (overt and subclinical) among infertile women ranged from $1 \%$ to $43 \%$ in different studies (69).

10) Women with prior therapeutic head or neck irradiation. The 8-year prevalence of hypothyroidism has been calculated to be up to $67 \%$ following external radiation to the head and neck (313).

11) Women with morbid obesity. A body mass index $\geq 40$ $\mathrm{kg} / \mathrm{m}^{2}$ has been associated with an increased prevalence of hypothyroidism: in two recent studies cohorts of morbidly obese women had an overall prevalence of SCH and $\mathrm{OH}$ of $13.7 \%$ (314) and 19.5\% (315), respectively.

12) Women age 30 or older. The prevalence of hypothyroidism increases with age. The prevalence of an elevated serum TSH $(>5 \mathrm{mIU} / \mathrm{L})$ increases from about $4 \%$ in women age $18-24$ years to almost $7 \%$ in women aged $35-44$ years $(308,316)$. 


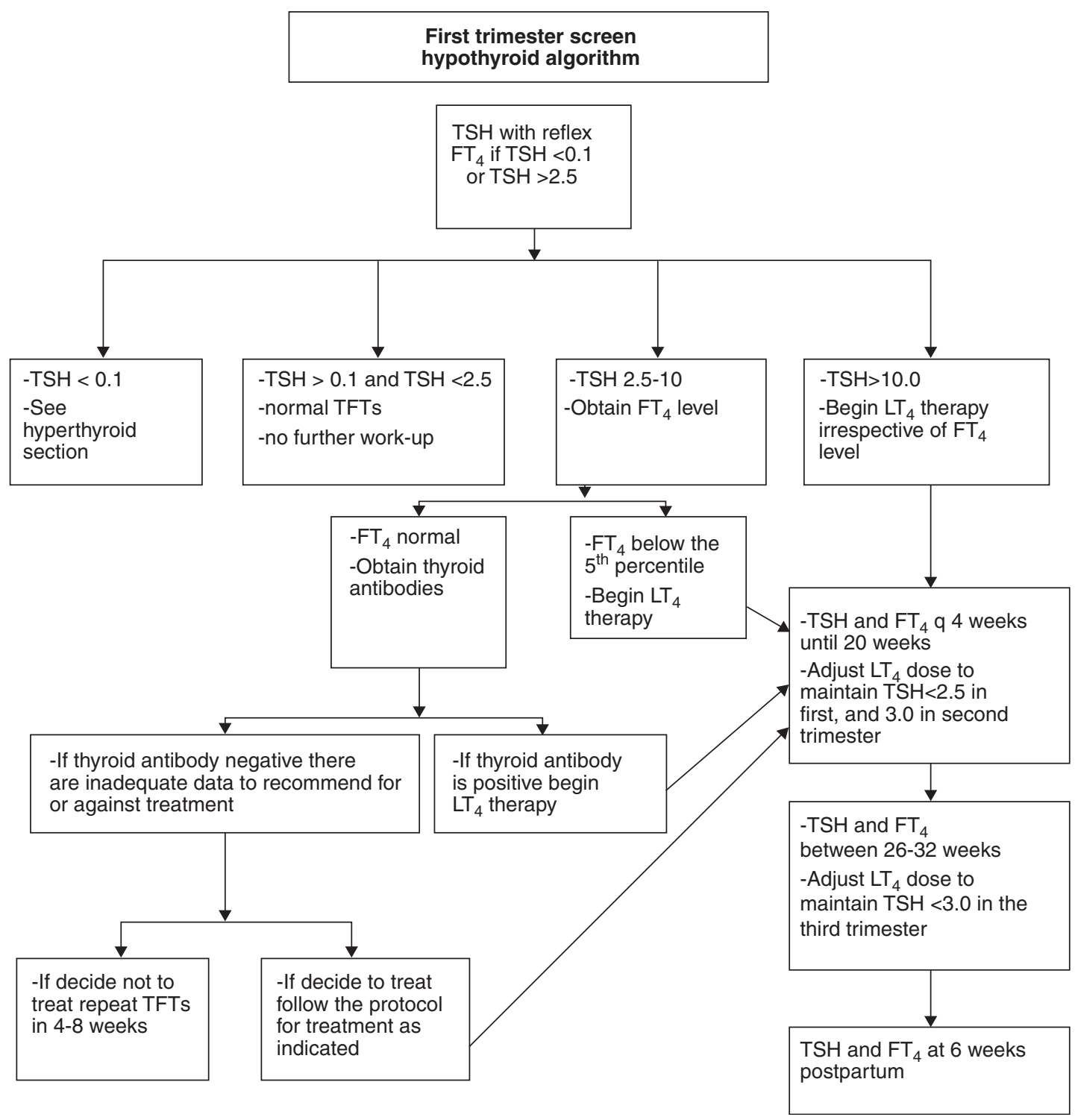

FIG. 3. An algorithm for the interpretation and management of the results of first trimester screening. TFT, thyroid function tests.

13) Women treated with amiodarone. The prevalence of thyroid dysfunction in individuals taking amiodarone varies depending whether regions are iodine deficient of sufficient, but overall $14 \%-18 \%$ of patients taking amiodarone will develop overt hyperthyroidism or overt hypothyroidism (317).

14) Women treated with lithium. Recent estimates of the prevalence of hypothyroidism in patients using lithium have been variable, ranging between $6 \%$ and $52 \%$ (318).

15) Women with a recent (in the past 6 weeks) exposure to iodinated radiological contrast agents. The prevalence of iodine-induced thyroid dysfunction may be as high as $20 \%$, depending on the dietary iodine status of the exposed individuals (319).

It might be reasonable to consider preconception TSH testing in high-risk women who desire pregnancy since early diag- nosis could potentially improve outcomes. However, studies on this particular issue have not been done.

Finally, women with a previous personal history of thyroid dysfunction should always be identified at their initial antenatal visit so that their thyroid function can be appropriately monitored and treated.

\section{- RECOMMENDATION 74}

There is insufficient evidence to recommend for or against TSH testing preconception in women at high risk for hypothyroidism. Level I-USPSTF

\section{- RECOMMENDATION 75}

All pregnant women should be verbally screened at the initial prenatal visit for any history of thyroid dysfunction and/or use of thyroid hormone $\left(\mathrm{LT}_{4}\right)$ or anti-thyroid medications (MMI, carbimazole, or PTU). Level B-USPSTF 


\section{- RECOMMENDATION 76}

Serum TSH values should be obtained early in pregnancy in the following women at high risk for overt hypothyroidism:

History of thyroid dysfunction or prior thyroid surgery Age $>30$ years

Symptoms of thyroid dysfunction or the presence of goiter TPOAb positivity

Type 1 diabetes or other autoimmune disorders

History of miscarriage or preterm delivery

History of head or neck radiation

Family history of thyroid dysfunction

Morbid obesity (BMI $\geq 40 \mathrm{~kg} / \mathrm{m}^{2}$ )

Use of amiodarone or lithium, or recent administration of iodinated radiologic contrast

Infertility

Residing in an area of known moderate to severe iodine insufficiency

\section{Level B-USPSTF}

Dissent from one committee member: There is no good evidence that improved maternal or perinatal outcomes will be obtained if the criteria for thyroid function screening were different for a pregnant than a nonpregnant population. Correspondingly, criteria for screening pregnant women should not differ from the nonpregnant population.

Figure 3 is an algorithm for the interpretation and management of the results of first trimester screening.

\section{FUTURE RESEARCH DIRECTIONS}

In developing the Guidelines the task force frequently struggled with the paucity of high-quality double-blind placebo controlled trials in the field of thyroid and pregnancy. In fact, only 18 of the 76 recommendations (24\%) in the present Guidelines were graded at the highest USPSTF Level (Level A). The Guidelines task force identified topics for future research that will be critical in resolving many of the unanswered questions in the field of thyroid and pregnancy. Of concern to the task force is that the double-blind placebo control studies either recently completed, or presently underway, began screening and intervention after the first trimester. As such these studies will not be able to address the impact of $\mathrm{LT}_{4}$ treatment in the first trimester in women with $\mathrm{SCH}$, isolated hypothyroxinemia, or thyroid antibody positivity on the mother and developing fetus. A trial that screens women preconception and then randomizes women with $\mathrm{SCH}$ or isolated hypothroxinemia and $\mathrm{TAb}+$ euthyroid women to either a treatment or no treatment arm is needed. The task force is aware of the difficulties inherent in performing such a trial, and the ethical challenges to be faced. Nevertheless, we believe that such a trial is feasible, can be ethically performed with appropriate study design and safeguards, and will yield invaluable information related to the optimal care of the pregnant women and the developing fetus. Other areas for future research include:

- A comprehensive cost-effectiveness study of screening for thyroid disease in pregnancy.

- A study evaluating the impact of iodine supplementation in pregnant women with the mildest form of iodine deficiency (median urinary iodine concentrations 100$150 \mu \mathrm{g} / \mathrm{L})$

- A study focused on the effects of iodine supplementation during lactation on infant thyroid function and cognition.

- A study to determine safe upper limits for iodine ingestion in pregnancy and lactation.

- A comprehensive study to asses the iodine status of pregnant and lactating women in the United States.

- A trial assessing the optimal targeted $\mathrm{FT}_{4}$ level in pregnant women treated for hyperthyroidism.

- Another well powered, prospective, randomized interventional trial of $\mathrm{LT}_{4}$ in euthyroid patients who are $\mathrm{TPOAb}+$ for the prevention of spontaneous abortion and preterm delivery

- A study to evaluate the impact of $\mathrm{LT}_{4}$ therapy in $\mathrm{TAb}+$ euthyroid women with recurrent spontaneous abortion.

\section{ACKNOWLEDGMENTS}

The committee would like to express special gratitude to Adonia Calhoun Coates, CMP, Director and Meeting Program Services ATA, for the exceptional job that she has performed over the last 2 years functioning as the support individual from the ATA. The committee would like to also express its appreciation to Hiwot Mengesha, Administrative Associate at George Washington University School of Medicine and Health Sciences. Finally, we would like to acknowledge Dr. Richard Kloos, Secretary/Chief Operating Officer of the ATA, who has provided constant guidance, insight and encouragement.

\section{AUTHOR DISCLOSURE STATEMENT}

None of the members of the Guidelines task force had any conflicts of interest.

\section{REFERENCES}

1. Abalovich M, Amino N, Barbour LA, Cobin RH, De Groot LJ, Glinoer D, Mandel SJ, Stagnaro-Green A 2007 Management of thyroid dysfunction during pregnancy and postpartum: an Endocrine Society Clinical Practice Guideline. J Clin Endocrinol Metab 92(8 Suppl):S1-47.

2. Gharib H, Cobin RH, Dickey RA 1999 Subclinical hypothyroidism during pregnancy: position statement from the American Association of Clinical Endocrinologists. Endocr Pract 5:367-368.

3. U.S. Preventive Services Task Force Ratings: Strength of Recommendations and Quality of Evidence. 2003 Guide to Clinical Preventive Services, Third Edition: Period Updates, 2000-2003. Available at: www .uspreventiveservicestaskforce.org/3rduspstf/ratings.htm (accessed June 13, 2011).

4. van Raaij JM, Vermaat-Miedema SH, Schonk CM, Peek ME, Hautvast JG 1987 Energy requirements of pregnancy in The Netherlands. Lancet 2:953-955.

5. Glinoer D 1997 The regulation of thyroid function in pregnancy: pathways of endocrine adaptation from physiology to pathology. Endocr Rev 18:404-433.

6. Baloch Z, Carayon P, Conte-Devolx B, Demers LM, FeldtRasmussen U, Henry JF, LiVosli VA, Niccoli-Sire P, John R, Ruf J, Smyth PP, Spencer CA, Stockigt JR; Guidelines 
Committee, National Academy of Clinical Biochemistry 2003 Laboratory medicine practice guidelines. Laboratory support for the diagnosis and monitoring of thyroid disease. Thyroid 13:3-126.

7. Soldin OP, Tractenberg RE, Hollowell JG, Jonklaas J, Janicic N, Soldin SJ 2004 Trimester-specific changes in maternal thyroid hormone, thyrotropin, and thyroglobulin concentrations during gestation: trends and associations across trimesters in iodine sufficiency. Thyroid 14:10841090.

8. Negro R 2009 Significance and management of low TSH in pregnancy. In: Lazarus J, Pirags V, Butz S (eds) The Thyroid and Reproduction. Georg Thieme Verlag, New York, pp 84-95.

9. Kahric-Janicic N, Soldin SJ, Soldin OP, West T, Gu J, Jonklaas J 2007 Tandem mass spectrometry improves the accuracy of free thyroxine measurements during pregnancy. Thyroid 17:303-311.

10. Soldin OP, Hilakivi-Clarke L, Weiderpass E, Soldin SJ 2004 Trimester-specific reference intervals for thyroxine and triiodothyronine in pregnancy in iodine-sufficient women using isotope dilution tandem mass spectrometry and immunoassays. Clin Chim Acta 349:181-189.

11. Roti E, Gardini E, Minelli R, Bianconi L, Flisi M 1991 Thyroid function evaluation by different commercially available free thyroid hormone measurement kits in term pregnant women and their newborns. J Endocrinol Invest 14:1-9.

12. Sapin R, D'Herbomez M, Schlienger JL 2004 Free thyroxine measured with equilibrium dialysis and nine immunoassays decreases in late pregnancy. Clin Lab 50:581-584.

13. Haddow JE, Knight GJ, Palomaki GE, McClain MR, Pulkkinen AJ 2004 The reference range and within-person variability of thyroid stimulating hormone during the first and second trimesters of pregnancy. J Med Screen 11:170-174.

14. Stricker R, Echenard M, Eberhart R, Chevailler MC, Perez V, Quinn FA, Stricker R 2007 Evaluation of maternal thyroid function during pregnancy: the importance of using gestational age-specific reference intervals. Eur J Endocrinol 157:509-514.

15. Panesar NS, Li CY, Rogers MS 2001 Reference intervals for thyroid hormones in pregnant Chinese women. Ann Clin Biochem 38:329-332.

16. Soldin OP, Soldin D, Sastoque M 2007 Gestation-specific thyroxine and thyroid stimulating hormone levels in the United States and worldwide. Ther Drug Monit 29:553-559.

17. Bocos-Terraz JP, Izquierdo-Alvarez S, Bancalero-Flores JL, Alvarez-Lahuerta R, Aznar-Sauca A, Real-Lopez E, IbanezMarco R, Bocanegra-Garcia V, Rivera-Sanchez G 2009 Thyroid hormones according to gestational age in pregnant Spanish women. BMC Res Notes 2:237.

18. Marwaha RK, Chopra S, Gopalakrishnan S, Sharma B, Kanwar RS, Sastry A, Singh S 2008 Establishment of reference range for thyroid hormones in normal pregnant Indian women. BJOG 115:602-606.

19. Dashe JS, Casey BM, Wells CE, McIntire DD, Byrd EW, Leveno KJ, Cunningham FG 2005 Thyroid-stimulating hormone in singleton and twin pregnancy: importance of gestational age-specific reference ranges. Obstet Gynecol 106:753-757.

20. Lockwood CM, Grenache DG, Gronowski AM 2009 Serum human chorionic gonadotropin concentrations greater than $400,000 \mathrm{IU} / \mathrm{L}$ are invariably associated with suppressed serum thyrotropin concentrations. Thyroid 19:863-868.
21. Price A, Obel O, Cresswell J, Catch I, Rutter S, Barik S, Heller SR, Weetman AP 2001 Comparison of thyroid function in pregnant and non-pregnant Asian and western Caucasian women. Clin Chim Acta 308:91-98.

22. Walker JA, Illions EH, Huddleston JF, Smallridge RC 2005 Racial comparisons of thyroid function and autoimmunity during pregnancy and the postpartum period. Obstet Gynecol 106:1365-1371.

23. Benhadi N, Wiersinga WM, Reitsma JB, Vrijkotte TG, van der Wal MF, Bonsel GJ 2007 Ethnic differences in TSH but not in free $\mathrm{T}_{4}$ concentrations or TPO antibodies during pregnancy. Clin Endocrinol (Oxf) 66:765-770.

24. Thienpont LM, Van Uytfanghe K, Beastall G, Faix JD, Ieiri T, Miller WG, Nelson JC, Ronin C, Ross HA, Thijssen JH, Toussaint B, IFCC Working Group on Standardization of Thyroid Function Tests 2010 Report of the IFCC Working Group for Standardization of Thyroid Function Tests; part 1: thyroid-stimulating hormone. Clin Chem 56:902-911.

25. Casey BM, Dashe JS, Wells CE, McIntire DD, Leveno KJ, Cunningham FG 2006 Subclinical hyperthyroidism and pregnancy outcomes. Obstet Gynecol 107:337-341.

26. Toft AD, Beckett GJ 2005 Measuring serum thyrotropin and thyroid hormone and assessing thyroid hormone transport. In: Braverman LE, Utiger RD (eds) Werner \& Ingbar's The Thyroid: A Fundamental and Clinical Text, 9th edition. Lippincott, Williams \& Wilkins, Philadelphia, pp 329-344.

27. Anckaert E, Poppe K, Van Uytfanghe K, Schiettecatte J, Foulon W, Thienpont LM 2010 FT4 immunoassays may display a pattern during pregnancy similar to the equilibrium dialysis ID-LC/tandem MS candidate reference measurement procedure in spite of susceptibility towards binding protein alterations. Clin Chim Acta 411:1348-1353.

28. Negro R, Formoso G, Mangieri T, Pezzarossa A, Dazzi D, Hassan H 2006 Levothyroxine treatment in euthyroid pregnant women with autoimmune thyroid disease: effects on obstetrical complications. J Clin Endocrinol Metab 91:2587-2591.

29. Sapin R, d'Herbomez M 2003 Free thyroxine measured by equilibrium dialysis and nine immunoassays in sera with various serum thyroxine-binding capacities. Clin Chem 49:1531-1535.

30. Lee RH, Spencer CA, Mestman JH, Miller EA, Petrovic I, Braverman LE, Goodwin TM 2009 Free T4 immunoassays are flawed during pregnancy. Am J Obstet Gynecol 200:260.e1-260.e6.

31. Stockigt J 2003 Assessment of thyroid function: towards an integrated laboratory-clinical approach. Clin Biochem Rev 24:109-122.

32. Yue B, Rockwood AL, Sandrock T, La'ulu SL, Kushnir MM, Meikle AW 2008 Free thyroid hormones in serum by direct equilibrium dialysis and online solid-phase extractionliquid chromatography/tandem mass spectrometry. Clin Chem 54:642-651.

33. Jonklaas J, Kahric-Janicic N, Soldin OP, Soldin SJ 2009 Correlations of free thyroid hormones measured by tandem mass spectrometry and immunoassay with thyroidstimulating hormone across 4 patient populations. Clin Chem 55:1380-1388.

34. Thienpont LM, Van Uytfanghe K, Beastall G, Faix JD, Ieiri T, Miller WG, Nelson JC, Ronin C, Ross HA, Thijssen JH, Toussaint B, IFCC Working Group on Standardization of Thyroid Function Tests 2010 Report of the IFCC Working Group for Standardization of Thyroid Function Tests; part 
2: free thyroxine and free triiodothyronine. Clin Chem 56:912-920.

35. Casey BM, Dashe JS, Wells CE, McIntire DD, Byrd W, Leveno KJ, Cunningham FG 2005 Subclinical hypothyroidism and pregnancy outcomes. Obstet Gynecol 105:239-245.

36. Allan WC, Haddow JE, Palomaki GE, Williams JR, Mitchell ML, Hermos RJ, Faix JD, Klein RZ 2000 Maternal thyroid deficiency and pregnancy complications: implications for population screening. J Med Screen 7:127-130.

37. Haddow JE, Palomaki GE, Allan WC, Williams JR, Knight GJ, Gagnon J, O'Heir CE, Mitchell ML, Hermos RJ, Waisbren SE, Faix JD, Klein RZ 1999 Maternal thyroid deficiency during pregnancy and subsequent neuropsychological development of the child. N Engl J Med 341:549-555.

38. Abalovich M, Gutierrez S, Alcaraz G, Maccallini G, Garcia A, Levalle O 2002 Overt and subclinical hypothyroidism complicating pregnancy. Thyroid 12:63-68.

39. Leung AS, Millar LK, Koonings PP, Montoro M, Mestman JH 1993 Perinatal outcome in hypothyroid pregnancies. Obstet Gynecol 81:349-353.

40. Negro R, Schwartz A, Gismondi R, Tinelli A, Mangieri T, Stagnaro-Green A 2010 Universal screening versus case finding for detection and treatment of thyroid hormonal dysfunction during pregnancy. J Clin Endocrinol Metab 95:1699-1707.

41. Negro R, Schwartz A, Gismondi R, Tinelli A, Mangieri T, Stagnaro-Green A 2010 Increased pregnancy loss rate in thyroid antibody negative women with TSH levels between 2.5 and 5.0 in the first trimester of pregnancy. J Clin Endocrinol Metab 95:E44-8.

42. Benhadi N, Wiersinga WM, Reitsma JB, Vrijkotte TG, Bonsel GJ 2009 Higher maternal TSH levels in pregnancy are associated with increased risk for miscarriage, fetal or neonatal death. Eur J Endocrinol 160:985-991.

43. Cleary-Goldman J, Malone FD, Lambert-Messerlian G, Sullivan L, Canick J, Porter TF, Luthy D, Gross S, Bianchi DW, D'Alton ME 2008 Maternal thyroid hypofunction and pregnancy outcome. Obstet Gynecol 112:85-92.

44. Mannisto T, Vaarasmaki M, Pouta A, Hartikainen AL, Ruokonen A, Surcel HM, Bloigu A, Jarvelin MR, SuvantoLuukkonen E 2009 Perinatal outcome of children born to mothers with thyroid dysfunction or antibodies: a prospective population-based cohort study. J Clin Endocrinol Metab 94:772-779.

45. Mannisto T, Vaarasmaki M, Pouta A, Hartikainen AL, Ruokonen A, Surcel HM, Bloigu A, Jarvelin MR, Suvanto E 2010 Thyroid dysfunction and autoantibodies during pregnancy as predictive factors of pregnancy complications and maternal morbidity in later life. J Clin Endocrinol Metab 95:1084-1094.

46. Ashoor G, Maiz N, Rotas M, Jawdat F, Nicolaides KH 2010 Maternal thyroid function at 11 to 13 weeks of gestation and subsequent fetal death. Thyroid 20:989-993.

47. Man EB, Brown JF, Serunian SA 1991 Maternal hypothyroxinemia: psychoneurological deficits of progeny. Ann Clin Lab Sci 21:227-239.

48. Man EB, Jones WS, Holden RH, Mellits ED 1971 Thyroid function in human pregnancy. 8. Retardation of progeny aged 7 years; relationships to maternal age and maternal thyroid function. Am J Obstet Gynecol 111:905916.

49. de Escobar GM, Obregon MJ, del Rey FE 2004 Maternal thyroid hormones early in pregnancy and fetal brain de- velopment. Best Pract Res Clin Endocrinol Metab 18:225248.

50. Pop VJ, Brouwers EP, Vader HL, Vulsma T, van Baar AL, de Vijlder JJ 2003 Maternal hypothyroxinaemia during early pregnancy and subsequent child development: a 3year follow-up study. Clin Endocrinol (Oxf) 59:282-288.

51. Li Y, Shan Z, Teng W, Yu X, Li Y, Fan C, Teng X, Guo R, Wang H, Li J, Chen Y, Wang W, Chawinga M, Zhang L, Yang L, Zhao Y, Hua T 2010 Abnormalities of maternal thyroid function during pregnancy affect neuropsychological development of their children at 25-30 months. Clin Endocrinol (Oxf) 72:825-829.

52. Henrichs J, Bongers-Schokking JJ, Schenk JJ, Ghassabian A, Schmidt HG, Visser TJ, Hooijkaas H, de Muinck KeizerSchrama SM, Hofman A, Jaddoe VV, Visser W, Steegers EA, Verhulst FC, de Rijke YB, Tiemeier H 2010 Maternal thyroid function during early pregnancy and cognitive functioning in early childhood: the Generation R Study. J Clin Endocrinol Metab 95:4227-4234.

53. Mandel SJ, Larsen PR, Seely EW, Brent GA 1990 Increased need for thyroxine during pregnancy in women with primary hypothyroidism. N Engl J Med 323:91-96.

54. Alexander EK, Marqusee E, Lawrence J, Jarolim P, Fischer GA, Larsen PR 2004 Timing and magnitude of increases in levothyroxine requirements during pregnancy in women with hypothyroidism. N Engl J Med 351:241-249.

55. Kaplan MM 1992 Monitoring thyroxine treatment during pregnancy. Thyroid 2:147-152.

56. Loh JA, Wartofsky L, Jonklaas J, Burman KD 2009 The magnitude of increased levothyroxine requirements in hypothyroid pregnant women depends upon the etiology of the hypothyroidism. Thyroid 19:269-275.

57. Yassa L, Marqusee E, Fawcett R, Alexander EK 2010 Thyroid hormone early adjustment in pregnancy (the THERAPY) trial. J Clin Endocrinol Metab 95:3234-3241.

58. Abalovich M, Alcaraz G, Kleiman-Rubinsztein J, Pavlove MM, Cornelio C, Levalle O, Gutierrez S 2010 The relationship of preconception thyrotropin levels to requirements for increasing the levothyroxine dose during pregnancy in women with primary hypothyroidism. Thyroid 20:1175-1178.

59. Galofre JC, Haber RS, Mitchell AA, Pessah R, Davies TF 2010 Increased postpartum thyroxine replacement in Hashimoto's thyroiditis. Thyroid 20:901-908.

60. Glinoer D, Riahi M, Grun JP, Kinthaert J 1994 Risk of subclinical hypothyroidism in pregnant women with asymptomatic autoimmune thyroid disorders. J Clin Endocrinol Metab 79:197-204.

61. Gartner R, Gasnier BC, Dietrich JW, Krebs B, Angstwurm MW 2002 Selenium supplementation in patients with autoimmune thyroiditis decreases thyroid peroxidase antibodies concentrations. J Clin Endocrinol Metab 87:1687-1691.

62. Duntas LH, Mantzou E, Koutras DA 2003 Effects of a six month treatment with selenomethionine in patients with autoimmune thyroiditis. Eur J Endocrinol 148:389-393.

63. Mazokopakis EE, Papadakis JA, Papadomanolaki MG, Batistakis AG, Giannakopoulos TG, Protopapadakis EE, Ganotakis ES 2007 Effects of 12 months treatment with Lselenomethionine on serum anti-TPO Levels in Patients with Hashimoto's thyroiditis. Thyroid 17:609-612.

64. Karanikas G, Schuetz M, Kontur S, Duan H, Kommata S, Schoen R, Antoni A, Kletter K, Dudczak R, Willheim M 2008 No immunological benefit of selenium in consecutive patients with autoimmune thyroiditis. Thyroid 18:7-12. 
65. Negro R, Greco G, Mangieri T, Pezzarossa A, Dazzi D, Hassan H 2007 The influence of selenium supplementation on postpartum thyroid status in pregnant women with thyroid peroxidase autoantibodies. J Clin Endocrinol Metab 92:1263-1268.

66. Stranges S, Marshall JR, Natarajan R, Donahue RP, Trevisan M, Combs GF, Cappuccio FP, Ceriello A, Reid ME 2007 Effects of long-term selenium supplementation on the incidence of type 2 diabetes: a randomized trial. Ann Intern Med 147:217-223.

67. Braverman LE, Utiger RD 2005 Introduction to thyrotoxicosis. In: Braverman LE, Utiger RD (eds) Werner and Ingbar's The Thyroid: A Fundamental and Clinical Text, 9th edition. Lippincott, Williams and Wilkins, Philadelphia, pp 453-455.

68. Patil-Sisodia K, Mestman JH 2010 Graves hyperthyroidism and pregnancy: a clinical update. Endocr Pract 16:118-129.

69. Krassas GE, Poppe K, Glinoer D 2010 Thyroid function and human reproductive health. Endocr Rev 31:702-755.

70. Goodwin TM, Montoro M, Mestman JH 1992 Transient hyperthyroidism and hyperemesis gravidarum: clinical aspects. Am J Obstet Gynecol 167:648-652.

71. Tan JY, Loh KC, Yeo GS, Chee YC 2002 Transient hyperthyroidism of hyperemesis gravidarum. BJOG 109: 683-688.

72. Niebyl JR 2010 Clinical practice. Nausea and vomiting in pregnancy. N Engl J Med 363:1544-1550.

73. Verberg MF, Gillott DJ, Al-Fardan N, Grudzinskas JG 2005 Hyperemesis gravidarum, a literature review. Hum Reprod Update 11:527-539.

74. Hershman JM 1999 Human chorionic gonadotropin and the thyroid: hyperemesis gravidarum and trophoblastic tumors. Thyroid 9:653-657.

75. Grun JP, Meuris S, De Nayer P, Glinoer D 1997 The thyrotrophic role of human chorionic gonadotrophin (hCG) in the early stages of twin (versus single) pregnancies. Clin Endocrinol (Oxf) 46:719-725.

76. Rodien P, Bremont C, Sanson ML, Parma J, Van Sande J, Costagliola S, Luton JP, Vassart G, Duprez L 1998 Familial gestational hyperthyroidism caused by a mutant thyrotropin receptor hypersensitive to human chorionic gonadotropin. N Engl J Med 339:1823-1826.

77. Glinoer D, Spencer CA 2010 Serum TSH determinations in pregnancy: how, when and why? Nat Rev Endocrinol 6:526-529.

78. Bouillon R, Naesens M, Van Assche FA, De Keyser L, De Moor P, Renaer M, De Vos P, De Roo M 1982 Thyroid function in patients with hyperemesis gravidarum. Am J Obstet Gynecol 143:922-926.

79. Laurberg P, Bournaud C, Karmisholt J, Orgiazzi J 2009 Management of Graves' hyperthyroidism in pregnancy: focus on both maternal and foetal thyroid function, and caution against surgical thyroidectomy in pregnancy. Eur J Endocrinol 160:1-8.

80. Davis LE, Lucas MJ, Hankins GD, Roark ML, Cunningham FG 1989 Thyrotoxicosis complicating pregnancy. Am J Obstet Gynecol 160:63-70.

81. Millar LK, Wing DA, Leung AS, Koonings PP, Montoro MN, Mestman JH 1994 Low birth weight and preeclampsia in pregnancies complicated by hyperthyroidism. Obstet Gynecol 84:946-949.

82. Papendieck P, Chiesa A, Prieto L, Gruneiro-Papendieck L 2009 Thyroid disorders of neonates born to mothers with Graves' disease. J Pediatr Endocrinol Metab 22:547-553.
83. Phoojaroenchanachai $M$, Sriussadaporn S, Peerapatdit T, Vannasaeng S, Nitiyanant W, Boonnamsiri V, Vichayanrat A 2001 Effect of maternal hyperthyroidism during late pregnancy on the risk of neonatal low birth weight. Clin Endocrinol (Oxf) 54:365-370.

84. Sheffield JS, Cunningham FG 2004 Thyrotoxicosis and heart failure that complicate pregnancy. Am J Obstet Gynecol 190:211-217.

85. Mandel SJ, Cooper DS 2001 The use of antithyroid drugs in pregnancy and lactation. J Clin Endocrinol Metab 86:23542359.

86. Azizi F 2006 The safety and efficacy of antithyroid drugs. Expert Opin Drug Saf 5:107-116.

87. Clementi M, Di Gianantonio E, Pelo E, Mammi I, Basile RT, Tenconi R 1999 Methimazole embryopathy: delineation of the phenotype. Am J Med Genet 83:43-46.

88. Barbero P, Valdez R, Rodriguez H, Tiscornia C, Mansilla E, Allons A, Coll S, Liascovich R 2008 Choanal atresia associated with maternal hyperthyroidism treated with methimazole: a case-control study. Am J Med Genet A 146A: 2390-2395.

89. Clementi M, Di Gianantonio E, Cassina M, Leoncini E, Botto LD, Mastroiacovo P, SAFE-Med Study Group 2010 Treatment of hyperthyroidism in pregnancy and birth defects. J Clin Endocrinol Metab 95:E337-41.

90. Rivkees SA, Mattison DR 2009 Propylthiouracil (PTU) hepatoxicity in children and recommendations for discontinuation of use. Int J Pediatr Endocrinol 2009:132041.

91. Russo MW, Galanko JA, Shrestha R, Fried MW, Watkins P 2004 Liver transplantation for acute liver failure from drug induced liver injury in the United States. Liver Transpl 10:1018-1023.

92. Bahn RS, Burch HS, Cooper DS, Garber JR, Greenlee CM, Klein IL, Laurberg P, McDougall IR, Rivkees SA, Ross D, Sosa JA, Stan MN 2009 The role of propylthiouracil in the management of Graves' disease in adults: report of a meeting jointly sponsored by the American Thyroid Association and the Food and Drug Administration. Thyroid 19:673-674.

93. Rubin PC 1981 Current concepts: beta-blockers in pregnancy. N Engl J Med 305:1323-1326.

94. Sherif IH, Oyan WT, Bosairi S, Carrascal SM 1991 Treatment of hyperthyroidism in pregnancy. Acta Obstet Gynecol Scand 70:461-463.

95. Mestman JH, Manning PR, Hodgman J 1974 Hyperthyroidism and pregnancy. Arch Intern Med 134:434-439.

96. Glinoer D 1998 Thyroid hyperfunction during pregnancy. Thyroid 8:859-864.

97. Momotani N, Noh J, Oyanagi H, Ishikawa N, Ito K 1986 Antithyroid drug therapy for Graves' disease during pregnancy. Optimal regimen for fetal thyroid status. $\mathrm{N}$ Engl J Med 315:24-28.

98. Ochoa-Maya MR, Frates MC, Lee-Parritz A, Seely EW 1999 Resolution of fetal goiter after discontinuation of propylthiouracil in a pregnant woman with Graves' hyperthyroidism. Thyroid 9:1111-1114.

99. Hamburger JI 1992 Diagnosis and management of Graves' disease in pregnancy. Thyroid 2:219-224.

100. Amino N, Tanizawa $\mathrm{O}$, Mori H, Iwatani $\mathrm{Y}$, Yamada $\mathrm{T}$, Kurachi K, Kumahara Y, Miyai K 1982 Aggravation of thyrotoxicosis in early pregnancy and after delivery in Graves' disease. J Clin Endocrinol Metab 55:108-112.

101. Laurberg P, Nygaard B, Glinoer D, Grussendorf M, Orgiazzi J 1998 Guidelines for TSH-receptor antibody measurements in pregnancy: results of an evidence-based 
symposium organized by the European Thyroid Association. Eur J Endocrinol 139:584-586.

102. Momotani N, Hisaoka T, Noh J, Ishikawa N, Ito K 1992 Effects of iodine on thyroid status of fetus versus mother in treatment of Graves' disease complicated by pregnancy. J Clin Endocrinol Metab 75:738-744.

103. Kempers MJ, van Tijn DA, van Trotsenburg AS, de Vijlder JJ, Wiedijk BM, Vulsma T 2003 Central congenital hypothyroidism due to gestational hyperthyroidism: detection where prevention failed. J Clin Endocrinol Metab 88:58515857.

104. Zwaveling-Soonawala N, van Trotsenburg P, Vulsma T 2009 Central hypothyroidism in an infant born to an adequately treated mother with Graves' disease: an effect of maternally derived thyrotrophin receptor antibodies?. Thyroid 19:661-662.

105. Gruner C, Kollert A, Wildt L, Dorr HG, Beinder E, Lang N 2001 Intrauterine treatment of fetal goitrous hypothyroidism controlled by determination of thyroid-stimulating hormone in fetal serum. A case report and review of the literature. Fetal Diagn Ther 16:47-51.

106. Luton D, Le Gac I, Vuillard E, Castanet M, Guibourdenche J, Noel M, Toubert ME, Leger J, Boissinot C, Schlageter MH, Garel C, Tebeka B, Oury JF, Czernichow P, Polak M 2005 Management of Graves' disease during pregnancy: the key role of fetal thyroid gland monitoring. J Clin Endocrinol Metab 90:6093-6098.

107. McKenzie JM, Zakarija M 1992 Fetal and neonatal hyperthyroidism and hypothyroidism due to maternal TSH receptor antibodies. Thyroid 2:155-159.

108. Mitsuda N, Tamaki H, Amino N, Hosono T, Miyai K, Tanizawa O 1992 Risk factors for developmental disorders in infants born to women with Graves disease. Obstet Gynecol 80:359-364.

109. Peleg D, Cada S, Peleg A, Ben-Ami M 2002 The relationship between maternal serum thyroid-stimulating immunoglobulin and fetal and neonatal thyrotoxicosis. Obstet Gynecol 99:1040-1043.

110. Zimmerman D 1999 Fetal and neonatal hyperthyroidism. Thyroid 9:727-733.

111. Polak M, Le Gac I, Vuillard E, Guibourdenche J, Leger J, Toubert ME, Madec AM, Oury JF, Czernichow P, Luton D 2004 Fetal and neonatal thyroid function in relation to maternal Graves' disease. Best Pract Res Clin Endocrinol Metab 18:289-302.

112. Cohen O, Pinhas-Hamiel O, Sivan E, Dolitski M, Lipitz S, Achiron R 2003 Serial in utero ultrasonographic measurements of the fetal thyroid: a new complementary tool in the management of maternal hyperthyroidism in pregnancy. Prenat Diagn 23:740-742.

113. Huel C, Guibourdenche J, Vuillard E, Ouahba J, Piketty M, Oury JF, Luton D 2009 Use of ultrasound to distinguish between fetal hyperthyroidism and hypothyroidism on discovery of a goiter. Ultrasound Obstet Gynecol 33:412420.

114. Porreco RP, Bloch CA 1990 Fetal blood sampling in the management of intrauterine thyrotoxicosis. Obstet Gynecol 76:509-512.

115. Daffos F, Capella-Pavlovsky M, Forestier F 1985 Fetal blood sampling during pregnancy with use of a needle guided by ultrasound: a study of 606 consecutive cases. Am J Obstet Gynecol 153:655-660.

116. Nachum Z, Rakover Y, Weiner E, Shalev E 2003 Graves' disease in pregnancy: prospective evaluation of a selective invasive treatment protocol. Am J Obstet Gynecol 189:159_ 165.

117. Kilpatrick S 2003 Umbilical blood sampling in women with thyroid disease in pregnancy: is it necessary? Am J Obstet Gynecol 189:1-2.

118. Stagnaro-Green A 2004 Postpartum thyroiditis. Best Pract Res Clin Endocrinol Metab 18:303-316.

119. Azizi F 2006 Treatment of post-partum thyrotoxicosis. J Endocrinol Invest 29:244-247.

120. Rotondi M, Cappelli C, Pirali B, Pirola I, Magri F, Fonte R, Castellano M, Rosei EA, Chiovato L 2008 The effect of pregnancy on subsequent relapse from Graves' disease after a successful course of antithyroid drug therapy. J Clin Endocrinol Metab 93:3985-3988.

121. Benhaim Rochester D, Davies TF 2005 Increased risk of Graves' disease after pregnancy. Thyroid 15:1287-1290.

122. Rotondi M, Pirali B, Lodigiani S, Bray S, Leporati P, Chytiris S, Balzano S, Magri F, Chiovato L 2008 The post partum period and the onset of Graves' disease: an overestimated risk factor. Eur J Endocrinol 159:161-165.

123. Azizi F, Hedayati M 2002 Thyroid function in breast-fed infants whose mothers take high doses of methimazole. J Endocrinol Invest 25:493-496.

124. Azizi F, Bahrainian M, Khamseh ME, Khoshniat M 2003 Intellectual development and thyroid function in children who were breast-fed by thyrotoxic mothers taking methimazole. J Pediatr Endocrinol Metab 16:1239-1243.

125. Glinoer D 2007 The importance of iodine nutrition during pregnancy. Public Health Nutr 10:1542-1546.

126. Liberman CS, Pino SC, Fang SL, Braverman LE, Emerson CH 1998 Circulating iodide concentrations during and after pregnancy. J Clin Endocrinol Metab 83:3545-3549.

127. Brander L, Als C, Buess $H$, Haldimann F, Harder $M$, Hanggi W, Herrmann U, Lauber K, Niederer U, Zurcher T, Burgi U, Gerber H 2003 Urinary iodine concentration during pregnancy in an area of unstable dietary iodine intake in Switzerland. J Endocrinol Invest 26:389-396.

128. Azizi F, Smyth P 2009 Breastfeeding and maternal and infant iodine nutrition. Clin Endocrinol (Oxf) 70:803-809.

129. Andersen S, Karmisholt J, Pedersen KM, Laurberg P 2008 Reliability of studies of iodine intake and recommendations for number of samples in groups and in individuals. Br J Nutr 99:813-818.

130. Berghout A, Wiersinga W 1998 Thyroid size and thyroid function during pregnancy: an analysis. Eur J Endocrinol 138:536-542.

131. Delange FM, Dunn JT 2005 Iodine deficiency. In: Braverman LE, Utiger RD (eds) Werner and Ingbar's The Thyroid: A Fundamental and Clinical Text, 9th edition. Lippincott, Williams and Wilkins, Philadelphia, pp 264-288.

132. World Health Organization/International Council for the Control of the Iodine Deficiency Disorders/United Nations Children's Fund (WHO/ICCIDD/UNICEF) 2007 Assessment of the iodine deficiency disorders and monitoring their elimination. World Health Organization, Geneva.

133. Vermiglio F, Lo Presti VP, Castagna MG, Violi MA, Moleti M, Finocchiaro MD, Mattina F, Artemisia A, Trimarchi F 1999 Increased risk of maternal thyroid failure with pregnancy progression in an iodine deficient area with major iodine deficiency disorders. Thyroid 9:19-24.

134. de Escobar GM, Obregon MJ, del Rey FE 2007 Iodine deficiency and brain development in the first half of pregnancy. Public Health Nutr 10:1554-1570. 
135. Costeira MJ, Oliveira P, Santos NC, Ares S, Saenz-Rico B, Morreale de Escobar G, Palha JA 2011 Psychomotor development of children from an iodine-deficient region. J Pediatr 159:447-453

136. International Council for Control of Iodine Deficiency Disorders. Available at www.iccidd.org

137. Vermiglio F, Lo Presti VP, Moleti M, Sidoti M, Tortorella G, Scaffidi G, Castagna MG, Mattina F, Violi MA, Crisa A, Artemisia A, Trimarchi F 2004 Attention deficit and hyperactivity disorders in the offspring of mothers exposed to mild-moderate iodine deficiency: a possible novel iodine deficiency disorder in developed countries. J Clin Endocrinol Metab 89:6054-6060.

138. Soldin OP, Soldin SJ, Pezzullo JC 2003 Urinary iodine percentile ranges in the United States. Clin Chim Acta 328:185-190.

139. Caldwell KL, Jones R, Hollowell JG 2005 Urinary iodine concentration: United States National Health And Nutrition Examination Survey 2001-2002. Thyroid 15:692-699.

140. Caldwell KL, Makhmudov AA, Ely EK, Jarrett JM, Henahan D, Jones RL 2009 Iodine status of the U.S. population, NHANES 2005-2006. Thyroid 19:S26-S27.

141. Caldwell KL, Miller GA, Wang RY, Jain RB, Jones RL 2008 Iodine status of the U.S. population, National Health and Nutrition Examination Survey 2003-2004. Thyroid 18: 1207-1214.

142. Hollowell JG, Staehling NW, Hannon WH, Flanders DW, Gunter EW, Maberly GF, Braverman LE, Pino S, Miller DT, Garbe PL, DeLozier DM, Jackson RJ 1998 Iodine nutrition in the United States. Trends and public health implications: iodine excretion data from National Health and Nutrition Examination Surveys I and III (1971-1974 and 1988-1994). J Clin Endocrinol Metab 83:3401-3408.

143. Perrine CG, Herrick K, Serdula MK, Sullivan KM 2010 Some subgroups of reproductive age women in the United States may be at risk for iodine deficiency. J Nutr 140:14891494.

144. Pearce EN, Leung AM, Blount BC, Bazrafshan HR, He X, Pino S, Valentin-Blasini L, Braverman LE 2007 Breast milk iodine and perchlorate concentrations in lactating Bostonarea women. J Clin Endocrinol Metab 92:1673-1677.

145. Kirk AB, Martinelango PK, Tian K, Dutta A, Smith EE, Dasgupta PK 2005 Perchlorate and iodide in dairy and breast milk. Environ Sci Technol 39:2011-2017.

146. Zimmermann MB 2009 Iodine deficiency. Endocr Rev 30:376-408.

147. Pharoah PO, Buttfield IH, Hetzel BS 1971 Neurological damage to the fetus resulting from severe iodine deficiency during pregnancy. Lancet 1:308-310.

148. O'Donnell KJ, Rakeman MA, Zhi-Hong D, Xue-Yi C, Mei ZY, DeLong N, Brenner G, Tai M, Dong W, DeLong GR 2002 Effects of iodine supplementation during pregnancy on child growth and development at school age. Dev Med Child Neurol 44:76-81.

149. Fierro-Benitez R, Cazar R, Stanbury JB, Rodriguez P, Garces F, Fierro-Renoy F, Estrella E 1988 Effects on school children of prophylaxis of mothers with iodized oil in an area of iodine deficiency. J Endocrinol Invest 11:327-335.

150. Cao XY, Jiang XM, Dou ZH, Rakeman MA, Zhang ML, O’Donnell K, Ma T, Amette K, DeLong N, DeLong GR 1994 Timing of vulnerability of the brain to iodine deficiency in endemic cretinism. N Engl J Med 331:1739-1744.

151. DeLong GR, Leslie PW, Wang SH, Jiang XM, Zhang ML, Rakeman M, Jiang JY, Ma T, Cao XY 1997 Effect on infant mortality of iodination of irrigation water in a severely iodine-deficient area of China. Lancet 350:771-773.

152. Chaouki ML, Benmiloud M 1994 Prevention of iodine deficiency disorders by oral administration of lipiodol during pregnancy. Eur J Endocrinol 130:547-551.

153. Antonangeli L, Maccherini D, Cavaliere R, Di Giulio C, Reinhardt B, Pinchera A, Aghini-Lombardi F 2002 Comparison of two different doses of iodide in the prevention of gestational goiter in marginal iodine deficiency: a longitudinal study. Eur J Endocrinol 147:29-34.

154. Berbel P, Mestre JL, Santamaria A, Palazon I, Franco A, Graells M, Gonzalez-Torga A, de Escobar GM 2009 Delayed neurobehavioral development in children born to pregnant women with mild hypothyroxinemia during the first month of gestation: the importance of early iodine supplementation. Thyroid 19:511-519.

155. Glinoer D, De Nayer P, Delange F, Lemone M, Toppet V, Spehl M, Grun JP, Kinthaert J, Lejeune B 1995 A randomized trial for the treatment of mild iodine deficiency during pregnancy: maternal and neonatal effects. J Clin Endocrinol Metab 80:258-269.

156. Liesenkotter KP, Gopel W, Bogner U, Stach B, Gruters A 1996 Earliest prevention of endemic goiter by iodine supplementation during pregnancy. Eur J Endocrinol 134:443-448.

157. Nohr SB, Laurberg P 2000 Opposite variations in maternal and neonatal thyroid function induced by iodine supplementation during pregnancy. J Clin Endocrinol Metab 85:623-627.

158. Pedersen KM, Laurberg $P$, Iversen $E$, Knudsen $P R$, Gregersen HE, Rasmussen OS, Larsen KR, Eriksen GM, Johannesen PL 1993 Amelioration of some pregnancyassociated variations in thyroid function by iodine supplementation. J Clin Endocrinol Metab 77:1078-1083.

159. Romano R, Jannini EA, Pepe M, Grimaldi A, Olivieri M, Spennati P, Cappa F, D'Armiento M 1991 The effects of iodoprophylaxis on thyroid size during pregnancy. Am J Obstet Gynecol 164:482-485.

160. Velasco I, Carreira M, Santiago P, Muela JA, Garcia-Fuentes E, Sanchez-Munoz B, Garriga MJ, Gonzalez-Fernandez MC, Rodriguez A, Caballero FF, Machado A, GonzalezRomero S, Anarte MT, Soriguer F 2009 Effect of iodine prophylaxis during pregnancy on neurocognitive development of children during the first two years of life. J Clin Endocrinol Metab 94:3234-3241.

161. Trumbo P, Yates AA, Schlicker S, Poos M 2001 Dietary reference intakes: vitamin $\mathrm{A}$, vitamin $\mathrm{K}$, arsenic, boron, chromium, copper, iodine, iron, manganese, molybdenum, nickel, silicon, vanadium, and zinc. J Am Diet Assoc 101:294-301.

162. U.S. Salt Institute 2007 Iodized salt. Available at www .saltinstitute.org/Uses-benefits / Salt-in-Food/Essential -nutrient/Iodized-salt (accessed September 12, 2011).

163. Galton DM, Petersson LG, Erb HN 1986 Milk iodine residues in herds practicing iodophor premilking teat disinfection. J Dairy Sci 69:267-271.

164. Conrad LM 3rd, Hemken RW 1978 Milk iodine as influenced by an iodophor teat dip. J Dairy Sci 61:776-780.

165. Pearce EN, Pino S, He X, Bazrafshan HR, Lee SL, Braverman LE 2004 Sources of dietary iodine: bread, cows' milk, and infant formula in the Boston area. J Clin Endocrinol Metab 89:3421-3424.

166. Haldimann M, et al. 2005 Iodine content of food groups. J Food Comp Anal 18:461-471.

167. Public Health Committee of the American Thyroid Association; Becker DV, Braverman LE, Delange F, Dunn JT, 
Franklyn JA, Hollowell JG, Lamm SH, Mitchell ML, Pearce E, Robbins J, Rovet JF 2006 Iodine supplementation for pregnancy and lactation-United States and Canada: recommendations of the American Thyroid Association. Thyroid 16:949-951.

168. Gregory CO, Serdula MK, Sullivan KM 2009 Use of supplements with and without iodine in women of childbearing age in the United States. Thyroid 19:1019-1020.

169. Leung AM, Pearce EN, Braverman LE 2009 Iodine content of prenatal multivitamins in the United States. N Engl J Med 360:939-940.

170. Pennington JA 1990 A review of iodine toxicity reports. J Am Diet Assoc 90:1571-1581.

171. Wolff J, Chaikoff IL 1948 Plasma inorganic iodide as a homeostatic regulator of thyroid function. J Biol Chem 174:555-564.

172. Ellish NJ, Saboda K, O'Connor J, Nasca PC, Stanek EJ, Boyle C 1996 A prospective study of early pregnancy loss. Hum Reprod 11:406-412.

173. Fisher DA, Klein AH 1981 Thyroid development and disorders of thyroid function in the newborn. N Engl J Med 304:702-712.

174. Theodoropoulos T, Braverman LE, Vagenakis AG 1979 Iodide-induced hypothyroidism: a potential hazard during perinatal life. Science 205:502-503.

175. Fang MC, Stafford RS, Ruskin JN, Singer DE 2004 National trends in antiarrhythmic and antithrombotic medication use in atrial fibrillation. Arch Intern Med 164:55-60.

176. Aiba M, Ninomiya J, Furuya K, Arai H, Ishikawa H, Asaumi S, Takagi A, Ohwada S, Morishita Y 1999 Induction of a critical elevation of povidone-iodine absorption in the treatment of a burn patient: report of a case. Surg Today 29:157-159.

177. Wilcox AJ, Weinberg CR, O'Connor JF, Baird DD, Schlatterer JP, Canfield RE, Armstrong EG, Nisula BC 1988 Incidence of early loss of pregnancy. N Engl J Med 319: 189-194.

178. Toth B, Jeschke U, Rogenhofer N, Scholz C, Wurfel W, Thaler CJ, Makrigiannakis A 2010 Recurrent miscarriage: current concepts in diagnosis and treatment. J Reprod Immunol 85:25-32.

179. Dudley DJ 2007 Diabetic-associated stillbirth: incidence, pathophysiology, and prevention. Clin Perinatol 34:61126, vii.

180. De Vivo A, Mancuso A, Giacobbe A, Moleti M, Maggio Savasta L, De Dominici R, Priolo AM, Vermiglio F 2010 Thyroid function in women found to have early pregnancy loss. Thyroid 20:633-637.

181. Stagnaro-Green A, Roman SH, Cobin RH, el-Harazy E, Alvarez-Marfany M, Davies TF 1990 Detection of at-risk pregnancy by means of highly sensitive assays for thyroid autoantibodies. JAMA 264:1422-1425.

182. Iijima T, Tada H, Hidaka Y, Mitsuda N, Murata Y, Amino N 1997 Effects of autoantibodies on the course of pregnancy and fetal growth. Obstet Gynecol 90:364-369.

183. Glinoer D, Soto MF, Bourdoux P, Lejeune B, Delange F, Lemone M, Kinthaert J, Robijn C, Grun JP, de Nayer P 1991 Pregnancy in patients with mild thyroid abnormalities: maternal and neonatal repercussions. J Clin Endocrinol Metab 73:421-427.

184. Sieiro Netto L, Medina Coeli C, Micmacher E, Mamede Da Costa S, Nazar L, Galvao D, Buescu A, Vaisman M 2004 Influence of thyroid autoimmunity and maternal age on the risk of miscarriage. Am J Reprod Immunol 52:312-316.
185. Bagis T, Gokcel A, Saygili ES 2001 Autoimmune thyroid disease in pregnancy and the postpartum period: relationship to spontaneous abortion. Thyroid 11:1049-1053.

186. Sezer K, Kamel N, Unlu C, Celik HK 2009 Impact of first trimester and postpartum period thyroid autoantibodies on abortus incidence in Turkish pregnant women. Gynecol Endocrinol 25:387-391.

187. Prummel MF, Wiersinga WM 2004 Thyroid autoimmunity and miscarriage. Eur J Endocrinol 150:751-755.

188. Imaizumi M, Pritsker A, Kita M, Ahmad L, Unger P, Davies T 2001 Pregnancy and murine thyroiditis: thyroglobulin immunization leads to fetal loss in specific allogeneic pregnancies. Endocrinology 142:823-829.

189. Matalon ST, Blank M, Levy Y, Carp HJ, Arad A, Burek L, Grunebaum E, Sherer Y, Ornoy A, Refetoff S, Weiss RE, Rose NR, Shoenfeld Y 2003 The pathogenic role of antithyroglobulin antibody on pregnancy: evidence from an active immunization model in mice. Hum Reprod 18: 1094-1099.

190. Lee YL, Ng HP, Lau KS, Liu WM, O WS, Yeung WS, Kung AW 2009 Increased fetal abortion rate in autoimmune thyroid disease is related to circulating TPO autoantibodies in an autoimmune thyroiditis animal model. Fertil Steril 91:2104-2109.

191. Lee RM, Silver RM 2000 Recurrent pregnancy loss: summary and clinical recommendations. Semin Reprod Med 18:433-440.

192. Baek KH, Lee EJ, Kim YS 2007 Recurrent pregnancy loss: the key potential mechanisms. Trends Mol Med 13: 310-317.

193. Iravani AT, Saeedi MM, Pakravesh J, Hamidi S, Abbasi M 2008 Thyroid autoimmunity and recurrent spontaneous abortion in Iran: a case-control study. Endocr Pract 14: $458-464$.

194. Kutteh WH, Yetman DL, Carr AC, Beck LA, Scott RT Jr 1999 Increased prevalence of antithyroid antibodies identified in women with recurrent pregnancy loss but not in women undergoing assisted reproduction. Fertil Steril 71:843-848.

195. Esplin MS, Branch DW, Silver R, Stagnaro-Green A 1998 Thyroid autoantibodies are not associated with recurrent pregnancy loss. Am J Obstet Gynecol 179:1583-1586.

196. Pratt DE, Kaberlein G, Dudkiewicz A, Karande V, Gleicher N 1993 The association of antithyroid antibodies in euthyroid nonpregnant women with recurrent first trimester abortions in the next pregnancy. Fertil Steril 60:1001-1005.

197. Rushworth FH, Backos M, Rai R, Chilcott IT, Baxter N, Regan L 2000 Prospective pregnancy outcome in untreated recurrent miscarriers with thyroid autoantibodies. Hum Reprod 15:1637-1639.

198. De Carolis C, Greco E, Guarino MD, Perricone C, Dal Lago A, Giacomelli R, Fontana L, Perricone R 2004 Anti-thyroid antibodies and antiphospholipid syndrome: evidence of reduced fecundity and of poor pregnancy outcome in recurrent spontaneous aborters. Am J Reprod Immunol 52:263-266.

199. Kiprov DD, Nachtigall RD, Weaver RC, Jacobson A, Main EK, Garovoy MR 1996 The use of intravenous immunoglobulin in recurrent pregnancy loss associated with combined alloimmune and autoimmune abnormalities. Am J Reprod Immunol 36:228-234.

200. Stricker RB, Steinleitner A, Bookoff CN, Weckstein LN, Winger EE 2000 Successful treatment of immunologic abortion with low-dose intravenous immunoglobulin. Fertil Steril 73:536-540. 
201. Vaquero E, Lazzarin N, De Carolis C, Valensise H, Moretti C, Ramanini C 2000 Mild thyroid abnormalities and recurrent spontaneous abortion: diagnostic and therapeutical approach. Am J Reprod Immunol 43:204-208.

202. Poppe K, Glinoer D, Tournaye H, Devroey P, van Steirteghem A, Kaufman L, Velkeniers B 2003 Assisted reproduction and thyroid autoimmunity: an unfortunate combination? J Clin Endocrinol Metab 88:4149-4152.

203. Bussen S, Steck T, Dietl J 2000 Increased prevalence of thyroid antibodies in euthyroid women with a history of recurrent in-vitro fertilization failure. Hum Reprod 15: 545-548.

204. Kim CH, Chae HD, Kang BM, Chang YS 1998 Influence of antithyroid antibodies in euthyroid women on in vitro fertilization-embryo transfer outcome. Am J Reprod Immunol 40:2-8.

205. Negro R, Formoso G, Coppola L, Presicce G, Mangieri T, Pezzarossa A, Dazzi D 2007 Euthyroid women with autoimmune disease undergoing assisted reproduction technologies: the role of autoimmunity and thyroid function. J Endocrinol Invest 30:3-8.

206. Kilic S, Tasdemir N, Yilmaz N, Yuksel B, Gul A, Batioglu S 2008 The effect of anti-thyroid antibodies on endometrial volume, embryo grade and IVF outcome. Gynecol Endocrinol 24:649-655.

207. Toulis KA, Goulis DG, Venetis CA, Kolibianakis EM, Negro R, Tarlatzis BC, Papadimas I 2010 Risk of spontaneous miscarriage in euthyroid women with thyroid autoimmunity undergoing IVF: a meta-analysis. Eur J Endocrinol 162:643-652.

208. Negro R, Mangieri T, Coppola L, Presicce G, Casavola EC, Gismondi R, Locorotondo G, Caroli P, Pezzarossa A, Dazzi D, Hassan H 2005 Levothyroxine treatment in thyroid peroxidase antibody-positive women undergoing assisted reproduction technologies: a prospective study. Hum Reprod 20:1529-1533

209. Martin JA, Osterman MJ, Sutton PD 2010 Are preterm births on the decline in the United States? Recent data from the National Vital Statistics System. NCHS Data Brief 39:1-8.

210. Mathews TJ, Menacker F, MacDorman MF, Centers for Disease Control and Prevention, National Center for Health Statistics 2004 Infant mortality statistics from the 2002 period: linked birth/infant death data set. Natl Vital Stat Rep 53:1-29.

211. Petrou S 2005 The economic consequences of preterm birth during the first 10 years of life. BJOG 112 Suppl 1:10-15.

212. Goldenberg RL, Culhane JF, Iams JD, Romero R 2008 Epidemiology and causes of preterm birth. Lancet 371: 75-84.

213. Luewan S, Chakkabut P, Tongsong T 2010 Outcomes of pregnancy complicated with hyperthyroidism: a cohort study. Arch Gynecol Obstet 283:243.

214. Tietgens ST, Leinung MC 1995 Thyroid storm. Med Clin North Am 79:169-184.

215. Ghafoor F, Mansoor M, Malik T, Malik MS, Khan AU, Edwards R, Akhtar W 2006 Role of thyroid peroxidase antibodies in the outcome of pregnancy. J Coll Physicians Surg Pak 16:468-471.

216. Haddow JE, Cleary-Goldman J, McClain MR, Palomaki GE, Neveux LM, Lambert-Messerlian G, Canick JA, Malone FD, Porter TF, Nyberg DA, Bernstein PS, D'Alton ME; First- and Second-Trimester Risk of Aneuploidy (FaSTER) Research Consortium 2010 Thyroperoxidase and thyro- globulin antibodies in early pregnancy and preterm delivery. Obstet Gynecol 116:58-62.

217. Struve CW, Haupt S, Ohlen S 1993 Influence of frequency of previous pregnancies on the prevalence of thyroid nodules in women without clinical evidence of thyroid disease. Thyroid 3:7-9.

218. Kung AW, Chau MT, Lao TT, Tam SC, Low LC 2002 The effect of pregnancy on thyroid nodule formation. J Clin Endocrinol Metab 87:1010-1014.

219. Tan GH, Gharib H, Goellner JR, van Heerden JA, Bahn RS 1996 Management of thyroid nodules in pregnancy. Arch Intern Med 156:2317-2320.

220. Marley EF, Oertel YC 1997 Fine-needle aspiration of thyroid lesions in 57 pregnant and postpartum women. Diagn Cytopathol 16:122-125.

221. Rosen IB, Walfish PG, Nikore V 1985 Pregnancy and surgical thyroid disease. Surgery 98:1135-1140.

222. Smith LH, Danielsen B, Allen ME, Cress R 2003 Cancer associated with obstetric delivery: results of linkage with the California cancer registry. Am J Obstet Gynecol 189: 1128-1135.

223. Loh KC 1997 Familial nonmedullary thyroid carcinoma: a meta-review of case series. Thyroid 7:107-113.

224. Hegedus L 2004 Clinical practice. The thyroid nodule. N Engl J Med 351:1764-1771.

225. Tucker MA, Jones PH, Boice JD Jr, Robison LL, Stone BJ, Stovall M, Jenkin RD, Lubin JH, Baum ES, Siegel SE 1991 Therapeutic radiation at a young age is linked to secondary thyroid cancer. The Late Effects Study Group. Cancer Res 51:2885-2888.

226. Tan GH, Gharib H, Reading CC 1995 Solitary thyroid nodule. Comparison between palpation and ultrasonography. Arch Intern Med 155:2418-2423.

227. Gharib H, Papini E, Valcavi R, Baskin HJ, Crescenzi A, Dottorini ME, Duick DS, Guglielmi R, Hamilton CR Jr, Zeiger MA, Zini M; AACE/AME Task Force on Thyroid Nodules 2006 American Association of Clinical Endocrinologists and Associazione Medici Endocrinologi medical guidelines for clinical practice for the diagnosis and management of thyroid nodules. Endocr Pract 12: 63-102.

228. Brander A, Viikinkoski P, Tuuhea J, Voutilainen L, Kivisaari L 1992 Clinical versus ultrasound examination of the thyroid gland in common clinical practice. J Clin Ultrasound 20:37-42.

229. Papini E, Guglielmi R, Bianchini A, Crescenzi A, Taccogna S, Nardi F, Panunzi C, Rinaldi R, Toscano V, Pacella CM 2002 Risk of malignancy in nonpalpable thyroid nodules: predictive value of ultrasound and color-Doppler features. J Clin Endocrinol Metab 87:1941-1946.

230. Bennedbaek FN, Perrild H, Hegedus L 1999 Diagnosis and treatment of the solitary thyroid nodule. Results of a European survey. Clin Endocrinol (Oxf) 50:357-363.

231. Bennedbaek FN, Hegedus L 2000 Management of the solitary thyroid nodule: results of a North American survey. J Clin Endocrinol Metab 85:2493-2498.

232. Hegedus L, Bonnema SJ, Bennedbaek FN 2003 Management of simple nodular goiter: current status and future perspectives. Endocr Rev 24:102-132.

233. Costante G, Meringolo D, Durante C, Bianchi D, Nocera M, Tumino S, Crocetti U, Attard M, Maranghi M, Torlontano M, Filetti S 2007 Predictive value of serum calcitonin levels for preoperative diagnosis of medullary thyroid carcinoma in a cohort of 5817 consecutive patients 
with thyroid nodules. J Clin Endocrinol Metab 92: 450-455.

234. Belfiore A, La Rosa GL 2001 Fine-needle aspiration biopsy of the thyroid. Endocrinol Metab Clin North Am 30: 361-400.

235. Goellner JR, Gharib H, Grant CS, Johnson DA 1987 Fine needle aspiration cytology of the thyroid, 1980 to 1986. Acta Cytol 31:587-590.

236. Atkinson BF 1993 Fine needle aspiration of the thyroid. Monogr Pathol 35:166-199.

237. Solomon D 1993 Fine needle aspiration of the thyroid: an update. Thyroid Today 16:1-9.

238. Oertel YC 1996 Fine-needle aspiration and the diagnosis of thyroid cancer. Endocrinol Metab Clin North Am 25:69-91.

239. Singer PA 1996 Evaluation and management of the solitary thyroid nodule. Otolaryngol Clin North Am 29:577-591.

240. Powers CN, Frable WJ 1996 Fine Needle Aspiration Biopsy of the Head and Neck. Butterworth-Heinemann, Boston.

241. Choe W, McDougall IR 1994 Thyroid cancer in pregnant women: diagnostic and therapeutic management. Thyroid 4:433-435.

242. Hamburger JI 1992 Thyroid nodules in pregnancy. Thyroid 2:165-168.

243. Pauwels EK, Thomson WH, Blokland JA, Schmidt ME, Bourguignon M, El-Maghraby TA, Broerse JJ, Harding LK 1999 Aspects of fetal thyroid dose following iodine-131 administration during early stages of pregnancy in patients suffering from benign thyroid disorders. Eur J Nucl Med 26:1453-1457.

244. Berg GE, Nystrom EH, Jacobsson L, Lindberg S, Lindstedt RG, Mattsson S, Niklasson CA, Noren AH, Westphal OG 1998 Radioiodine treatment of hyperthyroidism in a pregnant women. J Nucl Med 39:357-361.

245. Zanzonico PB 1997 Radiation dose to patients and relatives incident to 131I therapy. Thyroid 7:199-204.

246. Herzon FS, Morris DM, Segal MN, Rauch G, Parnell T 1994 Coexistent thyroid cancer and pregnancy. Arch Otolaryngol Head Neck Surg 120:1191-1193.

247. Moosa M, Mazzaferri EL 1997 Outcome of differentiated thyroid cancer diagnosed in pregnant women. J Clin Endocrinol Metab 82:2862-2866.

248. Vini L, Hyer S, Pratt B, Harmer C 1999 Good prognosis in thyroid cancer found incidentally at surgery for thyrotoxicosis. Postgrad Med J 75:169-170.

249. Monroy-Lozano BE, Hurtado-Lopez LM, Zaldivar-Ramirez FR, Basurto-Kuba E 2001 Clinical behavior of thyroid papillary cancer in pregnancy: optimal time for its treatment. Ginecol Obstet Mex 69:359-362.

250. Yasmeen S, Cress R, Romano PS, Xing G, Berger-Chen S, Danielsen B, Smith LH 2005 Thyroid cancer in pregnancy. Int J Gynaecol Obstet 91:15-20.

251. Nam KH, Yoon JH, Chang HS, Park CS 2005 Optimal timing of surgery in well-differentiated thyroid carcinoma detected during pregnancy. J Surg Oncol 91:199-203.

252. Vannucchi G, Perrino M, Rossi S, Colombo C, Vicentini L, Dazzi D, Beck-Peccoz P, Fugazzola L 2010 Clinical and molecular features of differentiated thyroid cancer diagnosed during pregnancy. Eur J Endocrinol 162:145151.

253. Rosen IB, Walfish PG 1986 Pregnancy as a predisposing factor in thyroid neoplasia. Arch Surg 121:1287-1290.

254. Doherty CM, Shindo ML, Rice DH, Montero M, Mestman JH 1995 Management of thyroid nodules during pregnancy. Laryngoscope 105:251-255.
255. Chong KM, Tsai YL, Chuang J, Hwang JL, Chen KT 2007 Thyroid cancer in pregnancy: a report of 3 cases. J Reprod Med 52:416-418.

256. Kuy S, Roman SA, Desai R, Sosa JA 2009 Outcomes following thyroid and parathyroid surgery in pregnant women. Arch Surg 144:399-406; discussion 406.

257. Mestman JH, Goodwin TM, Montoro MM 1995 Thyroid disorders of pregnancy. Endocrinol Metab Clin North Am 24:41-71.

258. American Thyroid Association (ATA) Guidelines Taskforce on Thyroid Nodules and Differentiated Thyroid Cancer; Cooper DS, Doherty GM, Haugen BR, Kloos RT, Lee SL, Mandel SJ, Mazzaferri EL, McIver B, Pacini F, Schlumberger M, Sherman SI, Steward DL, Tuttle RM 2009 Revised American Thyroid Association management guidelines for patients with thyroid nodules and differentiated thyroid cancer. Thyroid 19:1167-1214.

259. Pacini F, Schlumberger M, Dralle H, Elisei R, Smit JW, Wiersinga W; European Thyroid Cancer Taskforce 2006 European consensus for the management of patients with differentiated thyroid carcinoma of the follicular epithelium. Eur J Endocrinol 154:787-803.

260. Sawka AM, Lakra DC, Lea J, Alshehri B, Tsang RW, Brierley JD, Straus S, Thabane L, Gafni A, Ezzat S, George SR, Goldstein DP 2008 A systematic review examining the effects of therapeutic radioactive iodine on ovarian function and future pregnancy in female thyroid cancer survivors. Clin Endocrinol (Oxf) 69:479-490.

261. Garsi JP, Schlumberger M, Rubino C, Ricard M, Labbe M, Ceccarelli C, Schvartz C, Henri-Amar M, Bardet S, de Vathaire F 2008 Therapeutic administration of 131I for differentiated thyroid cancer: radiation dose to ovaries and outcome of pregnancies. J Nucl Med 49:845-852.

262. Rosvoll RV, Winship T 1965 Thyroid carcinoma and pregnancy. Surg Gynecol Obstet 121:1039-1042.

263. Hill CS Jr, Clark RL, Wolf M 1966 The effect of subsequent pregnancy on patients with thyroid carcinoma. Surg Gynecol Obstet 122:1219-1222.

264. Leboeuf R, Emerick LE, Martorella AJ, Tuttle RM 2007 Impact of pregnancy on serum thyroglobulin and detection of recurrent disease shortly after delivery in thyroid cancer survivors. Thyroid 17:543-547.

265. Rosario PW, Barroso AL, Purisch S 2007 The effect of subsequent pregnancy on patients with thyroid carcinoma apparently free of the disease. Thyroid 17:11751176.

266. Hirsch D, Levy S, Tsvetov G, Weinstein R, Lifshitz A, Singer J, Shraga-Slutzky I, Grozinski-Glasberg S, Shimon I, Benbassat C 2010 Impact of pregnancy on outcome and prognosis of survivors of papillary thyroid cancer. Thyroid 20:1179-1185.

267. Amino N, Mori H, Iwatani $Y$, Tanizawa O, Kawashima M, Tsuge I, Ibaragi K, Kumahara Y, Miyai K 1982 High prevalence of transient post-partum thyrotoxicosis and hypothyroidism. N Engl J Med 306:849-852.

268. Stagnaro-Green A 2002 Clinical review 152: postpartum thyroiditis. J Clin Endocrinol Metab 87:4042-4047.

269. Stagnaro-Green A, Schwartz A, Gismondi R, Tinelli A, Mangieri T, Negro R 2011 High rate of persistent hypothyroidism in a large-scale prospective study of postpartum thyroiditis in southern Italy. J Clin Endocrinol Metab 96:652-657.

270. Muller AF, Drexhage HA, Berghout A 2001 Postpartum thyroiditis and autoimmune thyroiditis in women of 
childbearing age: recent insights and consequences for antenatal and postnatal care. Endocr Rev 22:605-630.

271. Kuijpens JL, De Hann-Meulman M, Vader HL, Pop VJ, Wiersinga WM, Drexhage HA 1998 Cell-mediated immunity and postpartum thyroid dysfunction: a possibility for the prediction of disease?. J Clin Endocrinol Metab 83:1959-1966.

272. Stagnaro-Green A, Roman SH, Cobin RH, el-Harazy E, Wallenstein S, Davies TF 1992 A prospective study of lymphocyte-initiated immunosuppression in normal pregnancy: evidence of a T-cell etiology for postpartum thyroid dysfunction. J Clin Endocrinol Metab 74:645-653.

273. Smallridge RC 2000 Postpartum thyroid disease: a model of immunologic dysfunction. Clin Appl Immunol Rev 1:89-103.

274. Adams H, Jones MC, Othman S, Lazarus JH, Parkes AB, Hall R, Phillips DI, Richards CJ 1992 The sonographic appearances in postpartum thyroiditis. Clin Radiol 45:311-315.

275. Nicholson WK, Robinson KA, Smallridge RC, Ladenson PW, Powe NR 2006 Prevalence of postpartum thyroid dysfunction: a quantitative review. Thyroid 16:573-582.

276. Gerstein HC 1993 Incidence of postpartum thyroid dysfunction in patients with type I diabetes mellitus. Ann Intern Med 118:419-423.

277. Alvarez-Marfany M, Roman SH, Drexler AJ, Robertson C, Stagnaro-Green A 1994 Long-term prospective study of postpartum thyroid dysfunction in women with insulin dependent diabetes mellitus. J Clin Endocrinol Metab 79:10-16.

278. Elefsiniotis IS, Vezali E, Pantazis KD, Saroglou G 2008 Postpartum thyroiditis in women with chronic viral hepatitis. J Clin Virol 41:318-319.

279. Stagnaro-Green A, Akhter E, Yim C, Davies TF, Magder L, Petri M 2011 Thyroid disease in pregnant women with systemic lupus erythematosus: increased preterm delivery. Lupus 20:690.

280. Tagami T, Hagiwara H, Kimura T, Usui T, Shimatsu A, Naruse M 2007 The incidence of gestational hyperthyroidism and postpartum thyroiditis in treated patients with Graves' disease. Thyroid 17:767-772.

281. Lazarus JH, Ammari F, Oretti R, Parkes AB, Richards CJ, Harris B 1997 Clinical aspects of recurrent postpartum thyroiditis. Br J Gen Pract 47:305-308.

282. Caixas A, Albareda M, Garcia-Patterson A, RodriguezEspinosa J, de Leiva A, Corcoy R 1999 Postpartum thyroiditis in women with hypothyroidism antedating pregnancy? J Clin Endocrinol Metab 84:4000-4005.

283. Marqusee E, Hill JA, Mandel SJ 1997 Thyroiditis after pregnancy loss. J Clin Endocrinol Metab 82:2455-2457.

284. Walfish PG, Meyerson J, Provias JP, Vargas MT, Papsin FR 1992 Prevalence and characteristics of post-partum thyroid dysfunction: results of a survey from Toronto, Canada. J Endocrinol Invest 15:265-272.

285. Hayslip CC, Fein HG, O'Donnell VM, Friedman DS, Klein TA, Smallridge RC 1988 The value of serum antimicrosomal antibody testing in screening for symptomatic postpartum thyroid dysfunction. Am J Obstet Gynecol 159:203-209.

286. Lazarus JH 1999 Clinical manifestations of postpartum thyroid disease. Thyroid 9:685-689.

287. Pop VJ, de Rooy HA, Vader HL, van der Heide D, van Son M, Komproe IH, Essed GG, de Geus CA 1991 Postpartum thyroid dysfunction and depression in an unselected population. N Engl J Med 324:1815-1816.
288. Lucas A, Pizarro E, Granada ML, Salinas I, Sanmarti A 2001 Postpartum thyroid dysfunction and postpartum depression: are they two linked disorders? Clin Endocrinol (Oxf) 55:809-814.

289. Harris B, Othman S, Davies JA, Weppner GJ, Richards CJ, Newcombe RG, Lazarus JH, Parkes AB, Hall R, Phillips DI 1992 Association between postpartum thyroid dysfunction and thyroid antibodies and depression. BMJ 305: 152-156.

290. Kuijpens JL, Vader HL, Drexhage HA, Wiersinga WM, van Son MJ, Pop VJ 2001 Thyroid peroxidase antibodies during gestation are a marker for subsequent depression postpartum. Eur J Endocrinol 145:579-584.

291. Pop VJ, de Rooy HA, Vader HL, van der Heide D, van Son MM, Komproe IH 1993 Microsomal antibodies during gestation in relation to postpartum thyroid dysfunction and depression. Acta Endocrinol (Copenh) 129:26-30.

292. Harris B, Oretti R, Lazarus J, Parkes A, John R, Richards C, Newcombe R, Hall R 2002 Randomised trial of thyroxine to prevent postnatal depression in thyroid-antibody-positive women. Br J Psychiatry 180:327-330.

293. Tachi J, Amino N, Tamaki H, Aozasa M, Iwatani Y, Miyai K 1988 Long term follow-up and HLA association in patients with postpartum hypothyroidism. J Clin Endocrinol Metab 66:480-484.

294. Fung HY, Kologlu M, Collison K, John R, Richards CJ, Hall R, McGregor AM 1988 Postpartum thyroid dysfunction in Mid Glamorgan. Br Med J (Clin Res Ed) 296:241-244.

295. Vargas MT, Briones-Urbina R, Gladman D, Papsin FR, Walfish PG 1988 Antithyroid microsomal autoantibodies and HLA-DR5 are associated with postpartum thyroid dysfunction: evidence supporting an autoimmune pathogenesis. J Clin Endocrinol Metab 67:327-333.

296. Rasmussen NG, Hornnes PJ, Hoier-Madsen M, FeldtRasmussen U, Hegedus L 1990 Thyroid size and function in healthy pregnant women with thyroid autoantibodies. Relation to development of postpartum thyroiditis. Acta Endocrinol (Copenh) 123:395-401.

297. Azizi F 2005 The occurrence of permanent thyroid failure in patients with subclinical postpartum thyroiditis. Eur J Endocrinol 153:367-371.

298. Nohr SB, Jorgensen A, Pedersen KM, Laurberg P 2000 Postpartum thyroid dysfunction in pregnant thyroid peroxidase antibody-positive women living in an area with mild to moderate iodine deficiency: is iodine supplementation safe? J Clin Endocrinol Metab 85:3191-3198.

299. Kampe O, Jansson R, Karlsson FA 1990 Effects of Lthyroxine and iodide on the development of autoimmune postpartum thyroiditis. J Clin Endocrinol Metab 70:10141018.

300. Klein RZ, Haddow JE, Faix JD, Brown RS, Hermos RJ, Pulkkinen A, Mitchell ML 1991 Prevalence of thyroid deficiency in pregnant women. Clin Endocrinol (Oxf) 35: 41-46.

301. Pop VJ, Kuijpens JL, van Baar AL, Verkerk G, van Son MM, de Vijlder JJ, Vulsma T, Wiersinga WM, Drexhage HA, Vader HL 1999 Low maternal free thyroxine concentrations during early pregnancy are associated with impaired psychomotor development in infancy. Clin Endocrinol (Oxf) 50:149-155.

302. Lazarus J 2010 Outcome of the CATS study. Oral presentation at the International Thyroid Congress (ITC), Paris, France, September 11-16. Symposium no. 18. 
303. Dosiou C, Sanders GD, Araki SS, Crapo LM 2008 Screening pregnant women for autoimmune thyroid disease: a costeffectiveness analysis. Eur J Endocrinol 158:841-851.

304. Thung SF, Funai EF, Grobman WA 2009 The costeffectiveness of universal screening in pregnancy for subclinical hypothyroidism. Am J Obstet Gynecol 200:267. e1-267.e7.

305. Vaidya B, Anthony S, Bilous M, Shields B, Drury J, Hutchison S, Bilous R 2007 Detection of thyroid dysfunction in early pregnancy: universal screening or targeted high-risk case finding? J Clin Endocrinol Metab 92:203-207.

306. Horacek J, Spitalnikova S, Dlabalova B, Malirova E, Vizda J, Svilias I, Cepkova J, Mc Grath C, Maly J 2010 Universal screening detects two-times more thyroid disorders in early pregnancy than targeted high-risk case finding. Eur J Endocrinol 163:645-650.

307. De Carlucci D Jr, Tavares MR, Obara MT, Martins LA, Hojaij FC, Cernea CR 2008 Thyroid function after unilateral total lobectomy: risk factors for postoperative hypothyroidism. Arch Otolaryngol Head Neck Surg 134: 1076-1079.

308. Canaris GJ, Manowitz NR, Mayor G, Ridgway EC 2000 The Colorado thyroid disease prevalence study. Arch Intern Med 160:526-534.

309. Canaris GJ, Steiner JF, Ridgway EC 1997 Do traditional symptoms of hypothyroidism correlate with biochemical disease? J Gen Intern Med 12:544-550.

310. Jovanovic-Peterson L, Peterson CM 1988 De novo clinical hypothyroidism in pregnancies complicated by type I diabetes, subclinical hypothyroidism, and proteinuria: a new syndrome. Am J Obstet Gynecol 159:442-446.

311. Ladenson PW 2005 Diagnosis of hypothyroidism. In: Braverman LE, Utiger RD (eds) Werner \& Ingbar's The Thyroid: A Fundamental and Clinical Text, 9th edition. Lippincott, Williams \& Wilkins, Philadelphia, pp 857-863.

312. Poppe K, Glinoer D, Van Steirteghem A, Tournaye H, Devroey P, Schiettecatte J, Velkeniers B 2002 Thyroid dys- function and autoimmunity in infertile women. Thyroid 12:997-1001.

313. Mercado G, Adelstein DJ, Saxton JP, Secic M, Larto MA, Lavertu P 2001 Hypothyroidism: a frequent event after radiotherapy and after radiotherapy with chemotherapy for patients with head and neck carcinoma. Cancer 92: 2892-2897.

314. Rotondi M, Leporati P, La Manna A, Pirali B, Mondello T, Fonte R, Magri F, Chiovato L 2009 Raised serum TSH levels in patients with morbid obesity: is it enough to diagnose subclinical hypothyroidism? Eur J Endocrinol 160:403-408.

315. Michalaki MA, Vagenakis AG, Leonardou AS, Argentou MN, Habeos IG, Makri MG, Psyrogiannis AI, Kalfarentzos FE, Kyriazopoulou VE 2006 Thyroid function in humans with morbid obesity. Thyroid 16:73-78.

316. Hollowell JG, Staehling NW, Flanders WD, Hannon WH, Gunter EW, Spencer CA, Braverman LE 2002 Serum TSH, $\mathrm{T}(4)$, and thyroid antibodies in the United States population (1988 to 1994): National Health and Nutrition Examination Survey (NHANES III). J Clin Endocrinol Metab 87:489-499.

317. Eskes SA, Wiersinga WM 2009 Amiodarone and thyroid. Best Pract Res Clin Endocrinol Metab 23:735-751.

318. Lazarus JH 2009 Lithium and thyroid. Best Pract Res Clin Endocrinol Metab 23:723-733.

319. Vagenakis AG, Braverman LE 1975 Adverse effects of iodides on thyroid function. Med Clin North Am 59:10751088.

Address correspondence to: Alex Stagnaro-Green, M.D., MHPE George Washington University School of Medicine and Health Sciences Senior Associate Dean for Education 2300 Eye Street, NW, Suite 712 Washington, DC 20037

E-mail: msdasg@gwumc.edu

\section{APPENDIX: PREGNANCY AND POSTPARTUM THYROID DISEASE MANAGEMENT GUIDELINES OF THE AMERICAN THYROID ASSOCIATION-SUMMARY OF RECOMMENDATIONS}

\section{Thyroid Function Tests in Pregnancy}

Recommendation 1 Trimester-specific reference ranges for TSH, as defined in populations with optimal iodine intake, should be applied. Level B-USPSTF

Recommendation 2 If trimester-specific reference ranges for TSH are not available in the laboratory, the following reference ranges are recommended: first trimester, $0.1-2.5 \mathrm{mIU} / \mathrm{L}$; second trimester, 0.2-3.0 mIU/L; third trimester, 0.3-3.0 mIU/L. Level I-USPSTF

Recommendation 3

The optimal method to assess serum $\mathrm{FT}_{4}$ during pregnancy is measurement of $\mathrm{T}_{4}$ in the dialysate or ultrafiltrate of serum samples employing on-line extraction/liquid chromatography/tandem mass spectrometry (LC/MS/MS). Level A-USPSTF

Recommendation 4

If $\mathrm{FT}_{4}$ measurement by $\mathrm{LC} / \mathrm{MS} / \mathrm{MS}$ is not available, clinicians should use whichever measure or estimate of $\mathrm{FT}_{4}$ is available in their laboratory, being aware of the limitations of each method. Serum TSH is a more accurate indication of thyroid status in pregnancy than any of these alternative methods. Level A-USPSTF

Recommendation 5 In view of the wide variation in the results of $\mathrm{FT}_{4}$ assays, method-specific and trimesterspecific reference ranges of serum $\mathrm{FT}_{4}$ are required. Level B-USPSTF

\section{Hypothyroidism in Pregnancy}

Recommendation 6

$\mathrm{OH}$ should be treated in pregnancy. This includes women with a TSH concentration above the trimester-specific reference interval with a decreased $\mathrm{FT}_{4}$, and all women with a TSH concentration above $10.0 \mathrm{mIU} / \mathrm{L}$ irrespective of the level of $\mathrm{FT}_{4}$. Level A-USPSTF

Recommendation 7 Recommendation 8

Isolated hypothyroxinemia should not be treated in pregnancy. Level C-USPSTF

$\mathrm{SCH}$ has been associated with adverse maternal and fetal outcomes. However, due to the lack of randomized controlled trials there is insufficient evidence to recommend for or against universal $\mathrm{LT}_{4}$ treatment in $\mathrm{TAb}$ - pregnant women with SCH. Level I-USPSTF 
Recommendation 9

Recommendation 10

Recommendation 11

Recommendation 12

Recommendation 13

Recommendation 14

Recommendation 15

Recommendation 16

Recommendation 17

Recommendation 18

Recommendation 19

Recommendation 20

Recommendation 21

Thyrotoxicosis in Pregnancy Recommendation 22

Recommendation 23

Recommendation 24

Recommendation 25

Recommendation 26

Recommendation 27
Women who are positive for TPOAb and have SCH should be treated with $\mathrm{LT}_{4}$. Level B-USPSTF*

The recommended treatment of maternal hypothyroidism is with administration of oral $\mathrm{LT}_{4}$. It is strongly recommended not to use other thyroid preparations such as $\mathrm{T}_{3}$ or desiccated thyroid. Level A-USPSTF

The goal of $\mathrm{LT}_{4}$ treatment is to normalize maternal serum TSH values within the trimesterspecific pregnancy reference range (first trimester, $0.1-2.5 \mathrm{mIU} / \mathrm{L}$, second trimester, 0.2-3.0 $\mathrm{mIU} / \mathrm{L}$, third trimester, 0.3-3.0 mIU/L). Level A-USPSTF

Women with $\mathrm{SCH}$ in pregnancy who are not initially treated should be monitored for progression to $\mathrm{OH}$ with a serum TSH and $\mathrm{FT}_{4}$ approximately every 4 weeks until 16-20 weeks gestation and at least once between 26 and 32 weeks gestation. This approach has not been prospectively studied. Level I-USPSTF

Treated hypothyroid patients (receiving $\mathrm{LT}_{4}$ ), who are newly pregnant should independently increase their dose of $\mathrm{LT}_{4}$ by $\sim 25 \%-30 \%$ upon a missed menstrual cycle or positive home pregnancy test and notify their caregiver promptly. One means of accomplishing this adjustment is to increase $\mathrm{LT}_{4}$ from once daily dosing to a total of nine doses per week $(29 \%$ increase). Level B-USPSTF

There exists great interindividual variability regarding the increased amount of $\mathrm{T}_{4}$ (or $\mathrm{LT}_{4}$ ) necessary to maintain a normal TSH throughout pregnancy, with some women requiring only $10 \%-20 \%$ increased dosing, while others may require as much as an $80 \%$ increase. The etiology of maternal hypothyroidism, as well as the preconception level of $\mathrm{TSH}$, may provide insight into the magnitude of necessary $\mathrm{LT}_{4}$ increase. Clinicians should seek this information upon assessment of the patient after pregnancy is confirmed. Level A-USPSTF

Treated hypothyroid patients (receiving $\mathrm{LT}_{4}$ ) who are planning pregnancy should have their dose adjusted by their provider in order to optimize serum TSH values to $<2.5 \mathrm{mIU} / \mathrm{L}$ preconception. Lower preconception TSH values (within the nonpregnant reference range) reduce the risk of TSH elevation during the first trimester. Level B-USPSTF

In pregnant patients with treated hypothyroidism, maternal serum TSH should be monitored approximately every 4 weeks during the first half of pregnancy because further $\mathrm{LT}_{4}$ dose adjustments are often required. Level B-USPSTF

In pregnant patients with treated hypothyroidism, maternal TSH should be checked at least once between 26 and 32 weeks gestation. Level I-USPSTF

Following delivery, $\mathrm{LT}_{4}$ should be reduced to the patient's preconception dose. Additional TSH testing should be performed at approximately 6 weeks postpartum. Level B-USPSTF

In the care of women with adequately treated Hashimoto's thyroiditis, no other maternal or fetal thyroid testing is recommended beyond measurement of maternal thyroid function (such as serial fetal ultrasounds, antenatal testing, and/or umbilical blood sampling) unless for other pregnancy circumstances. Level A-USPSTF

Euthyroid women (not receiving $\mathrm{LT}_{4}$ ) who are $\mathrm{TAb}+$ require monitoring for hypothyroidism during pregnancy. Serum TSH should be evaluated every 4 weeks during the first half of pregnancy and at least once between 26 and 32 weeks gestation. Level B-USPSTF

A single RCT has demonstrated a reduction in postpartum thyroiditis from selenium therapy. No subsequent trials have confirmed or refuted these findings. At present, selenium supplementation is not recommended for TPOAb + women during pregnancy. Level C-USPSTF

In the presence of a suppressed serum TSH in the first trimester (TSH $<0.1 \mathrm{mIU} / \mathrm{L})$, a history and physical examination are indicated. $\mathrm{FT}_{4}$ measurements should be obtained in all patients. Measurement of $\mathrm{TT}_{3}$ and $\mathrm{TRAb}$ may be helpful in establishing a diagnosis of hyperthyroidism. Level B-USPSTF

There is not enough evidence to recommend for or against the use of thyroid ultrasound in differentiating the cause of hyperthyroidism in pregnancy. Level I-USPSTF

Radioactive iodine (RAI) scanning or radioiodine uptake determination should not be performed in pregnancy. Level D-USPSTF

The appropriate management of women with gestational hyperthyroidism and hyperemesis gravidarum includes supportive therapy, management of dehydration, and hospitalization if needed. Level A-USPSTF

ATDs are not recommended for the management of gestational hyperthyroidism. Level D-USPSTF

Thyrotoxic women should be rendered euthyroid before attempting pregnancy. Level A-USPSTF

\footnotetext{
*Dissent from one committee member: There is no consistent prospective evidence demonstrating that women who are TPOAb+, but who have $\mathrm{SCH}$ only, achieve maternal or perinatal benefit from $\mathrm{LT}_{4}$ treatment. Correspondingly, there is no indication to treat women who are $\mathrm{TPOAb}+$ and have $\mathrm{SCH}$ with $\mathrm{LT}_{4}$.
} 
Recommendation 28 PTU is preferred for the treatment of hyperthyroidism in the first trimester. Patients on MMI should be switched to PTU if pregnancy is confirmed in the first trimester. Following the first trimester, consideration should be given to switching to MMI. Level I-USPSTF

Recommendation 29

A combination regimen of $\mathrm{LT}_{4}$ and an ATD should not be used in pregnancy, except in the rare situation of fetal hyperthyroidism. Level D-USPSTF

Recommendation 30 In women being treated with ATDs in pregnancy, $\mathrm{FT}_{4}$ and TSH should be monitored approximately every 2-6 weeks. The primary goal is a serum $\mathrm{FT}_{4}$ at or moderately above the normal reference range. Level B-USPSTF

Recommendation 31 Thyroidectomy in pregnancy is rarely indicated. If required, the optimal time for thyroidectomy is in the second trimester. Level A-USPSTF

Recommendation 32 If the patient has a past or present history of Graves' disease, a maternal serum determination of TRAb should be obtained at 20-24 weeks gestation. Level B-USPSTF

Recommendation 33 Fetal surveillance with serial ultrasounds should be performed in women who have uncontrolled hyperthyroidism and/or women with high TRAb levels (greater than three times the upper limit of normal). A consultation with an experienced obstetrician or maternal-fetal medicine specialist is optimal. Such monitoring may include ultrasound for heart rate, growth, amniotic fluid volume and fetal goiter. Level I-USPSTF

Recommendation 34 Cordocentesis should be used in extremely rare circumstances and performed in an appropriate setting. It may occasionally be of use when fetal goiter is detected in women taking ATDs to help determine whether the fetus is hyperthyroid or hypothyroid. Level I-USPSTF

Recommendation $35 \quad \mathrm{MMI}$ in doses up to $20-30 \mathrm{mg} / \mathrm{d}$ is safe for lactating mothers and their infants. PTU at doses up to $300 \mathrm{mg} / \mathrm{d}$ is a second-line agent due to concerns about severe hepatotoxicity. ATDs should be administered following a feeding and in divided doses. Level A-USPSTF

\section{Clinical Guidelines for Iodine Nutrition}

Recommendation 36 All pregnant and lactating women should ingest a minimum of $250 \mu \mathrm{g}$ iodine daily. Level A-USPSTF

Recommendation 37 To achieve a total of $250 \mu \mathrm{g}$ of iodine ingestion daily in North America all women who are planning to be pregnant or are pregnant or breastfeeding should supplement their diet with a daily oral supplement that contains $150 \mu \mathrm{g}$ of iodine. This is optimally delivered in the form of potassium iodide because kelp and other forms of seaweed do not provide a consistent delivery of daily iodide. Level B-USPSTF

Recommendation 38 In areas of the world outside of North America, strategies for ensuring adequate iodine intake during preconception, pregnancy, and lactation should vary according to regional dietary patterns and availability of iodized salt. Level A-USPSTF

Recommendation 39 Pharmacologic doses of iodine exposure during pregnancy should be avoided, except in preparation for thyroid surgery for Graves' disease. Clinicians should carefully weigh the risks and benefits when ordering medications or diagnostic tests that will result in high iodine exposure. Level C-USPSTF

Recommendation 40 Sustained iodine intake from diet and dietary supplements exceeding 500-1100 $\mu \mathrm{g}$ daily should be avoided due to concerns about the potential for fetal hypothyroidism. Level C-USPSTF

Spontaneous Pregnancy Loss, Preterm Delivery, and Thyroid Antibodies

Recommendation 41 There is insufficient evidence to recommend for or against screening all women for antithyroid antibodies in the first trimester of pregnancy. Level I-USPSTF

Recommendation 42 There is insufficient evidence to recommend for or against screening for thyroid antibodies, or treating in the first trimester of pregnancy with $\mathrm{LT}_{4}$ or IVIG, in euthyroid women with sporadic or recurrent abortion, or in women undergoing in vitro fertilization (IVF). Level I-USPSTF

Recommendation 43 There is insufficient evidence to recommend for or against $\mathrm{LT}_{4}$ therapy in TAb + euthyroid women during pregnancy. Level I-USPSTF

Recommendation 44 There is insufficient evidence to recommend for or against $\mathrm{LT}_{4}$ therapy in euthyroid TAb+ women undergoing assisted reproduction technologies. Level I-USPSTF

Recommendation 45 There is insufficient evidence to recommend for or against screening for anti-thyroid antibodies in the first trimester of pregnancy, or treating TAb+ euthyroid women with $\mathrm{LT}_{4}$, to prevent preterm delivery. Level I-USPSTF

Thyroid Nodules and Thyroid Cancer

Recommendation 46 The optimal diagnostic strategy for thyroid nodules detected during pregnancy is based on risk stratification. All women should have the following: a complete history and clinical examination, serum TSH testing, and ultrasound of the neck. Level A-USPSTF

Recommendation 47 The utility of measuring calcitonin in pregnant women with thyroid nodules is unknown. Level I-USPSTF

Recommendation 48 Recommendation 49

Thyroid or lymph node FNA confers no additional risks to a pregnancy. Level A-USPSTF

Thyroid nodules discovered during pregnancy that have suspicious ultrasound features, as delineated by the 2009 ATA guidelines, should be considered for FNA. In instances in which nodules are likely benign, FNA may be deferred until after delivery based on patients' preference. Level I-USPSTF 
Recommendation 50

Recommendation 51

Recommendation 52

Recommendation 53

Recommendation 54

Recommendation 55

Recommendation 56

Recommendation 57

Recommendation 58

Recommendation 59

Recommendation 60

Recommendation 61

Recommendation 62

Postpartum Thyroiditis

Recommendation 63

Recommendation 64

Recommendation 65

Recommendation 66

Recommendation 67

Recommendation 68

Recommendation 69
The use of radioiodine imaging and/or uptake determination or therapeutic dosing is contraindicated during pregnancy. Inadvertent use of radioiodine prior to 12 weeks of gestation does not appear to damage the fetal thyroid. Level A-USPSTF

Because the prognosis of women with well-differentiated thyroid cancer identified but not treated during pregnancy is similar to that of nonpregnant patients, surgery may be generally deferred until postpartum. Level B-USPSTF

The impact of pregnancy on women with medullary carcinoma is unknown. Surgery is recommended during pregnancy in the presence of a large primary tumor or extensive lymph node metastases. Level I-USPSTF

Surgery for thyroid carcinoma during the second trimester of pregnancy has not been demonstrated to be associated with increased maternal or fetal risk. Level B-USPSTF

Pregnant women with thyroid nodules that are read as benign on FNA cytology do not require surgery during pregnancy except in cases of rapid nodule growth and/or if severe compressive symptoms develop. Postpartum, nodules should be managed according to the 2009 ATA guidelines. Level B-USPSTF

When a decision has been made to defer surgery for well-differentiated thyroid carcinoma until after delivery, neck ultrasounds should be performed during each trimester to assess for rapid tumor growth, which may indicate the need for surgery. Level I-USPSTF

Surgery in women with well-differentiated thyroid carcinoma may be deferred until postpartum without adversely affecting the patient's prognosis. However, if substantial growth of the well-differentiated thyroid carcinoma occurs or the emergence of lymph node metastases prior to midgestation occurs, then surgery is recommended. Level B-USPSTF

Thyroid hormone therapy may be considered in pregnant women who have deferred surgery for well-differentiated thyroid carcinoma until postpartum. The goal of $\mathrm{LT}_{4}$ therapy is a serum TSH level of $0.1-1.5 \mathrm{mIU} / \mathrm{L}$. Level I-USPSTF

Pregnant patients with an FNA sample that is suspicious for thyroid cancer do not require surgery while pregnant except in cases of rapid nodular growth and/or the appearance of lymph node metastases. Thyroid hormone therapy is not recommended. Level I-USPSTF

The preconception TSH goal in women with DTC, which is determined by risk stratification, should be maintained during pregnancy. TSH should be monitored approximately every 4 weeks until 16-20 weeks of gestation and once between 26 and 32 weeks of gestation. Level B-USPSTF

There is no evidence that previous exposure to radioiodine affects the outcomes of subsequent pregnancies and offspring. Pregnancy should be deferred for 6 months following RAI treatment. $\mathrm{LT}_{4}$ dosing should be stabilized following RAI treatment before pregnancy is attempted. Level B-USPSTF

Ultrasound and $\mathrm{Tg}$ monitoring during pregnancy in patients with a history of previously treated DTC is not required for low-risk patients with no $\mathrm{Tg}$ or structural evidence of disease prior to pregnancy. Level B-USPSTF

Ultrasound monitoring should be performed each trimester during pregnancy in patients with previously treated DTC and who have high levels of Tg or evidence of persistent structural disease prior to pregnancy. Level B-USPSTF

Women with postpartum depression should have TSH, $\mathrm{FT}_{4}$, and TPOAb tests performed. Level B-USPSTF

During the thyrotoxic phase of PPT, symptomatic women may be treated with beta blockers. Propranolol at the lowest possible dose to alleviate symptoms is the treatment of choice. Therapy is typically required for a few months. Level B-USPSTF

ATDs are not recommended for the treatment of the thyrotoxic phase of PPT. Level D-USPSTF

Following the resolution of the thyrotoxic phase of PPT, TSH should be tested every 2 months (or if symptoms are present) until 1 year postpartum to screen for the hypothyroid phase. Level B-USPSTF

Women who are symptomatic with hypothyroidism in PPT should either have their TSH level retested in 4-8 weeks or be started on $\mathrm{LT}_{4}$ (if symptoms are severe, if conception is being attempted, or if the patient desires therapy). Women who are asymptomatic with hypothyroidism in PPT should have their TSH level retested in 4-8 weeks. Level B-USPSTF

Women who are hypothyroid with PPT and attempting pregnancy should be treated with $\mathrm{LT}_{4}$. Level A-USPSTF

If $\mathrm{LT}_{4}$ is initiated for PPT, future discontinuation of therapy should be attempted. Tapering of treatment can be begun 6-12 months after the initiation of treatment. Tapering of $\mathrm{LT}_{4}$ should be avoided when a woman is actively attempting pregnancy, is breastfeeding, or is pregnant. Level C-USPSTF 
Recommendation $70 \quad$ Women with a prior history of PPT should have an annual TSH test performed to evaluate for permanent hypothyroidism. Level A-USPSTF

Recommendation 71 Treatment of TAb+ euthyroid pregnant woman with either $\mathrm{LT}_{4}$ or iodine to prevent PPT is ineffective and is not recommended. Level D-USPSTF

Thyroid Function Screening in Pregnancy

Recommendation 72 There is insufficient evidence to recommend for or against universal TSH screening at the first trimester visit. Level I-USPSTF

Recommendation 73

Because no studies to date have demonstrated a benefit to treatment of isolated maternal hypothyroximenia, universal $\mathrm{FT}_{4}$ screening of pregnant women is not recommended. Level D-USPSTF

Recommendation 74 There is insufficient evidence to recommend for or against TSH testing preconception in women at high risk for hypothyroidism. Level I-USPSTF

Recommendation 75

All pregnant women should be verbally screened at the initial prenatal visit for any history of thyroid dysfunction and/or use of thyroid hormone $\left(\mathrm{LT}_{4}\right)$ or anti-thyroid medications (MMI, carbimazole, or PTU). Level B-USPSTF

Recommendation 76 Serum TSH values should be obtained early in pregnancy in the following women at high risk for overt hypothyroidism:

History of thyroid dysfunction or prior thyroid surgery

Age $>30$ years

Symptoms of thyroid dysfunction or the presence of goiter

TPOAb positivity

Type 1 diabetes or other autoimmune disorders

History of miscarriage or preterm delivery

History of head or neck radiation

Family history of thyroid dysfunction

Morbid obesity (BMI $\geq 40 \mathrm{~kg} / \mathrm{m}^{2}$ )

Use of amiodarone or lithium, or recent administration of iodinated radiologic contrast Infertility

Residing in an area of known moderate to severe iodine sufficiency

Level B-USPSTF

\footnotetext{
${ }^{\dagger}$ Dissent from one committee member: There is no good evidence that improved maternal or perinatal outcomes will be obtained if the criteria for thyroid function screening were different for a pregnant than a nonpregnant population. Correspondingly, criteria for screening pregnant women should not differ from the nonpregnant population.
}

This article has been revised since its original e-publication on July 25, 2011, in order to merge duplicate terminology and correct typographical errors. The terms "anti-thyroid antibodies," "anti-TPO antibodies," and "Ab+" have been replaced by "thyroid antibodies," "TPO antibodies," and "TAb+," respectively. In Recommendation 37, "planning to be pregnancy" has been changed to "planning to be pregnant." Also, the endorsement of these guidelines by the American Association of Clinical Endocrinologists (AACE) and Endocrine Society of Australia (ESA) is acknowledged. Correction date: September 12, 2011. 
